Jorge Henrique Bidinotto

\title{
PROPOSTA CONCEITUAL DE EXCITADOR DE "FLUTTER" ALTERNATIVO PARA ENSAIOS EM VÔO
}

Dissertação apresentada à Escola de Engenharia de São Carlos da Universidade de São Paulo para obtenção do título de Mestre em Engenharia Mecânica.

Área de Concentração: Aeronaves

Orientador: Prof. Titular. Eduardo Morgado Belo 


\begin{abstract}
AUTORIZO A REPRODUÇÃO E DIVULGAÇÃO TOTAL OU PARCIAL DESTE TRABALHO, POR MEIO CONVENCIONAL OU ELETRÔNICO, PARA FINS DE ESTUDO E PESQUISA, DESDE QUE CITADA A FONTE
\end{abstract}




\section{AGRADECIMENTOS}

Agradeço primeiramente a Deus, pelas condições que me deu de realizar não só este trabalho, mas tudo o que busquei e realizei em minha vida.

À minha família: meus pais Paulo e Josefina, que nunca mediram esforços para a minha formação, seja acadêmica, seja de caráter e aos meus irmãos Paulo e Lucas, pela amizade, apoio e exemplo (nem sempre positivo!).

À Dani, pela sua paciência, pelo apoio e pelo carinho que sempre dedicou a mim, seja nas horas boas ou naquelas as quais as circunstâncias não tornaram tão boas assim.

Ao professor e amigo Eduardo Morgado Belo, que em quase 10 anos de convivência sempre me apoiou e acreditou em mim, me dando total liberdade para realizar as coisas dentro das minhas limitações de tempo ou de distância.

Aos professores e funcionários do LAE e LADinC, que sempre estiveram à disposição para ajudar e facilitar nossa vida. Em especial a Gisele, De Marqui e Greco, sempre dedicados a ajudar no que quer que fosse.

À EMBRAER, na pessoa dos engenheiros Roberto Becker e Marcelo Basile, pelo apoio e incentivo à capacitação de seus funcionários, e ao Celso Braga, pelos compartilhamento de sua experiência, seja na empresa, seja nas sugestões em prol da melhoria deste trabalho.

Aos amigos do LADinC: Mauricio, Caixeta, Edson, Luciane, Daniela, Elizângela, Cráudião e todos os que conviveram comigo em todos esses anos de estudo e conversas.

Aos amigos da EMBRAER, pelos momentos de alegria, churrascos, cerveja..... ah! E de ensaios em vôo também!

Ao Barretos e ao Jota, pela grande ajuda nas simulações. Devo uma gelada pra vocês! 
A todos que de alguma forma me incentivaram ou contribuíram para que eu chegasse até esse momento, com minha bagagem (ainda bem modesta), de conhecimentos técnicos ou pessoais, meus mais sinceros agradecimentos. 


\section{SUMÁRIO}

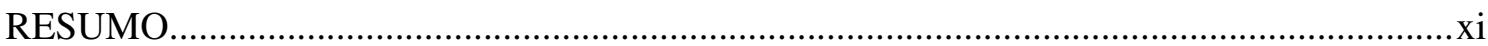

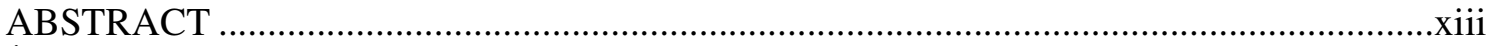

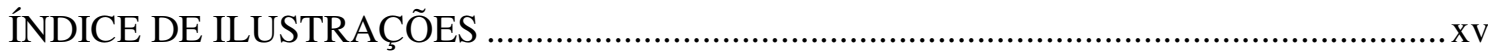

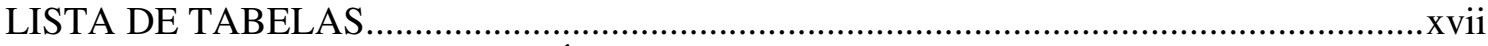

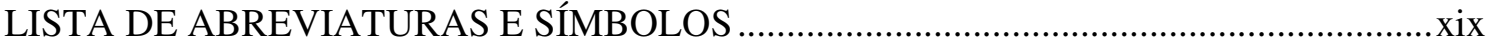

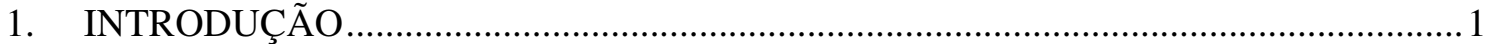

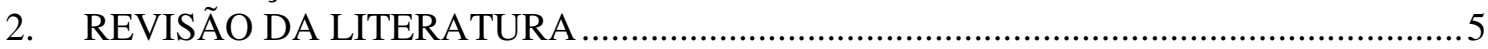

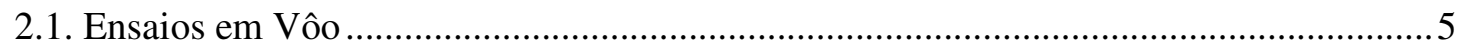

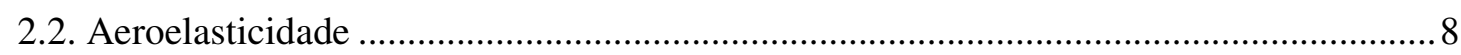

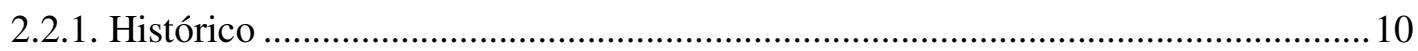

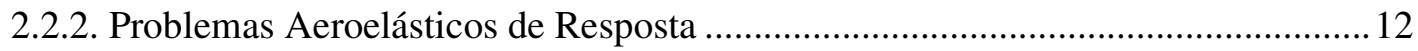

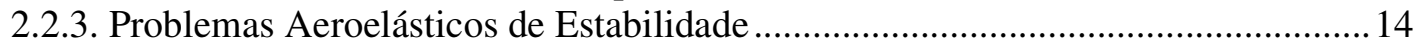

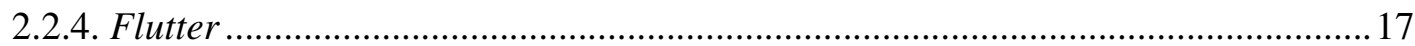

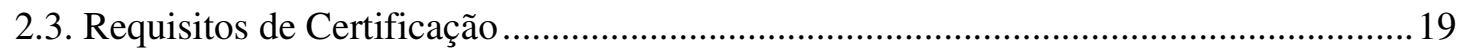

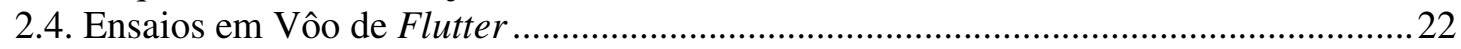

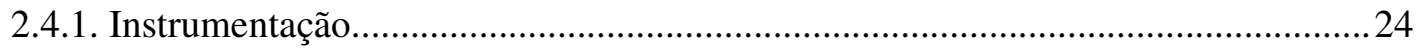

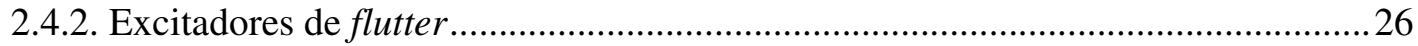

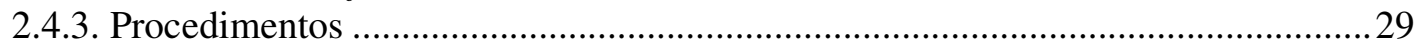

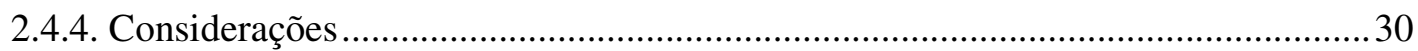

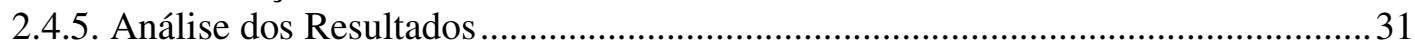

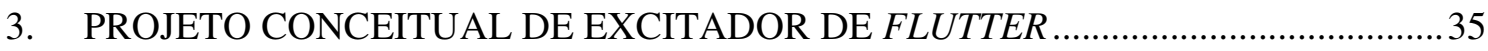

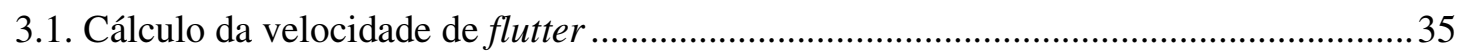

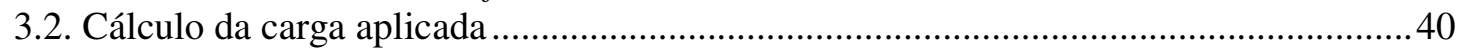

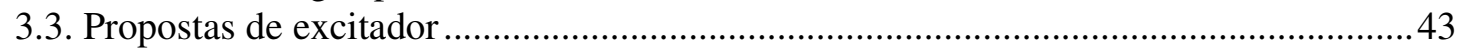

3.3.1. Aerofólio fino de arqueamento variável .......................................................44

3.3.2. Perfil aerodinâmico com ângulo de ataque variável..............................................52

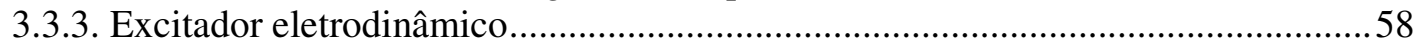

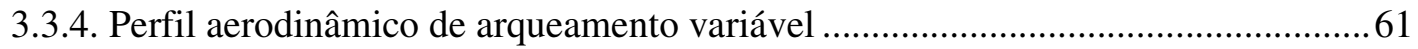

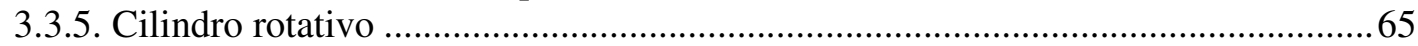

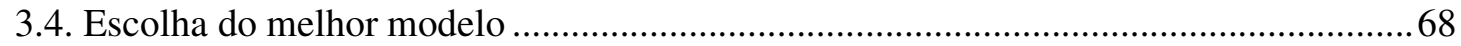

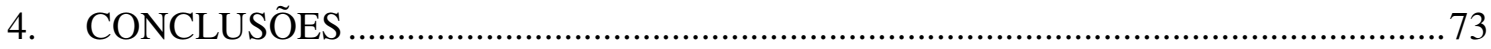

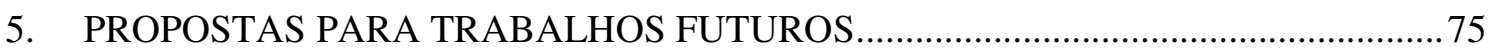

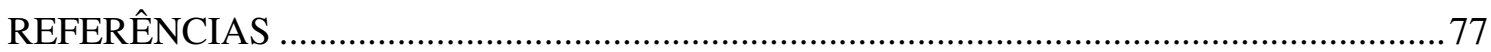

APÊNDICE A - Superfície aerodinâmica utilizada para o projeto......................................... 81

ANEXO A - Requisito de certificação utilizado para estabilidade aeroelástica........................89 
Intencionalmente em branco 
Haverá hoje, talvez, quem ridicularize minhas predições sobre o futuro comercial dos aeroplanos.

Quem viver, porém, verá.

(Santos=Dumont, 1905) 
Intencionalmente em branco 


\section{RESUMO}

BIDINOTTO, J. H. Proposta conceitual de excitador de flutter alternativo para ensaios em vôo. Dissertação (Mestrado). Escola de Engenharia de São Carlos, Universidade de São Paulo. São Carlos, 2007.

Os novos materiais utilizados nas estruturas de aeronaves, mais leves e flexíveis, tornam estas estruturas mais sujeitas a fenômenos aeroelásticos, sendo que o mais sério deles é o flutter, que deve ser cuidadosamente investigado com uma boa campanha de ensaios em vôo durante o desenvolvimento e certificação da aeronave. Este trabalho propõe um projeto conceitual de um excitador de flutter que atenda às necessidades dos ensaios, tentando resolver problemas encontrados nos modelos utilizados comumente. Para isso, é feita uma revisão da literatura pertinente, apresentando conceitos de ensaios em vôo e do fenômeno em questão, além de apresentar um histórico dos ensaios e modelos de excitadores utilizados ao longo da história. Em seguida, são apresentados alguns conceitos de excitadores, que são dimensionados e analisados segundo suas vantagens e desvantagens para finalmente escolher o modelo mais pertinente visando no futuro um projeto detalhado, construção e testes em túnel de vento.

Palavras-chave: Flutter, Excitador, Ensaios em Vôo, Aeroelasticidade. 
Intencionalmente em branco 


\begin{abstract}
BIDINOTTO, J. H. Conceptual purpose of na alternative flutter exciter for flight testing. Dissertação (Mestrado). Escola de Engenharia de São Carlos, Universidade de São Paulo. São Carlos, 2007.
\end{abstract}

The ultimate materials used in aircraft structures, lighter and more flexibles, make these structures more susceptible to aeroelastic phenomena including flutter, the most dangerous of all. This kind of phenomena must be carefully investigated with satisfactory flight test campaigns during the aircraft development and certification. This work proposes a flutter exciter conceptual design that attends the test necessities, trying to solve problems found in the models used actually. So, a bibliographic revision is done, presenting flight test concepts and the studied phenomena, regarding a flight test history and the exciter models used through the years. Finally, some exciter concepts are presented, dimensioned and analyzed considering their advantages and disadvantages in order to choose the most pertinent model, considering, in a near future, the detailed design, manufacturing and wind tunnel tests.

Keywords: Flutter, Exciter, Flight Test, Aeroelasticity 
Intencionalmente em branco 


\section{ÍNDICE DE ILUSTRAÇÕES}

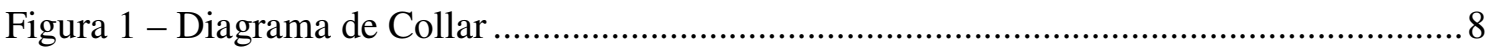

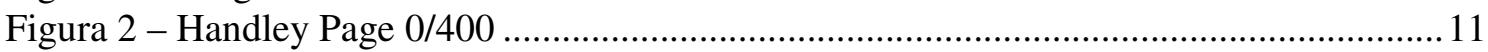

Figura 3 - Situações de aplicação da carga aerodinâmica sobre uma superfície aeronáutica.. 15

Figura 4 - Modelo de Dowel para o cálculo da velocidade de divergência ............................. 16

Figura 5 - Modelo simplificado para estudo do fenômeno flutter .......................................... 17

Figura 6 - Envelope de operação de uma aeronave, conforme descrito pelos requisitos de

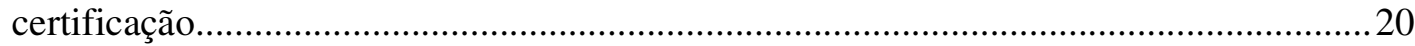

Figura 7 - Gráfico de amortecimento versus velocidade, adaptado da AC ..........................21

Figura 8 - Gráfico de freqüência versus velocidade, adaptado da AC....................................22

Figura 9 - Gráfico dos resultados de ensaio utilizado por Von Schlippe................................23

Figura 10 - Fluxograma do desenvolvimento do modelo aeroelástico de uma estrutura ........24

Figura 11 - Posição dos acelerômetros utilizados em ensaios de flutter...................................25

Figura 12 - Posição dos mecanismos de excitação na aeronave .............................................27

Figura 13 - Condições do envelope de vôo ensaiadas em uma campanha de ensaios em vôo de flutter .

Figura 14 - Comportamento de uma aeronave em termos de frequiência e amortecimento em

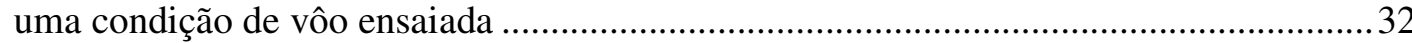

Figura 15 - Resposta da aeronave a excitações realizadas pelos comandos de vôo .................33

Figura 16 -Influência do piloto automático em uma condição simulada.................................34

Figura 17 - Lugar das raízes (evolução das raízes) da equação característica em função da

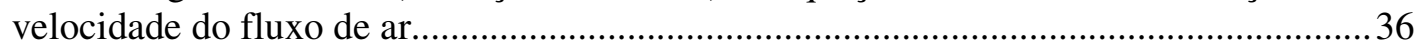

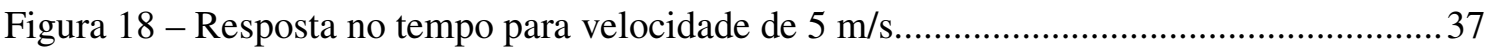

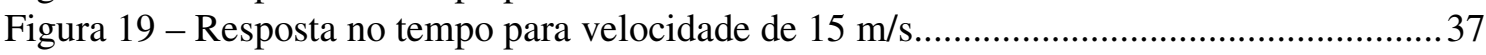

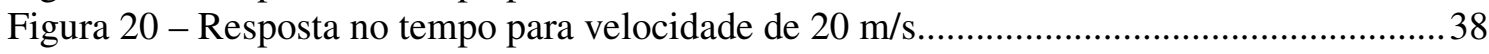

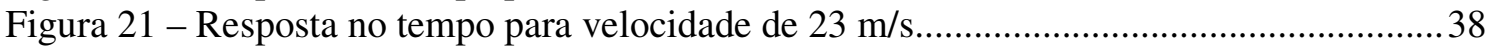

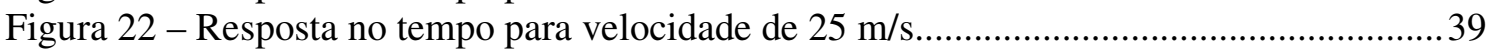

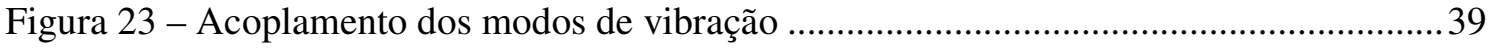

Figura 24 - Viga semi-engastada sujeita a flexão na sua extremidade .................................. 41

Figura 25 - Cargas atuantes no centro aerodinâmico (CA) e no centro de pressão (CP) ........ 42

Figura 26 - Carga aplicada a uma determinada distância do centro de pressão .......................43

Figura 27 - Excitador com aerofólio fino de arqueamento variável .......................................44

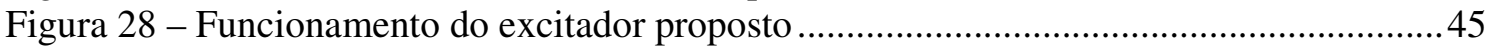

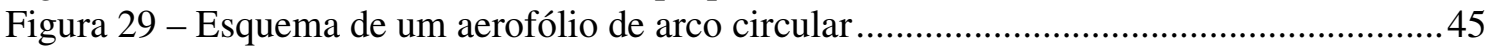

Figura 30 - Malha gerada para a simulação da estrutura e excitador em CFD .........................46

Figura 31 - Detalhes da malha gerada para a simulação................................................... 47

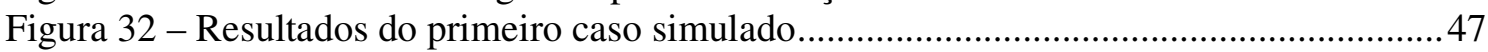

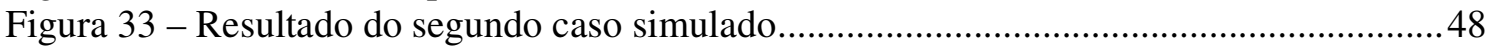

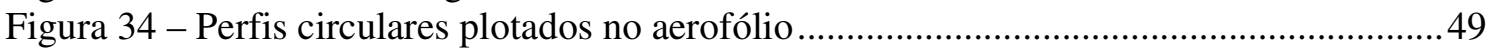

Figura 35 - Grandezas calculadas no dimensionamento do excitador ..................................49

Figura 36 - Excitador de aerofólio fino com arqueamento variável ......................................50

Figura 37 - Esquema da instalação do excitador ...............................................................51

Figura 38 - Esquema do excitador com perfil aerodinâmico com ângulo de ataque variável.52

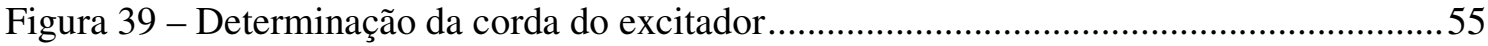

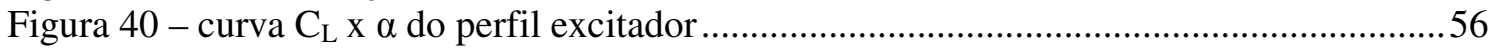

Figura 41 - Perfil aerodinâmico com ângulo de ataque variável ...........................................57

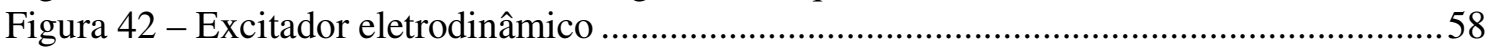


Figura 43 - Esquema de excitação por perfil aerodinâmico com arqueamento variável .........61

Figura 44 - Pressão dinâmica em função da corda do aerofólio .............................................64

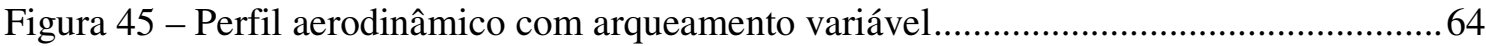

Figura 46 - Cilindro rotativo em fluxo aerodinâmico uniforme - caso bidimensional ...........66

Figura 47 - Medida do máximo diâmetro do cilindro rotativo ............................................67

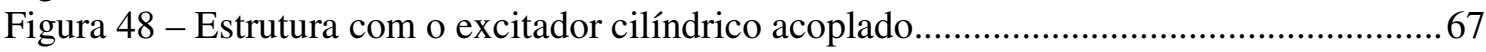

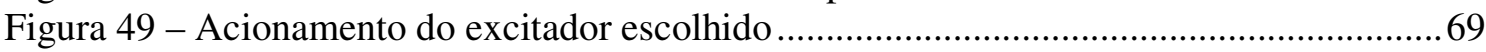

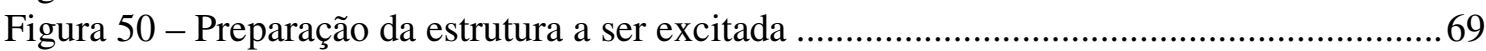

Figura 51 - Material flexível utilizado na montagem do excitador ........................................ 70

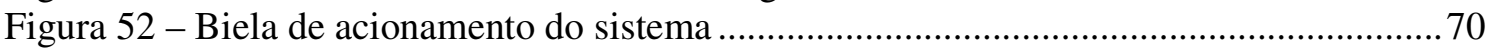

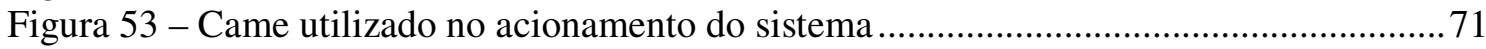

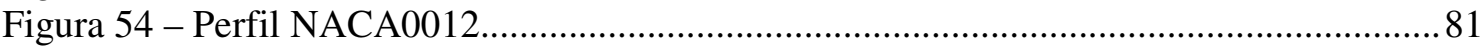

Figura 55 - Fotos asa engastada na estrutura, utilizada no trabalho .....................................82

Figura 56 - Estrutura flexível utilizada como apoio do aerofólio......................................... 83

Figura 57 - Esquema de montagem do sistema e seu posicionamento no túnel de vento ........83

Figura 58 - Primeiro modo de vibração da estrutura (flexão) determinado a $1,3 \mathrm{~Hz}$.............8 84

Figura 59 - Segundo modo de vibração da estrutura (torsão) determinado a $2,1 \mathrm{~Hz}$..............84

Figura 60 - Terceiro modo de vibração da estrutura (flexão) determinado a 13,6 Hz............85

Figura 61 - Quinto modo de vibração da estrutura (barra central) determinado a 27,8 Hz .... 85

Figura 62 - Sexto modo de vibração da estrutura (eixos) determinado a 45,1 Hz.................. 85 


\section{LISTA DE TABELAS}

Tabela 1 - Classificação dos problemas aeroelásticos

Tabela 2 - Vantagens e desvantagens de cada tipo de excitação ............................................28

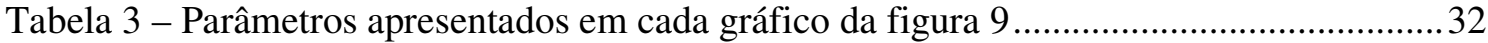

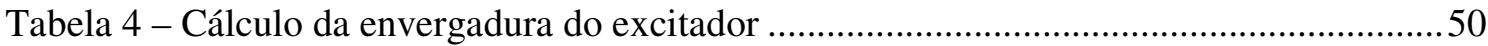

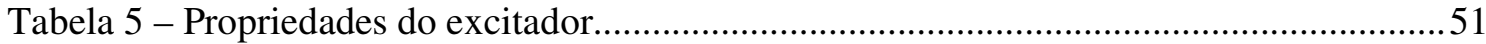

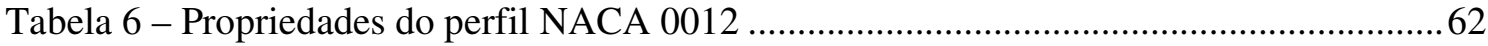

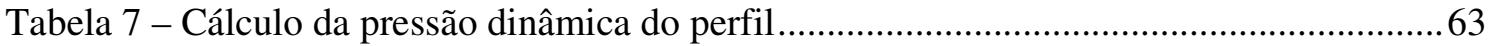

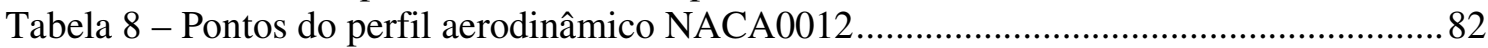

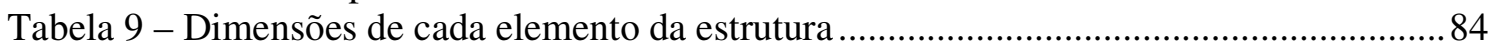

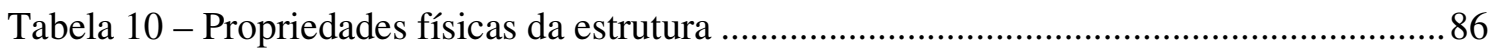

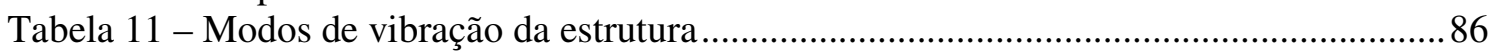

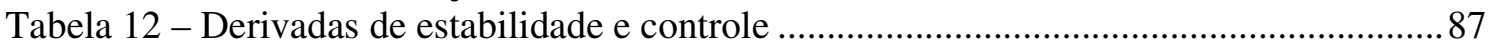


xviii

Intencionalmente em branco 


\title{
LISTA DE ABREVIATURAS E SÍMBOLOS
}

\author{
Abreviaturas: \\ AC Advisory Circular \\ APU Auxiliary Power Unit (Unidade Auxiliar de Potência) \\ CA Centro Aerodinâmico \\ CAD Computer Aided Design (Projeto Assistido por Computador) \\ CFD Computational Fluid Dynamics (Dinâmica dos Fluidos Computacional) \\ CG Centro de Gravidade \\ CP Centro de Pressão \\ EESC Escola de Engenharia de São Carlos \\ GVT Ground Vibration Tests (Ensaios de Vibração em Solo) \\ LADinC Laboratório de Aeroelasticidade, Dinâmica de Vôo e Controle \\ LAE Laboratório de Aerodinâmica \\ NPA Núcleo de Pesquisas em Aeronáutica \\ USP Universidade de São Paulo
}

\section{Símbolos:}

A Amplitude

$\overline{A R} \quad$ Razão de Aspecto

$b \quad$ Envergadura, semi corda do aerofólio

$\bar{c}, c \quad$ Corda média aerodinâmica

$C_{L \alpha} \quad$ Coeficiente de sustentação em função do ângulo de ataque

$C_{M a c} \quad$ Coeficiente de momento em torno do centro aerodinâmico

D Força de arrasto 
$d x, d z \quad$ Fatores de integração

$e \quad$ Distância entre o centro aerodinâmico e a linha elástica

F $\quad$ Força

$f \quad$ Deformação da estrutura devido a flexão, frequiência de excitação

H Campo magnético

$i \quad$ Corrente elétrica

I Momento de Inércia

$k_{C P} \quad$ Posição do centro de pressão

$K_{x} \quad$ Rigidez da mola (tração/compressão)

$K_{h} \quad$ Rigidez de flexão

$K_{\theta} \quad$ Rigidez torsional

$K_{\alpha} \quad$ Rigidez da mola torsional

$l, l_{P} \quad$ Distância

$l \quad$ Força de sustentação para aerofólio bidimensional

$L \quad$ Força de sustentação para o caso tridimensional, comprimento do enrolamento da bobina

$m \quad$ Massa

M Número de Mach

$M_{C A} \quad$ momento em torno do centro aerodinâmico

$M_{C} \quad$ Mach máximo previsto em projeto para cruzeiro

$M_{D} \quad$ Mach máximo previsto em projeto (para mergulho

$M_{F C} \quad$ Mach máximo de efetividade dos comandos

$M_{t} \quad$ Momento torsor

$n \quad$ Número de espiras de um enrolamento

$P \quad$ Carga aplicada na estrutura 


$\begin{array}{ll}q & \text { Pressão dinâmica } \\ q_{d} & \text { Pressão dinâmica de divergência } \\ R & \text { Raio } \\ S & \text { Área do aerofólio } \\ S_{\alpha} & \text { Momento estático } \\ U & \text { Velocidade do ar } \\ v & \text { Velocidade do ar em um determinado ponto } \\ V & \text { Velocidade do ar } \\ V_{C} & \text { Velocidade máxima prevista em projeto para cruzeiro } \\ V_{d} & \text { Velocidade de divergência } \\ V_{D} & \text { Velocidade máxima prevista em projeto (para mergulho) } \\ V_{F C} & \text { Velocidade máxima de efetividade dos comandos } \\ V_{f l u t t e r} & \text { Velocidade de flutter } \\ x_{C A} & \text { Posição do centro aerodinâmico } \\ x & \text { deformação da estrutura por flexão }\end{array}$

\section{Símbolos gregos:}

$\alpha \quad$ Ângulo de ataque

$\alpha_{r} \quad$ Ângulo de ataque para a superfície rígida

$\beta \quad$ Constante dependente de Mach, Ângulo do aerofólio circular

$\Delta p \quad$ Pressão dinâmica

$\zeta_{h} \quad$ Razão de amortecimento em flexão

$\zeta_{\theta} \quad$ Razão de amortecimento torsional

$\mu \quad$ Permeabilidade magnética 
xxii

$\eta \quad$ Constante dependente do formato do aerofólio

$\theta \quad$ Ângulo causado pela torção do aerofólio, Ângulo de incidência

$\rho \quad$ Densidade do ar

$\Lambda_{c / 2} \quad$ Enflechamento da corda média

$\Gamma \quad$ Circulação

$\omega \quad$ Freqüência, velocidade angular

$\omega_{h} \quad$ Freqüência natural de flexão

$\omega_{\theta} \quad$ Freqüência natural de torção

\section{Matrizes e vetores:}

$[M] \quad$ Matriz de massa

$[K] \quad$ Matriz de rigidez

$[Q] \quad$ Matriz de entrada

$\{q\} \quad$ Vetor de variáveis

$\{u\} \quad$ Vetor de carga 


\section{INTRODUÇÃO}

Com o passar dos anos, a engenharia aeronáutica tem se desenvolvido rapidamente para atender melhor às necessidades das missões para as quais as aeronaves são projetadas. Dentre as principais melhorias conquistadas recentemente, pode-se citar o desenvolvimento de novos materiais, tornando as estruturas aeronáuticas mais leves e, consequentemente, mais flexíveis. Dois exemplos conhecidos são as aeronaves Phenom 100 e 787 Dreamliner, desenvolvidas respectivamente pelos fabricantes Embraer e Boeing. O primeiro possui sua empenagem em material composto, enquanto o outro exemplo assumiu o desafio de construir a aeronave toda com este tipo de material.

Tais características, porém, tornam as estruturas mais sujeitas a certos fenômenos, já que uma estrutura exposta a um fluxo de ar possui um determinado carregamento aerodinâmico, que pode modificar o formato da estrutura flexível. Essa mudança de formato modifica seu carregamento, causando novas deformações na estrutura, que novamente pode modificar o carregamento, e assim sucessivamente. Este comportamento é observado até que seja alcançada uma condição de equilíbrio, ou o colapso da estrutura. Tal fenômeno é classificado como aeroelástico. 
Um dos principais fenômenos deste tipo é conhecido como flutter, e se dá pelo acoplamento de dois ou mais modos de vibração, gerando uma condição vibratória instável que pode causar sérios danos ou até mesmo o colapso da estrutura.

Para se evitar a ocorrência deste tipo de vibração, são construídos modelos matemáticos das estruturas aeronáuticas, que são validados de duas formas:

- $\quad$ Ensaios em solo, em que se medem, com a ajuda de acelerômetros, as deformações das estruturas excitadas por shakers e,

- Ensaios em vôo, onde se excita a estrutura em todas as condições de vôo possíveis e num intervalo de freqüências previamente determinado.

Para os casos de ensaios em vôo, são utilizados equipamentos denominados excitadores de flutter ou vanes, que são montados em pontos adequados da estrutura para se excitar esta e levantar os modos de vibração. Tais equipamentos devem trabalhar de forma confiável e em condições muito diversas de pressão, temperatura, velocidade e freqüência, de forma a tornar o ensaio o mais seguro e confiável possível.

Assim, tendo presente os aspectos considerados, este trabalho apresenta a proposta de um projeto conceitual de excitador para os ensaios em questão, cuja construção seria de baixo custo e boa confiabilidade.

Inicialmente é realizada uma revisão bibliográfica, abordando temas que normalmente são específicos para pessoas que atuam na área. Primeiramente é abordado o tema "Ensaios em Vôo", onde se explica esta área de atuação, com um enfoque maior na função do Engenheiro de Ensaios em Vôo durante o desenvolvimento de uma aeronave. Em seguida é feita uma explanação da ciência denominada Aeroelasticidade, com um breve histórico de sua descoberta e ensaios, além de uma explicação resumida de cada um dos fenômenos aeroelásticos conhecidos, dando maior ênfase àquele conhecido como flutter, do qual é fornecido um tratamento matemático simplificado. 
A seguir é apresentado o Requisito de Certificação imposto pelos órgãos homologadores quanto à ocorrência de fenômenos aeroelásticos, e sua interpretação, para em seguida explicar-se os tipos de ensaios realizados na investigação do fenômeno flutter, abordando detalhadamente instrumentação, procedimentos, e análise dos resultados, tomando como base os ensaios realizados em uma aeronave comercial em recente campanha de certificação.

Em seguida são apresentadas propostas conceituais de excitadores de flutter para ensaios. Tais propostas são analisadas levando-se em conta seu dimensionamento, baseado em teorias aerodinâmicas, e levantando-se as vantagens e desvantagens de cada um dos exemplos apresentados. Os excitadores são dimensionados para se adequarem a ensaios no túnel de vento do LAE (Laboratório de Aerodinâmica) do NPA (Núcleo de Pesquisas em Aeronáutica) da Escola de Engenharia de São Carlos da USP, excitando-se uma estrutura já existente na instituição, que é detalhada no apêndice A deste texto.

Para a execução do dimensionamento, são utilizados os resultados de simulações e ensaios realizados na referida estrutura, onde é possível se obter propriedades importantes, como a velocidade de flutter e sua rigidez. Com esses dados em mãos foi calculada a carga que o excitador deveria aplicar na estrutura e seu posicionamento, para a partir deste valor se dimensionar cada uma das cinco diferentes propostas de excitadores, que são:

- $\quad$ Aerofólio fino de arqueamento variável;

- Perfil aerodinâmico com ângulo de ataque variável;

- $\quad$ Excitador eletrodinâmico;

- Perfil aerodinâmico de arqueamento variável;

- Cilindro rotativo.

O texto apresenta detalhadamente cada um dos excitadores, com esquemas e desenhos em CAD dos mesmos. 
Finalmente é feita a escolha do modelo que melhor se adequa às necessidades apresentadas, detalhando-se seu acionamento através de esquemas e apresentando desenhos de cada uma das peças necessárias para seu funcionamento.

Após a escolha o texto apresenta algumas conclusões obtidas no estudo e propostas para trabalhos que devem ser abordados em pesquisas futuras, visando a possível utilização do modelo de excitador apresentado em ensaios a serem realizados em aeronaves reais. 


\section{REVISÃO DA LITERATURA}

\subsection{Ensaios em Vôo}

Ensaios em vôo é um estágio fundamental no desenvolvimento e certificação de equipamentos aeronáuticos que, por envolver atividades muito diversas, como instrumentação, desempenho de aeronaves e sistemas, acaba abrigando engenheiros de diversas especialidades. Ward \& Strganac (1998) a definem como um dos problemas mais excitantes e desafiadores da engenharia, já que o Engenheiro de Ensaios em Vôo, além dos conceitos de engenharia e mecânica de vôo, deve ser um bom planejador, gestor de equipe, possuir um raciocínio rápido e preciso, além de ter boas noções de pilotagem, gerenciamento de riscos, primeiros socorros e boa saúde.

Cabe ao Engenheiro de Ensaios em Vôo tomar conhecimento do problema ou do que se quer testar na aeronave, avaliar e definir a melhor maneira de se fazer o teste, incluindo configuração da aeronave e instrumentação adequada, de forma que possam ser levantados os dados requisitados da melhor maneira possível. Em seguida, ele deve planejar o teste e discutir procedimentos com a área operacional (pilotos), sempre levando em conta os custos e

riscos envolvidos, fazendo tudo da maneira mais prática possível. É realizado, então, o ensaio, 
sempre acompanhado pelo engenheiro, seja a bordo da aeronave, seja via telemetria, que deve avaliar os parâmetros, validando ou não cada etapa do ensaio, anotando as impressões do piloto e as suas próprias. Finalmente cabe ao Engenheiro de Ensaios em Vôo disponibilizar os resultados para a área solicitante, a partir daqueles dados coletados pela instrumentação e de suas anotações que são apresentadas por meio de um relatório, onde especifica as técnicas utilizadas, problemas e discrepâncias encontrados, resultados qualitativos e quantitativos e possíveis sugestões para melhora do sistema, quando for o caso.

No planejamento de uma campanha de ensaios, sempre devem ser levados em conta dois fatores fundamentais: custos e segurança. O primeiro deve ser cuidadosamente mensurado e planejado, já que uma hora de vôo em um ensaio pode custar milhares de dólares. Por isso, ao se iniciar o planejamento deve-se sempre perguntar: o que é realmente indispensável para os resultados esperados? Algum dado pode ser aproveitado de um ensaio que já tenha sido realizado? Existe alguma maneira de reduzir custos ou horas de vôo neste ensaio?

O gerenciamento dos riscos de um ensaio também deve ser cuidadosamente pensado, já que um acidente ou incidente grave pode destruir um equipamento de milhões de dólares, acabar com vidas e até levar uma empresa toda à falência. Dessa forma, durante o planejamento os riscos devem ser medidos, mitigados, apresentados e discutidos tanto com a área operacional como com engenheiros mais experientes no assunto, que podem ter feito ensaio semelhante no passado ou que conhecem muito bem o sistema testado.

Antes do vôo, um briefing cuidadoso deve ser realizado com todas as pessoas envolvidas diretamente no ensaio, sejam engenheiros, pilotos ou equipe de solo (quando for o caso). Os procedimentos devem ser estudados e discutidos, de forma que ao final do briefing não haja nenhuma dúvida para nenhum dos presentes. 
Durante o vôo, os procedimentos devem ser revisados antes de cada ponto de ensaio, realizando-os fielmente de acordo com o cartão de vôo e com o que foi discutido no briefing, levando em conta sempre a segurança e os procedimentos necessários ao bom desempenho do equipamento. Tudo deve ser anotado pelo engenheiro, que deverá formalizar as informações em um relatório que será transmitido aos solicitantes do ensaio.

Ao término do vôo, a mesma equipe deve se reunir e realizar um debriefing, recordando o que ocorreu durante o ensaio, avaliando o comportamento do equipamento, pontos que podem ser melhorados e sugestões para próximos ensaios. Deve, depois, ser feita a disponibilização de todos os dados relevantes e a sugestão de melhorias para o equipamento (quando for o caso). Segundo a Naval Test Pilots School (1992), a tripulação deve ser cuidadosa com as sugestões e rápida na divulgação dos dados, sob o risco de travar todo o processo de desenvolvimento e certificação do equipamento.

A fase de testes normalmente é a mais cara do desenvolvimento de uma aeronave, pois envolve mão de obra de diversas naturezas, como preparação, manutenção, operação, etc., além de utilizar equipamentos caríssimos e pouco convencionais. Por ser a parte final de um longo processo, qualquer mudança proposta por uma equipe de ensaios em vôo pode tornar-se cara e pode demorar meses para ocorrer.

Resumindo, a atividade de ensaios em vôo é muito diversificada e desafiadora, já que todos os dias enfrentam-se problemas das mais variadas formas, além de envolver uma equipe dos mais variados profissionais como pilotos, engenheiros, técnicos, mecânicos e eletricistas, que têm em suas mãos a grande e nobre responsabilidade de garantir o funcionamento de equipamentos que garantirão o futuro da empresa em que trabalham, de suas famílias e até da atividade aeronáutica no país em que vivem. 


\subsection{Aeroelasticidade}

Collar (1946) define aeroelasticidade como a ciência que estuda as interações mútuas entre forças aerodinâmicas, elásticas e inerciais. Bisplinghoff et al. (1955) explicam que o fenômeno ocorre devido à flexibilidade das estruturas, sejam aeronáuticas ou não. Segundo ele, a carga aerodinâmica provoca uma deformação na estrutura, gerando uma distribuição aerodinâmica diferente, que provoca outro tipo de deformação. Em um caso estável, essa interação é cada vez menor, até que seja encontrado um ponto de equilíbrio. Em caso de instabilidade, essas interações divergem até causar falha estrutural.

Inicialmente, Collar (1946) propôs uma classificação para os problemas aeroelásticos utilizando um triângulo com a representação das forças inercial, aerodinâmica e elástica em seus vértices, distribuindo os fenômenos nos campos correspondentes a vibrações mecânicas, estabilidade dinâmica, aeroelasticidade estática e aeroelasticidade dinâmica, dependendo das forças envolvidas em cada fenômeno.

A figura 1 representa o diagrama de Collar, que mais tarde foi proposto por Bisplinghoff et al. (1955) com os fenômenos distribuídos em suas áreas correspondentes.

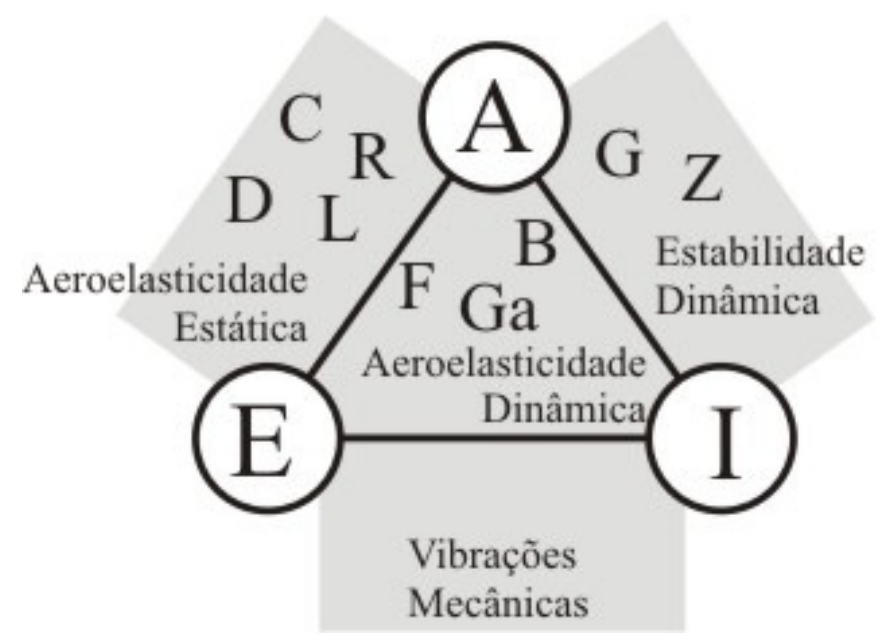

Figura 1 - Diagrama de Collar
A Forças Aerodinâmicas

E Forças Elásticas

I Forças Inerciais

C Efetividade de Comando

$\mathbf{R}$ reversão de Comando

D Divergência

L Distribuição de Carga

G Resposta a Rajadas

Z Resposta a Comandos

F Flutter

B Buffeting

Ga Galloping 
Nitzsche (2001) classifica ainda os problemas aeroelásticos segundo sua solução. Ele afirma que os problemas podem ser divididos em problemas de estabilidade e problemas de resposta, dividindo-os segundo a Tabela 1.

\begin{tabular}{|c|c|c|}
\hline & Estática & Dinâmica \\
\hline Estabilidade & - $\quad$ Divergência & - $\quad$ Flutter \\
\hline Resposta & $\begin{array}{ll}\text { - } & \text { Distribuição de carga } \\
\text { - } & \text { Efetividade de comando } \\
\text { - } & \text { Reversão de comando }\end{array}$ & $\begin{array}{ll}\text { - } & \text { Resposta a rajadas } \\
\text { - } & \text { Resposta a comandos } \\
\text { - } & \text { Buffeting } \\
\text { - } & \text { Galloping }\end{array}$ \\
\hline
\end{tabular}

Tabela 1 - Classificação dos problemas aeroelásticos

Segundo Nitzsche (2001), a solução destes problemas se dá pela solução de equações homogêneas (problemas de autovalor) para os casos de estabilidade, e de equações nãohomogêneas para os casos de resposta. Uma forma de se representar os operadores e sua solução seria a seguinte:

$$
(S+A+I)[x]=\left\{\begin{array}{cc}
0 & (\text { estabilidade }) \\
f(t) & (\text { resposta })
\end{array}\right.
$$

Onde:

$A$ é o operador aerodinâmico, que é função do número de Mach, da geometria da estrutura, da velocidade e do ângulo de ataque;

$S$ é o operador estrutural, que depende do tipo de estrutura utilizada (viga, placa, sólido, etc.);

I é o operador inercial (lei de Newton);

$x$ variável a ser calculada no problema;

$f(t)$ entrada (carga) aplicada no sistema.

Da equação (1) pode-se concluir que os problemas de estabilidade são auto-excitados, ou seja, se aplicada uma perturbação inicial, o fenômeno se desenvolve independentemente de 
fatores externos, diferentemente dos problemas de resposta, onde a remoção da carga aplicada (representada como $f(t))$ é suficiente para cessar a ocorrência do fenômeno.

Estruturas aeronáuticas, por estarem sujeitas a grandes cargas aerodinâmicas e por serem leves e flexíveis, são muito sujeitas à ocorrência de fenômenos deste tipo, portanto no projeto de qualquer nova estrutura aeronáutica deve-se demonstrar que ela é livre desses fenômenos por cálculos analíticos, simulações computacionais, ensaios em solo (incluindo testes em túnel de vento) e ensaios em vôo dentro das condições de operação previstas

A seguir é apresentado um breve histórico e depois a definição resumida de cada fenômeno aeroelástico citado anteriormente, conforme a classificação de Nitzsche (2001):

\subsubsection{Histórico}

De Marqui et al. (2001) relatam que desde os primeiros vôos realizados pelo homem houve a ocorrência de fenômenos aeroelásticos, mesmo a baixas velocidades e não sujeitando a aeronave a situações tão críticas.

Bisplinghoff et al. (1955) afirmam que o primeiro caso relatado de uma aeronave afetada por um fenômeno aeroelástico foi o projeto do professor Langley, que fracassou devido a uma falha estrutural na ponta das asas de seu monoplano, num possível caso de divergência. Esse caso, somado ao sucesso do "vôo" do biplano projetado pelos irmãos Wright e o vôo do 14-Bis de Santos Dummont influenciou os projetistas do início da era da aviação a favor dos biplanos, que seriam muito utilizados durante a primeira guerra mundial.

O primeiro estudo de um fenômeno aeroelástico ocorreu na primeira guerra mundial, devido a um caso de flutter no bombardeiro Handley Page 0/400. Uma solução simples, tal como a interligação das duas superfícies do profundor (que a princípio eram independentes), foi capaz de sanar o problema. Porém não foi tão simples a solução dos problemas ocorridos 
nas aeronaves alemãs Albatros D-III e Fokker D-VIII, que, no mesmo período, apresentaram sérios problemas de divergência.

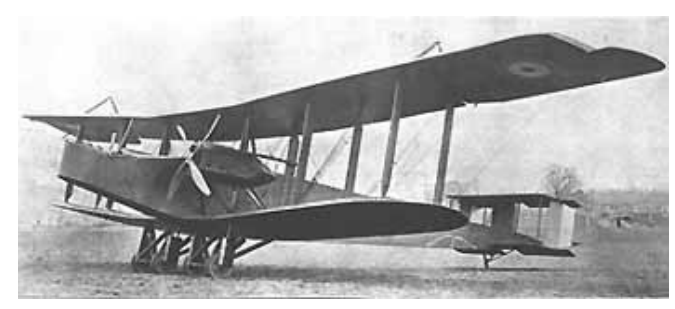

Figura 2 - Handley Page 0/400

Foram os estudos em aeroelasticidade, segundo De Marqui et al. (2001), que permitiram o início do desenvolvimento dos monoplanos, por volta de 1930. Foi nesta época também que surgiram conceitos como os de modo de vibração, modelos em escala, ensaios em túnel de vento, entre outros, que contribuíram de modo fundamental para o desenvolvimento da aeronáutica.

Foi ainda na década de 30 que os modelos teóricos do fenômeno flutter começaram a apresentar resultados próximos dos experimentais e Theodorsen desenvolveu uma das mais importante teoria sobre o fenômeno. Kehoe (1995) afirma que foi em 1935 que foi realizado o primeiro ensaio em vôo de flutter, onde von Shlippe utilizou técnicas que, apesar de primitivas, trouxeram bons resultados.

Com a Segunda Guerra Mundial as aeronaves passaram a alcançar velocidades próximas às do som e a carregar cargas externas como armamentos, tanques de ponta de asa, etc. De Marqui et al. (2001) relatam que isso gerou uma grande ocorrência de fenômenos aeroelásticos. Estes problemas levaram à necessidade de um desenvolvimento nas técnicas de ensaios.

Utilizando radares e telemetria, que na época estavam em desenvolvimento, iniciaramse testes onde se lançavam modelos de aeronaves ou se prendiam superfícies aeronáuticas 
excitadoras no avião para se realizarem testes durante o vôo. Tais técnicas foram fundamentais para o estudo do comportamento de aeronaves em regime transônico, levandose em conta os efeitos de compressibilidade.

No final da década de 40 as primeiras aeronaves passaram a romper a barreira do som, gerando problemas até então desconhecidos, como o flutter de painel, que depende de efeitos térmicos e compressibilidade. Tais problemas estimularam muitas pesquisas nas décadas de 50 e 60, principalmente no tocante a fenômenos supersônicos, fadiga e tensões devidas a efeitos térmicos.

Segundo De Marqui et al. (2001), a partir da década de 70, iniciou-se o desenvolvimento de sistemas de controle para o aumento de estabilidade e melhoria na resposta dinâmica das aeronaves. Paralelamente a isso, foram desenvolvidos computadores mais potentes que permitiram o uso de técnicas de simulação como o CFD. Ambos os fatores associados levaram a uma maior confiabilidade do projeto, permitindo que as aeronaves ficassem cada vez mais leves e atingissem condições de vôo cada vez mais críticas.

Atualmente são realizadas pesquisas no campo da aeroservoelasticidade, que envolvem a interação entre dinâmica estrutural, cargas aerodinâmicas e sistemas de controle. Esse campo, atualmente muito promissor, pode levar a um grande desenvolvimento das aeronaves no sentido de se evitar fenômenos aeroelásticos.

\subsubsection{Problemas Aeroelásticos de Resposta}

Como visto anteriormente, estes problemas podem ser classificados como estáticos ou dinâmicos e cada um dos fenômenos conhecidos serão brevemente descritos a seguir. Tais fenômenos são caracterizados por ocorrerem em situações de vôo extremas e influenciar na vida útil da estrutura, gerando fadiga ou outros efeitos indesejados. Por não serem objeto de 
estudo deste trabalho, serão apresentadas breves definições sugeridas por Bisplinghoff et al. (1955) e Dowell et al. (2004).

Distribuição de Carga (L): influência das deformações elásticas da estrutura na distribuição de pressões aerodinâmicas pela sua superfície.

Efetividade de Comando (C): influência das deformações elásticas da estrutura causadas por altas incidências aerodinâmicas, o que pode resultar em diminuição da eficiência aerodinâmica ou não-linearidade das respostas da aeronave aos comandos, afetando severamente sua controlabilidade.

Reversão de comando (R): fenômeno que ocorre a uma determinada velocidade, onde os efeitos causados pela deformação da estrutura fazem com que a carga aerodinâmica aplicada por um comando tenham efeito inverso ao esperado na resposta da aeronave.

Resposta a Rajadas $(\mathrm{G})$ : resposta dinâmica da aeronave a uma carga aplicada repentinamente resultante de uma rajada, levando em conta os efeitos da deformação da estrutura devido à pressão aerodinâmica.

Resposta a Comandos (Z): resposta dos componentes estruturais da aeronave a impulsos aerodinâmicos provocados por movimentos abruptos dos comandos de vôo.

Buffeting (B): vibração dos componentes estruturais da aeronave que ocorre quando alguma seção da estrutura é sujeita à ação de vórtices gerados por outras partes da aeronave, especialmente em manobras de alto ângulo de ataque. Normalmente esse fenômeno ocorre em aeronaves onde sua empenagem está sujeita à esteira aerodinâmica gerada pelas asas, que em condições de alto ângulo de ataque pode gerar o descolamento do fluxo aerodinâmico, deixando a empenagem sujeita a um fluxo aerodinâmico perturbado, causando vibrações indesejadas.

Galloping (Ga): vibração de grande amplitude que pode ocorrer no eixo vertical de estruturas, inclusive civis, sujeitas a um fluxo aerodinâmico, e que possuam formato e ângulo 
de incidência apropriados. Normalmente a formação de gelo em superfícies de aeronaves pode facilitar a ocorrência deste fenômeno.

\subsubsection{Problemas Aeroelásticos de Estabilidade}

Existem dois principais fenômenos de estabilidade aeroelástica, sendo um dinâmico e o outro estático. Tais fenômenos são de maior importância no estudo da aeroelasticidade, pois causam falha imediata da estrutura e podem ocorrer em situações de vôo típicas, ou seja, longe dos extremos do envelope operacional da aeronave. Por esse motivo, serão apresentadas definições mais detalhadas desse tipo de fenômeno.

Flutter (F): instabilidade dinâmica que ocorre em vôo na denominada "velocidade de flutter". Pela figura 1 pode-se observar que a elasticidade, a inércia e a carga aerodinâmica influenciam na sua ocorrência. Este fenômeno, por ser o objeto principal de estudo deste trabalho, será explicado detalhadamente em uma seção à parte.

Divergência (D): instabilidade estática de uma superfície aerodinâmica que ocorre na denominada "velocidade de divergência", onde a elasticidade da estrutura, aliada à carga aerodinâmica aplicada, tem papel fundamental na sua ocorrência.

A National Test Pilots School (1995) define divergência como a condição em que o momento aerodinâmico excede o momento restaurador elástico.

Se a resultante da carga aerodinâmica é aplicada sobre a linha neutra da asa, ela irá apenas fletir, como demonstrado na figura 2. Mas se esta é aplicada em qualquer outro ponto, a asa sofrerá também uma torção. Se a linha neutra está à frente da resultante da carga, a asa tende a se deformar de modo a diminuir seu ângulo de ataque. Nesse caso, a torção estará agindo em sentido contrário à sustentação da asa, fazendo com que a interação destas duas cargas levem a uma condição estável ou de equilíbrio. 
Se a resultante da carga aerodinâmica, por sua vez, for aplicada à frente da linha neutra, o momento torsional agirá de forma a aumentar o ângulo de ataque, o que aumentará a sustentação, aumentando o momento torsional. Dessa forma a deformação aumentará, fazendo com que a situação seja realimentada, agravando o fenômeno e gerando uma situação de instabilidade. Quando esta carga ultrapassar o limite estrutural, ocorrerá o rompimento da estrutura.

Carga sobre a linha neutra

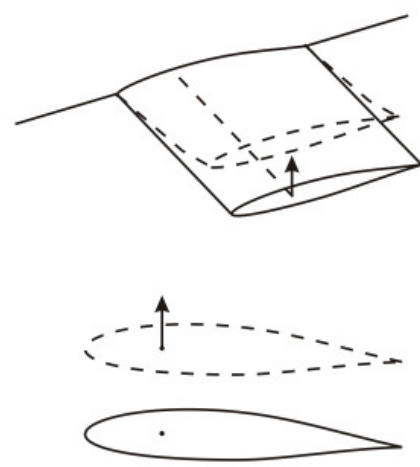

Somente flexão
Carga atrás da linha neutra
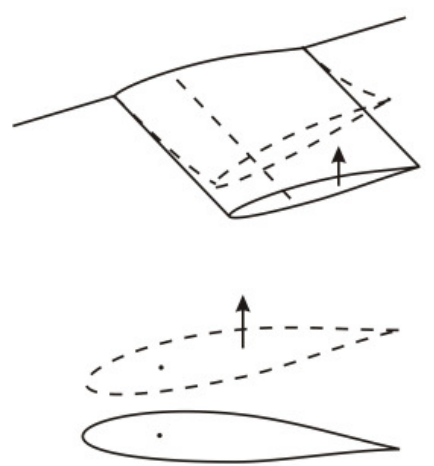

Situação estável
Carga à frente da linha neutra
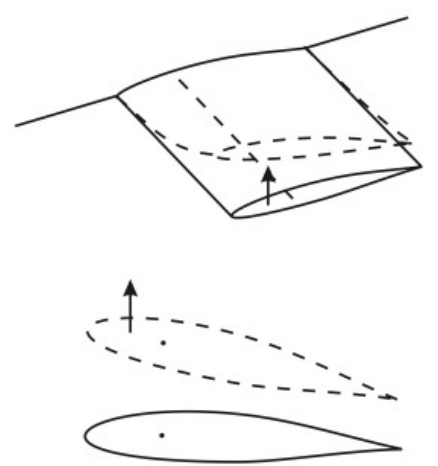

Situação instável

Figura 3 - Situações de aplicação da carga aerodinâmica sobre uma superfície aeronáutica

A sustentação e consequentemente o momento aerodinâmico são funções da pressão dinâmica. Sendo assim, existe uma velocidade onde o momento torsional se iguala ao momento restaurador, que é chamada velocidade de divergência $\left(V_{d}\right)$.

Um modelo típico de divergência aplicada em uma seção de aerofólio foi retirada de Dowel (1995) e é mostrado na figura 3.

Nela apresenta-se um aerofólio com uma força de sustentação $L$ aplicada no centro aerodinâmico, que sofre um momento $M_{a c}$ e é engastado por uma mola torsional na linha elástica, com uma constante $K_{\theta}$. O centro aerodinâmico se distancia da linha elástica por $e$ e o ângulo de ataque do aerofólio se divide em duas partes: o ângulo de ataque rígido $\alpha_{r}$ e o ângulo causado pela torção no aerofólio $\theta$. No equilíbrio, a soma o momento aerodinâmico com relação à linha elástica deve ser igual ao momento restaurador, $K_{\theta} \theta$. 


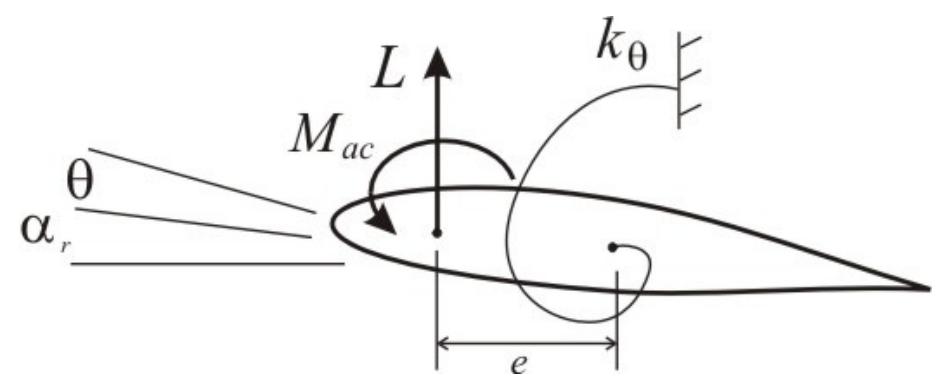

Figura 4 - Modelo de Dowel para o cálculo da velocidade de divergência

Somando os momentos aplicados em torno da linha elástica, tem-se:

$M=L e-M_{a c}=e q S C_{L \alpha}\left(\alpha_{r}+\theta\right)-q S \bar{c} C_{M a c}=K_{\theta} \theta$

Logo, $\theta=\frac{q S\left(e C_{L \alpha} \alpha_{r}-\bar{c} C_{M a c}\right)}{K_{\theta}-q S e C_{L \alpha}}$

Onde:

$q$ é a pressão dinâmica;

$S$ é a área do aerofólio

$C_{L \alpha}$ é o coeficiente de sustentação do aerofólio em função do seu ângulo de ataque;

$\bar{c}$ é a corda média aerodinâmica;

$C_{M a c}$ é o coeficiente de momento de arfagem em torno de seu centro aerodinâmico.

Na divergência, o ângulo de torção $\theta$ tende ao infinito, logo o denominador deve ser igual à zero.

$$
K_{\theta}-q S e C_{L \alpha}=0
$$

Para pressão dinâmica:

$$
q_{d}=1 / 2 \rho V_{d}^{2}=\frac{K_{\theta}}{S e C_{L \alpha}} \Rightarrow V_{d}=\sqrt{\frac{K_{\theta}}{1 / 2 \rho S e C_{L \alpha}}}
$$

Onde $q_{d}$ e $V_{d}$ são a pressão dinâmica e a velocidade de divergência, respectivamente. 
A National Test Pilots School (1995) afirma que tal modelo é simplista e possui hipóteses grosseiras, mas dá uma boa idéia dos parâmetros e como eles influenciam no valor da velocidade de divergência.

\subsubsection{Flutter}

Bisplinghoff et al. (1955) e Ward \& Strganac (1998) definem flutter como um fenômeno aeroelástico vibratório que ocorre quando há o acoplamento de dois ou mais modos de vibração, tornando a estrutura instável. Para uma viga semi-engastada (como no caso de superfícies aerodinâmicas típicas), normalmente os modos acoplados são do tipo de torção e de flexão.

A figura 5 apresenta um modelo clássico utilizado para equacionamento deste tipo de fenômeno. Tais dados foram obtidos de Bisplinghoff et al. (1955)

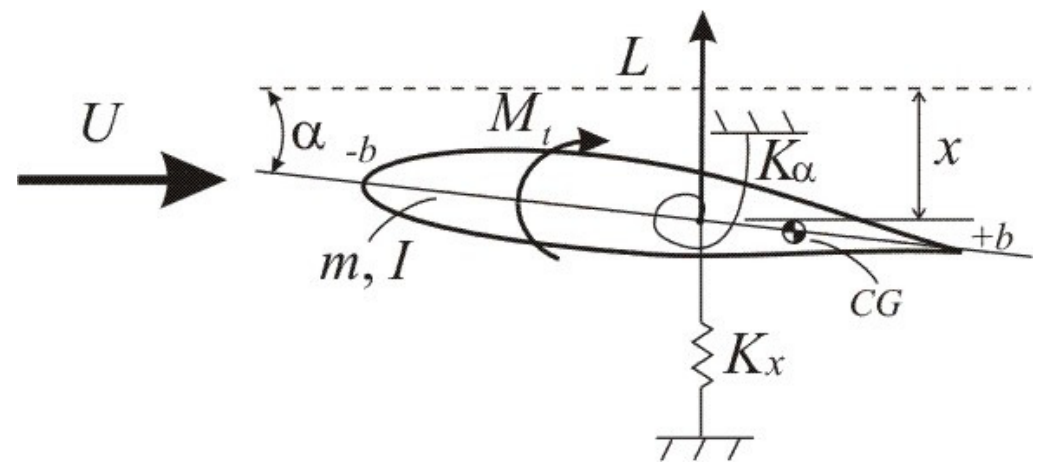

Figura 5 - Modelo simplificado para estudo do fenômeno flutter

O modelo apresenta uma seção típica com os dois modos em questão. A equação de movimento para cada grau de liberdade, utilizando a equação de Lagrange, é:

$$
\begin{aligned}
& m \ddot{x}+S_{\alpha} \ddot{\alpha}+K_{x} x=L \\
& -S_{\alpha} \ddot{x}+I \ddot{x}+K_{\alpha} \alpha=M_{t}
\end{aligned}
$$


Onde:

$S_{\alpha}$ é o momento estático da estrutura

Adimensionalizando as equações pelo fator $1 / \mathrm{mb}^{2}$ :

$\left(\frac{\ddot{x}}{b}\right)-x_{\alpha} \ddot{\alpha}+\left(\frac{x}{b}\right)=\frac{L b}{m b^{2}}$

$-x_{\alpha}\left(\frac{\ddot{x}}{b}\right)+r_{\alpha}^{2} \ddot{\alpha}+r_{\alpha}^{2} \omega_{\alpha}^{2} \alpha=\frac{M}{m b^{2}}$

Onde:

$x_{\alpha}=\frac{S_{\alpha}}{m b} ; \quad \omega_{x}^{2}=\frac{K_{x}}{m} ; \quad \omega_{\alpha}^{2}=\frac{K_{\alpha}}{I} ; \quad r_{\alpha}^{2}=\frac{I}{m b^{2}} ;$

$m=\mu \pi \rho b^{2}$

$\rho$ é a densidade do fluido;

$\mu$ é a razão de massa;

Adotando

$L=1 / 2 C_{L} \rho U^{2}(2 b)$

$M=1 / 2 C_{M} \rho U^{2}(2 b)^{2}$

Pode-se encontrar a equação de movimento para o caso bidimensional dada por:

$\left[\begin{array}{cc}1 & -x_{\alpha} \\ -x_{\alpha} & r_{\alpha}^{2}\end{array}\right]\left\{\begin{array}{c}\ddot{x} / b \\ \ddot{\alpha}\end{array}\right\}+\left[\begin{array}{cc}\omega_{x}^{2} & 0 \\ 0 & r_{\alpha}^{2} \omega_{\alpha}^{2}\end{array}\right]\left\{\begin{array}{c}x / b \\ \alpha\end{array}\right\}=\beta\left[\begin{array}{cc}1 & 0 \\ 0 & 2\end{array}\right]\left\{\begin{array}{c}C_{L} \\ C_{M}\end{array}\right\}$

Sendo $\beta=\frac{U^{2}}{\mu \pi b^{2}}$

Reescrevendo a equação acima de modo geral, tem-se:

$[M]\{\ddot{q}\}+[K]\{q\}=[Q]\{u\}$ 
Onde:

$$
\begin{aligned}
& {[M]=\left[\begin{array}{cc}
1 & -x_{\alpha} \\
-x_{\alpha} & r_{\alpha}^{2}
\end{array}\right] \text { é a matriz de massa; }} \\
& {[K]=\left[\begin{array}{cc}
\omega_{x}^{2} & 0 \\
0 & r_{\alpha}^{2} \omega_{\alpha}^{2}
\end{array}\right] \text { é a matriz de rigidez; }} \\
& {[Q]=\beta\left[\begin{array}{ll}
1 & 0 \\
0 & 2
\end{array}\right] \text { é a matriz de entrada; }} \\
& \{q\}=\left\{\begin{array}{c}
x / b \\
\alpha
\end{array}\right\} \text { é o vetor das variáveis; } \\
& \{u\}=\left\{\begin{array}{l}
C_{L} \\
C_{M}
\end{array}\right\} \text { é o vetor das cargas aplicadas. }
\end{aligned}
$$

A equação (13) é um bom modelo matemático para a simulação do comportamento do sistema quando sujeito ao fenômeno flutter.

\subsection{Requisitos de Certificação}

O Requisito Brasileiro de Homologação Aeronáutica (RBHA) para aeronaves de passageiros referencia, para certificação de aeronaves baseados na estabilidade aeroelástica, o parágrafo $§ 25.629$ do FAR 25.

O texto do requisito em questão é apresentado no apêndice A, em seu original em inglês.

O requisito de certificação prevê avaliação de estabilidade aeroelástica de flutter, divergência, reversão de comandos e perda de estabilidade devido a deformação estrutural. 
São utilizados para essa avaliação testes em túnel de vento, ensaios em solo, em vôo ou outro teste que possa ser solicitado pela autoridade certificadora.

É necessário que a aeronave seja estável e não apresente falhas em qualquer configuração ou combinação de altitude e velocidade até à $V_{D} / M_{D}$, acrescido de $15 \%$ na altitude, diminuindo-se a velocidade de forma que o número de Mach permaneça constante $\left(M_{D}\right)$, sempre limitando-se a Mach 1,0. Não devem ser observadas mudanças bruscas de comportamento próximo à $V_{D} / M_{D}$.

O envelope é definido como sendo uma extensão de $15 \%$ na $V_{C}$ a altitude constante, do nível do mar até à interseção de $1,15 V_{C}$ com a extensão do número de Mach. Então uma variação linear da velocidade até $M_{C}+0,05$ à menor altitude de interseção $V_{C} / M_{C}$. Em altitudes maiores define-se $M_{C}+0,05$ a altitude constante. A figura 6 mostra um esquema de envelope de operação de uma aeronave.

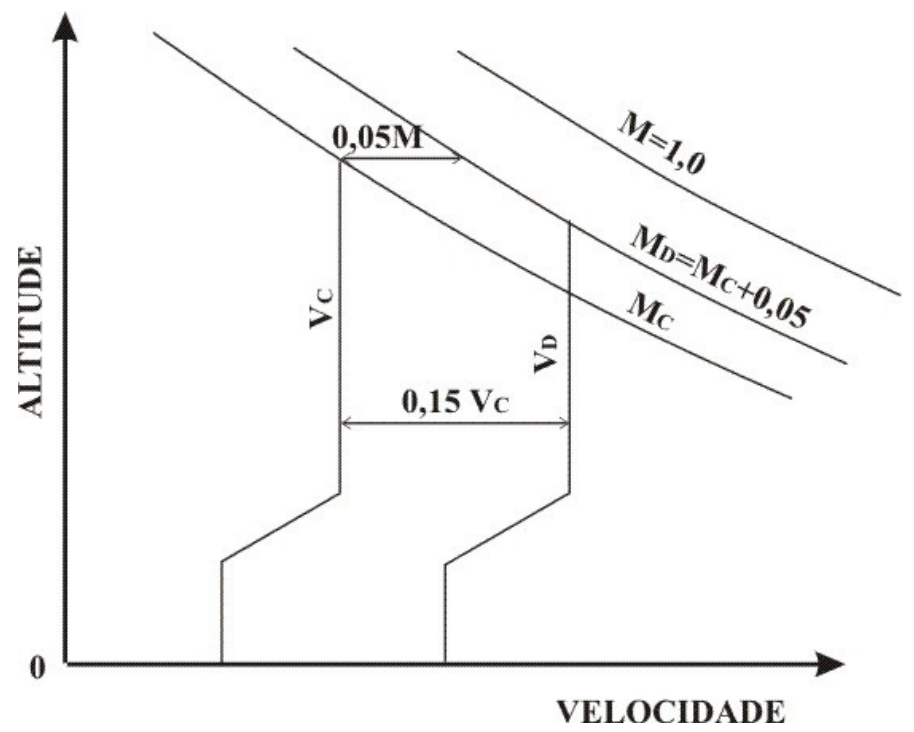

Figura 6 - Envelope de operação de uma aeronave, conforme descrito pelos requisitos de certificação 
O requisito exige que, em caso de cargas penduradas na aeronave, tais como tanques de combustível, elas devem ser consideradas no cálculo da estabilidade, além de todos os tipos de falhas e condições adversas possíveis.

Ensaios de flutter devem ser realizados até à $V_{D} / M_{D}$, demonstrando que até essa velocidade não deve existir redução brusca no amortecimento. Em caso de falha durante o ensaio, deve-se investigar até à $V_{F C} / M_{F C}$, podendo-se aproveitar dados de outros ensaios que atinjam essa velocidade.

As AC (Advisory Circulars) 23 e 25 (Federal Aviation Administration - U.S. Department of Transportation, 1998) sugerem que sejam analisados os gráficos de velocidade versus amortecimento e velocidade versus frequiência para a análise de fenômenos aeroelásticos.

A figura 7 apresenta um gráfico de velocidade por amortecimento adaptado da AC, onde mostra 5 diferentes modos de vibração medidos em uma estrutura hipotética.

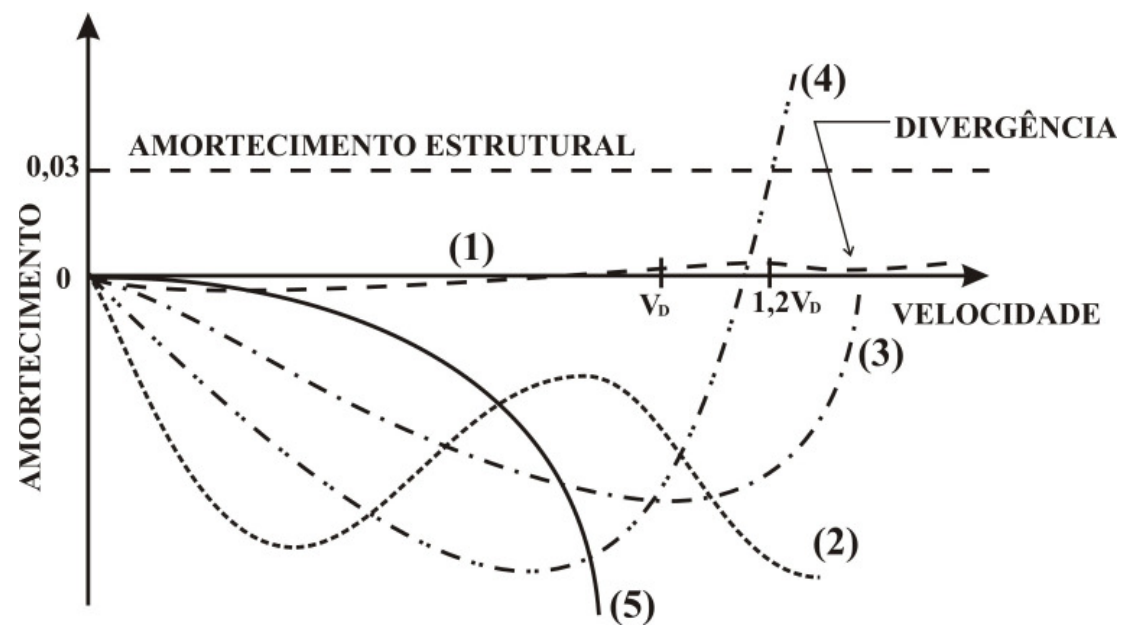

Figura 7 - Gráfico de amortecimento versus velocidade, adaptado da AC

O modo (1) refere-se a uma raíz que, adotado o amortecimento estrutural (tipicamente utilizado 0,03), torna-se estável, assim como (2) e (5). O modo (3) representa um caso típico de divergência, quando a raíz vai abruptamente a zero, mas isso ocorre a uma velocidade 
acima da margem utilizada para a análise. O modo (4) mostra uma raíz que torna-se instável exatamente a $20 \%$ acima da $V_{D}$, sendo considerada aceitável pela análise.

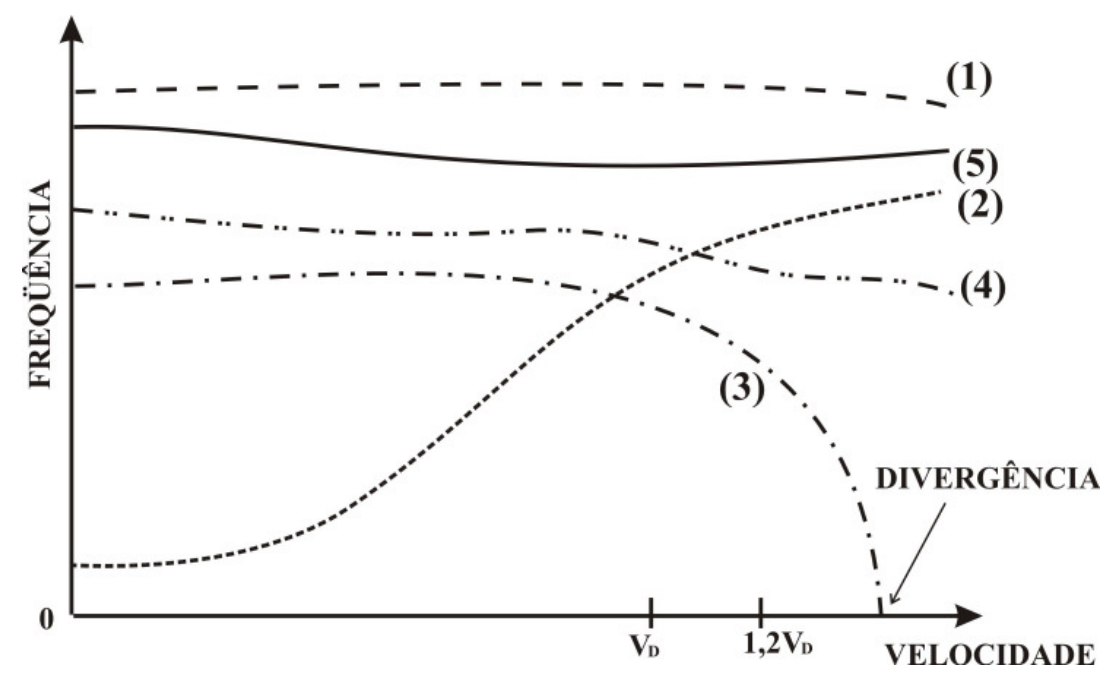

Figura 8 - Gráfico de freqüência versus velocidade, adaptado da AC

A figura 8 mostra um gráfico de freqüência por velocidade adaptado da $\mathrm{AC}$, que também ilustra 5 modos de vibração. A freqüência obtida à velocidade zero é gerada por ensaios em solo. Analisando este gráfico não é possível saber com certeza a existência de flutter, mas sabe-se que quando se aproxima da velocidade de flutter, as freqüências se aproximam para que haja o acoplamento, assim como ilustrado na figura pelos modos (1), (2) e (5) em velocidades acima de $1.2 V_{D}$. É possível também verificar divergência no modo (3), já que a freqüência vai a zero.

\subsection{Ensaios em Vôo de Flutter}

Kehoe (1995) afirma que os primeiros ensaios em vôo para estudo de flutter foram realizados em 1935 por von Schlippe e sua técnica consistia em excitar a aeronave em freqüências ressonantes em velocidades cada vez mais altas, plotando a amplitude da resposta em função da velocidade. Isso significa que o aumento da amplitude correspondia à 
diminuição no amortecimento. Com essa técnica, a velocidade de flutter era determinada pela assíntota da curva quando a amplitude tendesse ao infinito. A figura 9 mostra um gráfico semelhante ao obtido no ensaio de von Schlippe.

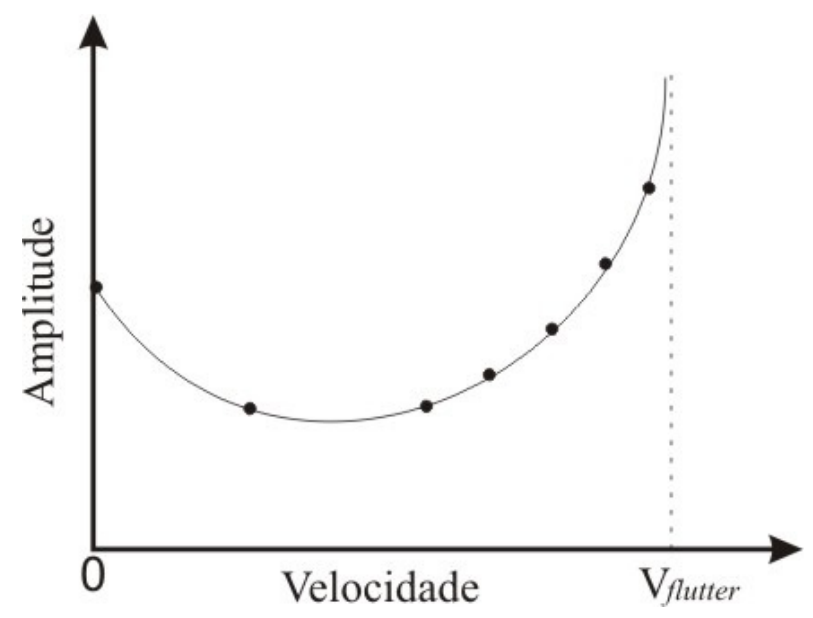

Figura 9 - Gráfico dos resultados de ensaio utilizado por Von Schlippe

Com o desenvolvimento dos instrumentos de medição, da computação e de novas técnicas, os ensaios de flutter tornaram-se mais acurados e seguros, porém ainda assim são considerados de alto risco e devem ser planejados e executados de forma cuidadosa.

As empresas realizam, hoje em dia, um método interativo para os testes de flutter, envolvendo modelos matemáticos, ensaios em solo e ensaios em vôo.

A National Test Pilots School (1995) relata que inicialmente são levantadas características importantes referentes ao comportamento da aeronave através de modelos teóricos que são validados com modelos em escala, como modos de vibração e frequiências naturais. Em seguida são realizados testes chamados GVT (ground vibration tests) e medidas de rigidez. Estes testes consistem em excitar a aeronave em determinadas frequiências, utilizando shakers ou martelos de impacto, e medir as respostas por meio de acelerômetros ou de strain-gages. Todos estes dados são utilizados para validação e refinamento do modelo matemático, para em seguida se realizarem os ensaios em vôo. 
Van Nunen \& Piazzoli (1979) apresentam um fluxograma de desenvolvimento do comportamento aeroelástico de uma estrutura, que é mostrado na figura 10.

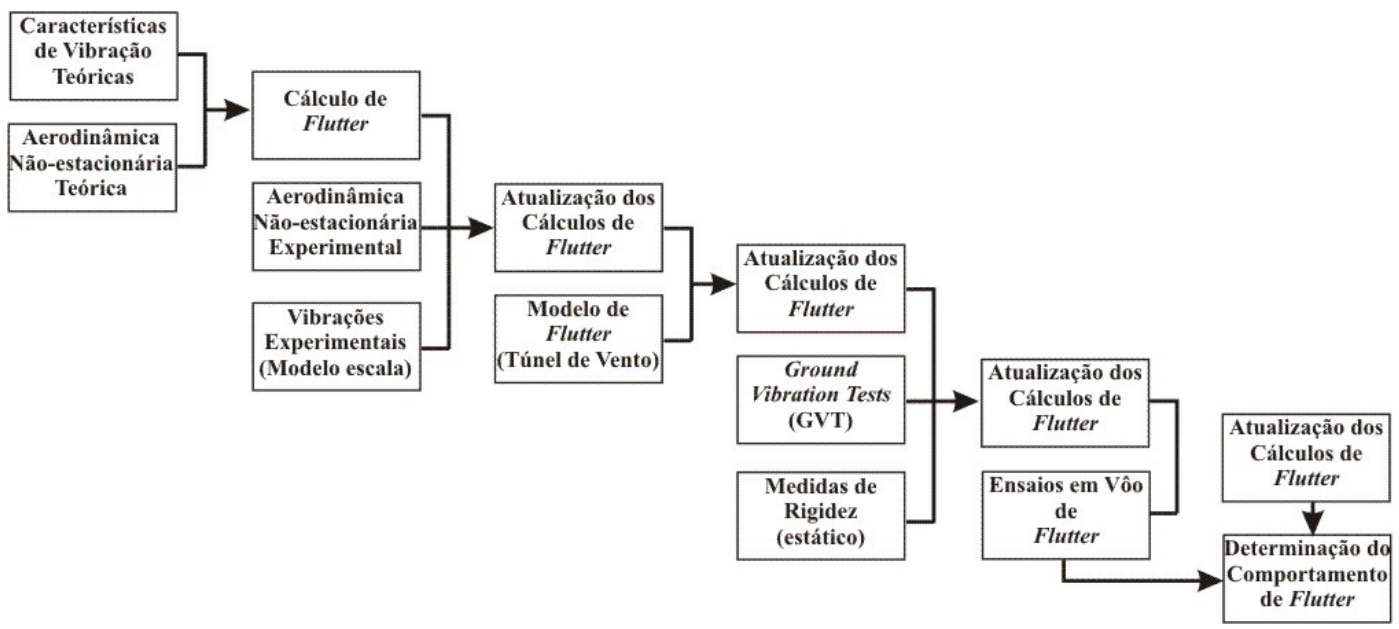

Figura 10 - Fluxograma do desenvolvimento do modelo aeroelástico de uma estrutura

São utilizados ainda ensaios em túnel de vento, com modelos em escala, para levantamento das cargas aerodinâmicas e da mesma forma melhorar o modelo matemático. Ward \& Strganac (1998) afirmam ainda que mesmo durante a campanha de ensaios em vôo, ajustes importantes podem ser feitos no modelo matemático. Por esse motivo, ensaios em vôo de flutter são caros, consomem tempo e, mesmo com instrumentação adequada, possuem alto risco envolvido.

\subsubsection{Instrumentação}

Ward \& Strganac (1998) afirma que a instrumentação necessária para ensaios deste tipo consiste apenas em acelerômetros colocados nas superfícies aerodinâmicas, tais como asas e empenagens, e regiões sujeitas a vibrações, tais como naceles e motores.

A National Test Pilots School (1995) reforça que a coleta de dados deve ser feita com alta taxa de amostragem, pois as características de estabilidade podem variar abruptamente 
com uma pequena variação na velocidade. A figura 11 mostra as posições dos acelerômetros utilizados nos ensaios típicos de flutter de uma aeronave durante sua campanha de ensaios de certificação. Nota-se que os acelerômetros são concentrados nas superfícies aerodinâmicas e em algumas regiões de interesse, como pilones e escapamento do APU. Alguns acelerômetros são colocados na fuselagem de modo a se determinar o comportamento vibratório da aeronave.

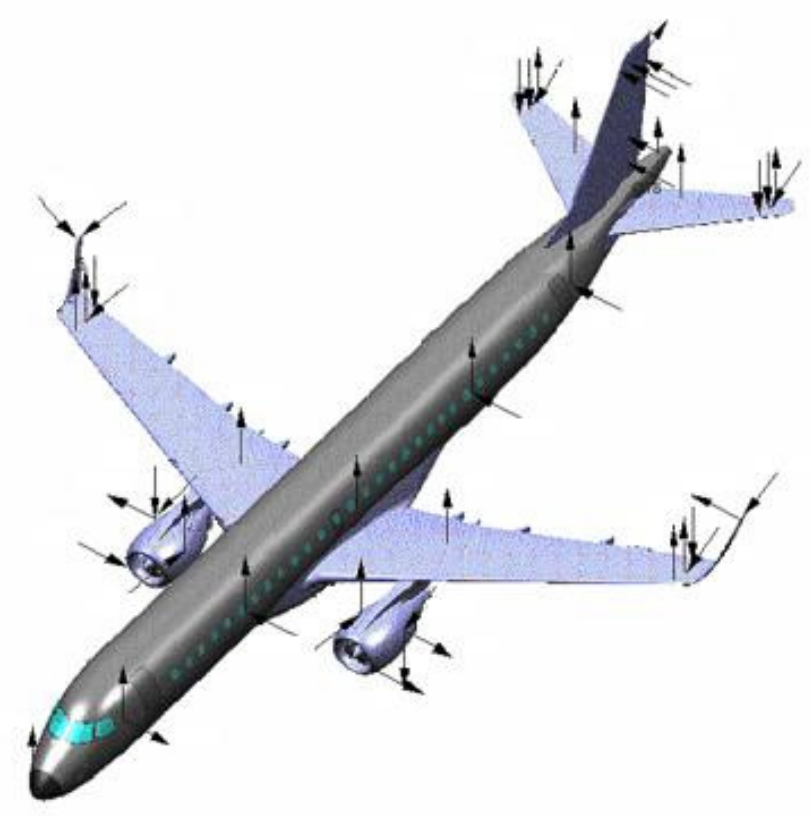

Figura 11 - Posição dos acelerômetros utilizados em ensaios de flutter

Segundo Brenner et al. (1997), Kehoe (1995) e EMBRAER - 190ALP002 (2005), é fundamental que os ensaios sejam acompanhados por telemetria, com engenheiros especializados em flutter em constante comunicação com a tripulação, de modo a interromper imediatamente o ensaio caso alguma anormalidade seja observada.

É importante lembrar que os acelerômetros não devem ser posicionados nos nós dos modos de vibração das superfícies, uma vez que pela definição de nó, não há vibração nos mesmos. Isso aumenta a importância de um modelo matemático bem construído, para se prever a posição adequada dos mesmos. 


\subsubsection{Excitadores de flutter}

Kehoe (1995), Bisplinghoff et al. (1955), National Test Pilos School (1995) e Ward \& Strganac (1998) descrevem os tipos de excitações possíveis de serem aplicadas nas estruturas aerodinâmicas durante a realização de ensaios de flutter. Tais tipos são descritos brevemente a seguir.

Turbulência atmosférica é o modo mais simples de excitação. Consiste em voar a aeronave em uma atmosfera turbulenta, a qual excitará vários modos de vibração ao mesmo tempo e aleatoriamente, independentemente se a excitação é simétrica ou assimétrica. Sua principal vantagem é a simplicidade e o fato de não se precisar fazer modificações físicas na aeronave, mas possui uma série de desvantagens, tais como ser impossível ter-se controle sobre os parâmetros da excitação; muitas vezes frequiências críticas acabam não sendo excitadas; necessitar-se aumentar o número de horas de vôo, já que nem sempre é possível encontrar atmosfera turbulenta com facilidade; requerer o uso de equipamento de aquisição mais preciso, para captar as variações de freqüência e a resposta da aeronave e o fato de a excitação mudar também com a variação da altitude da aeronave.

Comandos de vôo com excitação provocada pelo piloto, onde o piloto aplica cargas pontuais no comando de vôo, excitando a estrutura correspondente. Sua vantagem é o baixo custo e a manutenção das características dinâmicas da aeronave, mas sua principal desvantagem é a faixa limitada de freqüências que podem ser excitadas, já que dependem da habilidade do piloto. Normalmente freqüências críticas podem não ser excitadas, o que torna o ensaio inócuo. 
Comandos de vôo com dispositivo de excitação externa é outro tipo de excitação feita aplicando-se correntes oscilatórias nos comandos de vôo da aeronave ou no piloto automático, fazendo com que as superfícies de controle oscilem, induzindo um sinal oscilatório na estrutura. Sua vantagem mais uma vez é o baixo custo e a manutenção das características aerodinâmicas e dinâmicas da aeronave, mas, no entanto permitindo uma faixa de frequiências maior do que no caso anterior. Entretanto ela ainda é muito pequena, podendo não excitar freqüências importantes.

Excitadores inerciais são compostos por massas rotativas desbalanceadas, que podem rodar em diversas velocidades, variando assim a frequiência de excitação. Sua principal vantagem é a possibilidade de escolha da freqüência, e sua desvantagem é o baixo controle sobre a força aplicada, já que esta varia com o quadrado da velocidade, gerando força demais a altas freqüências e força de menos a baixas freqüências. Estes tipos de mecanismos de excitação (assim como os dois a seguir) normalmente são posicionados nas extremidades das superfícies aerodinâmicas, como mostrado na figura 12 .

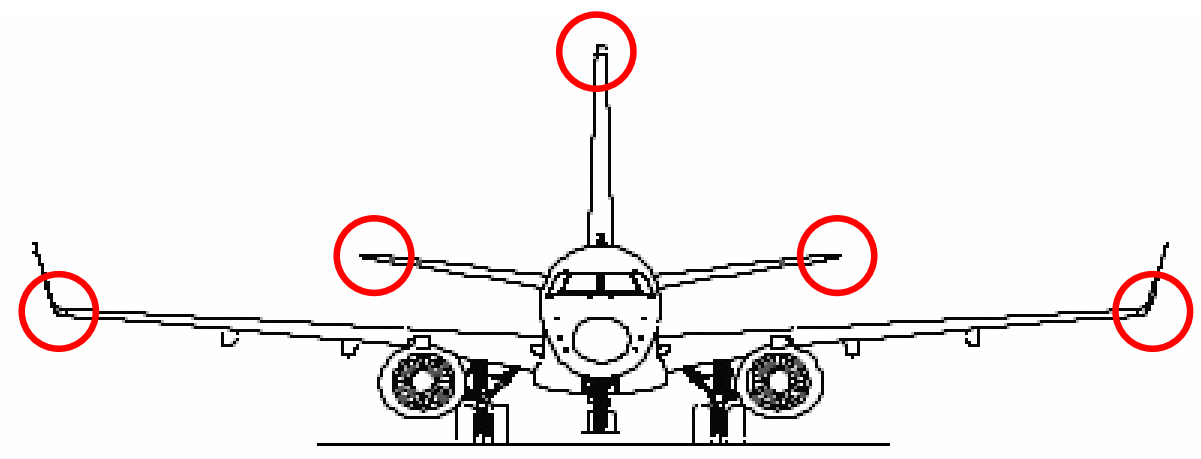

Figura 12 - Posição dos mecanismos de excitação na aeronave

Explosivos, ou excitadores balísticos, ou pirotécnicos ou geradores de impulso são mecanismos posicionados conforme a figura 12, e que queimam ou explodem gerando um pulso que excita a estrutura em diversas frequiências diferentes ao mesmo tempo nas 
condições desejadas do ensaio. Sua vantagem é a simplicidade e manutenção das características da superfície aerodinâmica. Suas desvantagens são a dificuldade de se aplicar a carga ao mesmo tempo em ambos os lados, sua pequena faixa de freqüências que pode ser excitada e o fato de cada explosivo só poder ser utilizado uma única vez.

Vanes aerodinâmicas é o modo de excitação mais utilizado hoje em dia, que usa carga aerodinâmica para aplicar força à estrutura. Consistem em aerofólios montados nas pontas das superfícies (figura 12) que rotacionam, variando a carga aerodinâmica. Pode ser um aerofólio rotativo ou um aerofólio fixo com um cilindro rotativo no seu interior. Sua vantagem é o baixo uso de energia elétrica no seu acionamento, o controle adequado sobre os parâmetros de excitação e a grande faixa de freqüências que pode atingir. Suas desvantagens são a mudança no fluxo aerodinâmico próximo às pontas das superfícies, e a força aplicada, que varia com o quadrado da velocidade da aeronave, causando a mesma desvantagem das massas rotativas.

A tabela 2 apresenta as principais vantagens e desvantagens de cada tipo de excitação apresentadas anteriormente.

\begin{tabular}{|c|c|c|}
\hline Excitação & Vantagens & Desvantagens \\
\hline Turbulência atmosférica & $\begin{array}{l}\text { - Baixo custo } \\
\text { - Não necessita manutenção } \\
\text { - Mantém as características da estrutura }\end{array}$ & $\begin{array}{l}\text { - Baixa previsibilidade } \\
\text { - Necessita de equipamento de } \\
\text { aquisição mais preciso }\end{array}$ \\
\hline $\begin{array}{l}\text { Comandos de vôo com } \\
\text { excitação do piloto }\end{array}$ & $\begin{array}{l}\text { - Baixo custo } \\
\text { - Não necessita manutenção } \\
\text { - Mantém as características da estrutura }\end{array}$ & $\begin{array}{l}\text { - Baixa confiabilidade } \\
\text { - Depende das habilidades do piloto }\end{array}$ \\
\hline $\begin{array}{l}\text { Comandos de vôo com } \\
\text { dispositivo de excitação } \\
\text { externa }\end{array}$ & $\begin{array}{l}\text { - Baixo custo } \\
\text { - Não necessita manutenção } \\
\text { - Mantém as características da estrutura }\end{array}$ & $\begin{array}{l}\text { - Baixa confiabilidade } \\
\text { - Pode não excitar frequiências } \\
\text { importantes }\end{array}$ \\
\hline Excitadores inerciais & - Pode controlar a escolha da frequiência & - Pouco controle sobre a força aplicada \\
\hline Explosivos & $\begin{array}{l}\text { - Simplicidade } \\
\text { - Mantém as características da estrutura }\end{array}$ & $\begin{array}{l}\text { - Pode ser utilizada uma única vez } \\
\text { - Pequena faixa de freqüências } \\
\text { - Dificuldade de aplicação simultânea } \\
\text { em ambos os lados }\end{array}$ \\
\hline Vanes aerodinâmicas & $\begin{array}{l}\text { - Controle sobre freqüência } \\
\text { - Controle sobre força } \\
\text { - Alta confiabilidade }\end{array}$ & $\begin{array}{l}\text { - Complexidade } \\
\text { - Altera características da estrutura }\end{array}$ \\
\hline
\end{tabular}

Tabela 2 - Vantagens e desvantagens de cada tipo de excitação 


\subsubsection{Procedimentos}

Em um ensaio típico, a aeronave deve ser estabilizada nas condições especificadas e aplicada a excitação correspondente, com acompanhamento do engenheiro de ensaios a bordo da aeronave e do engenheiro especializado via telemetria. A estrutura deve ser excitada em um espectro de frequiências tal que cubra toda a faixa de interesse exigida pela estrutura e determinada pelo modelo matemático, provando que a estrutura não está sujeita ao fenômeno de flutter.

Os pontos devem ser realizados com e sem o piloto automático acoplado e a excitação, quando for o caso, deve ser aplicada simétrica a assimetricamente, de forma a expor a aeronave a diferentes condições de carga.

Por requisitos de certificação já apresentados anteriormente, todo o envelope de vôo deve ser ensaiado até a $V_{D} / M_{D}$, sendo que não devem aparecer falhas e nem mudanças bruscas na estabilidade. A figura 13 apresenta as regiões do envelope de vôo que foram exploradas na campanha de ensaios de uma aeronave regional.

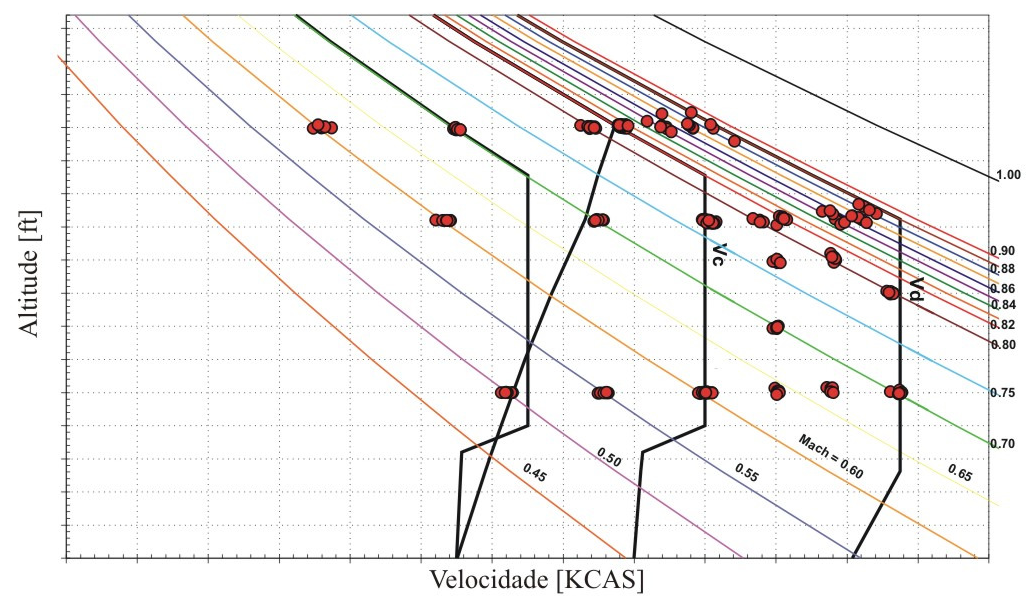

Figura 13 - Condições do envelope de vôo ensaiadas em uma campanha de ensaios em vôo de flutter - FONTE: EMBRAER - 190ALROO2 (2005) 
Algumas condições de vôo podem não ser alcançadas em vôo reto e nivelado, por exigirem altas velocidades ou Mach. Nesse caso podem ser realizados mergulhos para se alcançar a velocidade desejada. Após cada mergulho a aeronave deve recuperar sua altitude para o início de novo ponto de ensaio.

\subsubsection{Considerações}

Para a realização de qualquer tipo de ensaio em vôo, os custos devem sempre ser levados em conta até os mínimos detalhes. Na programação de uma campanha de testes, os vôos devem ser organizados de forma a serem o mais eficientes possível, evitando mudanças de altitude e velocidade desnecessárias. Deve ser avaliada também a real necessidade da realização de ensaio em cada ponto proposto. Tudo o que puder ser aproveitado de ensaios já realizados ou avaliado por análise teórica (desde que o modelo seja comprovadamente confiável) não deve ser ensaiado, de forma a diminuir custos e não expor a tripulação a riscos desnecessários.

Ensaios de flutter são especialmente arriscados, por isso a segurança deve ser levada em consideração detalhadamente. EMBRAER - 190ALP002 (2005), Ward \& Strganac (1998) e a National Test Pilots School (1995) colocam alguns pontos que devem ser considerados para a realização destes testes:

- O vôo deve ser preciso, já que as condições de estabilidade e amortecimento podem variar muito rapidamente com uma pequena mudança na velocidade;

- Tripulação mínima, para evitar a exposição de pessoas a riscos desnecessários;

- Os pilotos devem estar preparados e conhecer bem as manobras de recuperação da aeronave. Os engenheiros de flutter devem instruí-los de tais procedimentos; 
- Ensaios em número de Mach alto devem ser realizados a altas altitudes, pois diminui a necessidade de velocidades tão altas;

- A manobra deve ser interrompida caso o amortecimento passar a ser menor do que o esperado;

- A atmosfera deve estar calma, já que qualquer turbulência pode excitar um modo crítico de vibração;

- Os ensaios devem ser realizados em condições visuais de vôo, ou seja, durante todo o ensaio deve ser possível o contato visual com o solo, de forma a aumentar a segurança da execução;

- Os ensaios devem ser realizados em áreas não habitadas e possivelmente sobre água, já que esta diminui o número de vítimas em um caso de acidentes e normalmente a atmosfera é mais calma sobre essa superfície;

- A telemetria deve permitir o acompanhamento, em tempo real, de cada manobra realizada;

- Antes dos vôos deve ser realizada uma mitigação dos riscos, onde cada possível incidente deve ser previsto, juntamente com a melhor opção para uma possível restauração das condições de vôo.

\subsubsection{Análise dos Resultados}

EMBRAER - 190ALR002 (2005) apresenta a avaliação dos resultados de uma campanha de ensaios de flutter realizados em um protótipo da empresa.

Inicialmente são analisados a freqüência e a razão de amortecimento para cada condição ensaiada, assim como sugerido pela Federal Aviation Administration - U.S. Department of Transportation (1998) e explicado na seção 2.3 deste texto. A figura 14 mostra os gráficos construídos para uma das condições de vôo. 


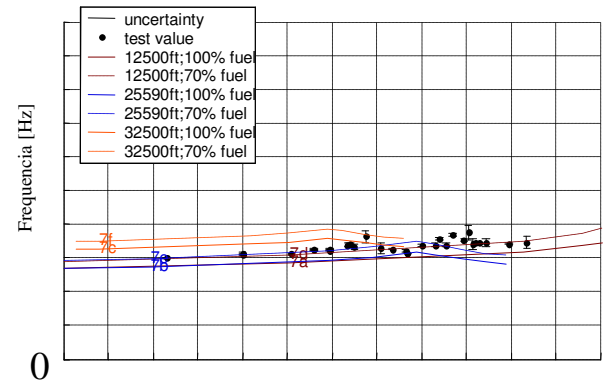

$\mathrm{V}$ [KEAS]

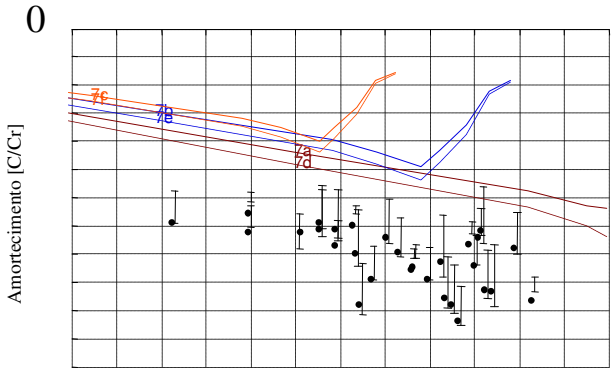

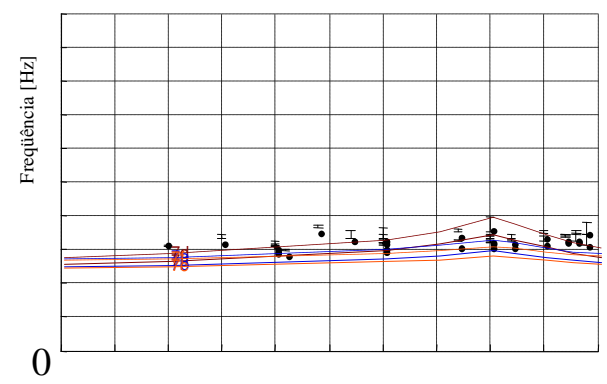

Mach

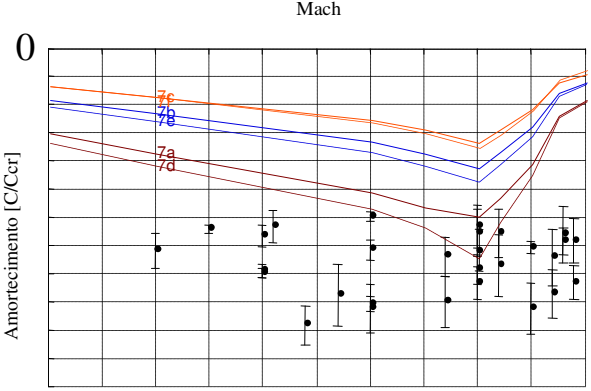

Figura 14 - Comportamento de uma aeronave em termos de freqüência e amortecimento em uma condição de vôo ensaiada - FONTE: EMBRAER - 190ALRO02 (2005)

Nos gráficos são mostrados os dados de ensaio junto com os dados teóricos para fins de comparação. Pode-se observar que nos gráficos de frequiência, não ocorre nenhum caso onde a mesma é levada a zero, demonstrando não haver tendência a divergência na estrutura ensaiada. Nos gráficos de amortecimento, não houve nenhum caso onde o valor ficasse positivo, demonstrando que para todos os casos ensaiados, a estrutura é aeroelasticamente estável.

Uma segunda análise realizada é a resposta da aeronave a uma carga em forma de pulso aplicada nos comandos de vôo pelo piloto, como pode ser observado na figura 15 , que apresenta os resultados de um caso ensaiado, cujos parâmetros são mostrados na tabela 3 .

\begin{tabular}{|c|l|c|}
\hline Parâmetro & \multicolumn{1}{|c|}{ Descrição } & Unidade \\
\hline \hline PDELE & Posição do profundor & grau \\
\hline A14 & Aceleração no assento do piloto (direção Z) & $\mathrm{g}$ \\
\hline A40005 & Aceleração na ponta do estabilizador horizontal esquerdo (direção Z) & $\mathrm{g}$ \\
\hline A40008 & Aceleração na ponta do estabilizador horizontal direito (direção Z) & $\mathrm{g}$ \\
\hline A40020 & Aceleração na ponta da asa esquerda (direção Z) - Bordo de ataque & $\mathrm{g}$ \\
\hline A40023 & Aceleração na ponta da asa direita (direção Z) - Bordo de ataque & $\mathrm{g}$ \\
\hline
\end{tabular}
Tabela 3 - Parâmetros apresentados em cada gráfico da figura 9 


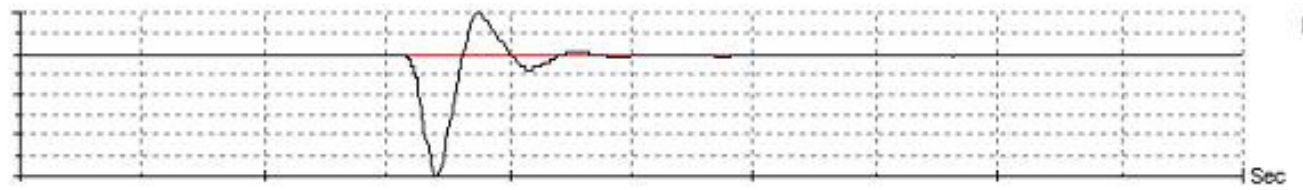

PDELE

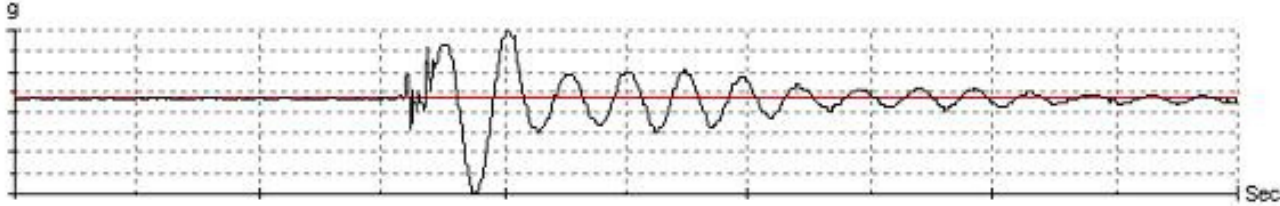

A14

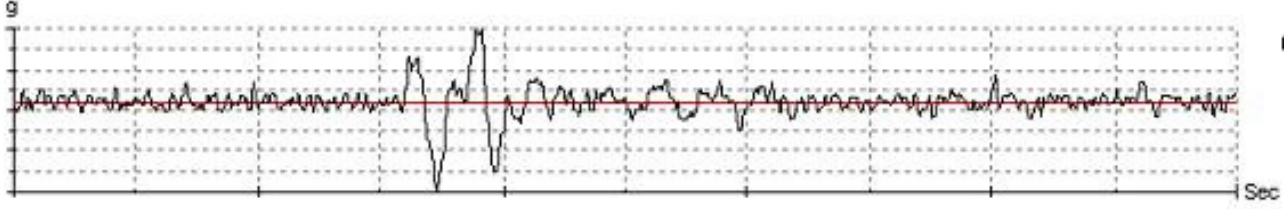

A46505

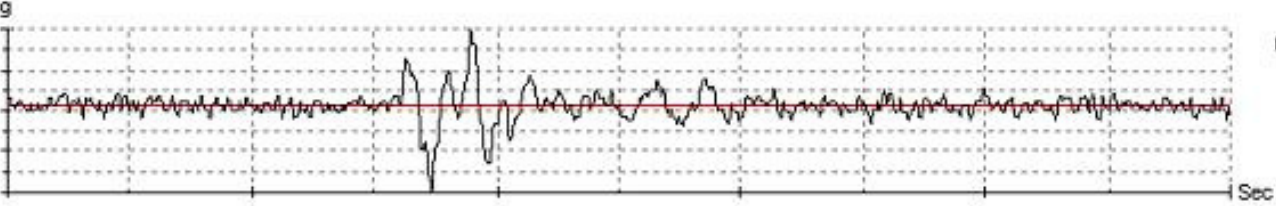

ค4 6568

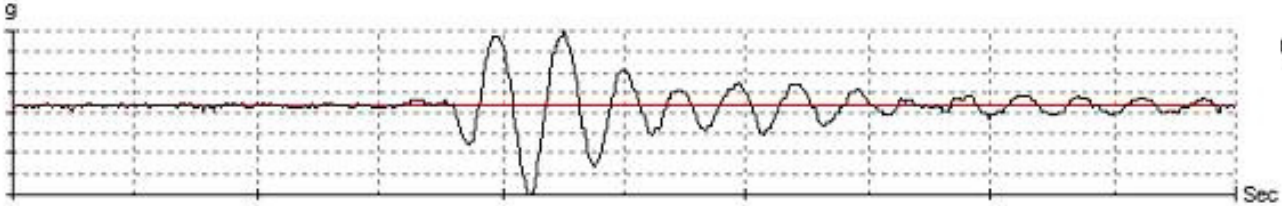

ค46อ2

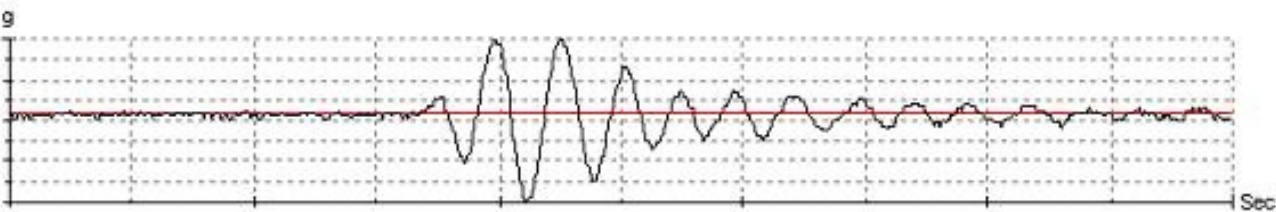

A40123

Figura 15 - Resposta da aeronave a excitações realizadas pelos comandos de vôo - FONTE: EMBRAER 190ALROO2 (2005)

Mais uma vez pode-se observar que a aeronave é estável com esse tipo de excitação, já que as oscilações são amortecidas no domínio do tempo.

Finalmente é analisada a influência do piloto automático na resposta às excitações. Para isso foi realizada uma simulação prevendo o comportamento da aeronave com o piloto automático acionado e não-acionado. A figura 16 mostra o resultado de uma das condições analisadas. 


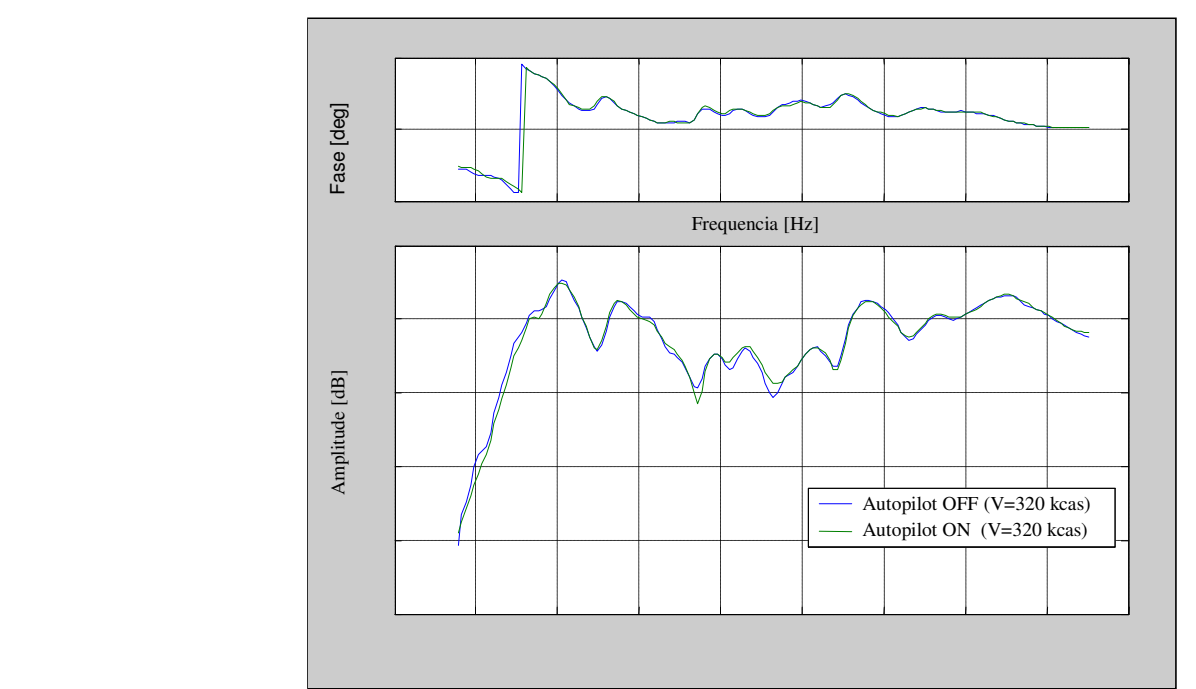

Figura 16 -Influência do piloto automático em uma condição simulada - FONTE: EMBRAER - 190ALR002 (2005)

Pode-se observar que o comportamento é muito próximo, concluindo-se que o acionamento do piloto automático tem pouca influência no comportamento da aeronave após aplicadas as excitações em questão. 


\section{PROJETO CONCEITUAL DE EXCITADOR DE FLUTTER}

Neste capítulo serão propostos vários conceitos de excitadores alternativos para uso em ensaios em vôo de flutter. Com o intuito de ensaiá-los em laboratório, protótipos desses mecanismos serão projetados para um dado modelo de asa fixo em um suporte flexível existente no Laboratório de Aeroelasticidade, Dinâmica de Vôo e Controle (LADinC) da EESC-USP. A asa foi analisada por De Marqui (2004) e os dados relevantes estão presentes no Apêndice A deste texto.

\subsection{Cálculo da velocidade de flutter}

Conforme explicado anteriormente, o fenômeno flutter se dá pelo acoplamento de dois modos de vibração de uma estrutura, resultando numa instabilidade dinâmica. Com as propriedades da estrutura apresentadas no apêndice A, pode-se observar que os dois primeiros modos de vibração são o primeiro modo de flexão e o primeiro modo de torção. Estes possuem freqüências próximas entre si e distante das dos modos de vibração seguintes, o que caracteriza um cenário propício ao estudo do fenômeno flutter na estrutura. 
A fim de se conhecer melhor a estrutura e para auxiliar nos cálculos do dimensionamento do excitador, efetuou-se, utilizando as informações do apêndice A, a simulação da estrutura para se prever a velocidade e freqüência de ocorrência do fenômeno em questão.

A análise de De Marqui (2004) na mesma estrutura partiu do princípio que as raízes do polinômio característico de um sistema linear estável deve ter a parte real negativa. A partir daí, variando-se a velocidade e plotando as raízes foi possível observar, a partir da figura 17, que o sistema se torna instável em uma velocidade em torno de $25 \mathrm{~m} / \mathrm{s}$.

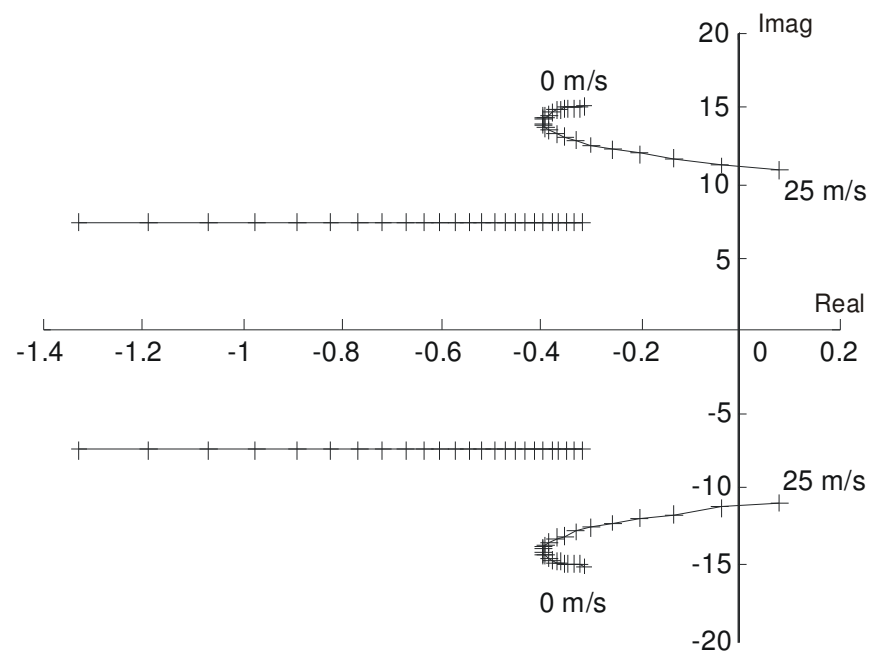

Figura 17 - Lugar das raízes (evolução das raízes) da equação característica em função da velocidade do fluxo de ar

Em seguida simulou-se a resposta no tempo da estrutura sujeita a um fluxo aerodinâmico em várias velocidades diferentes $(5,15,20,23$ e $25 \mathrm{~m} / \mathrm{s})$. As figuras abaixo mostram o resultado das simulações 

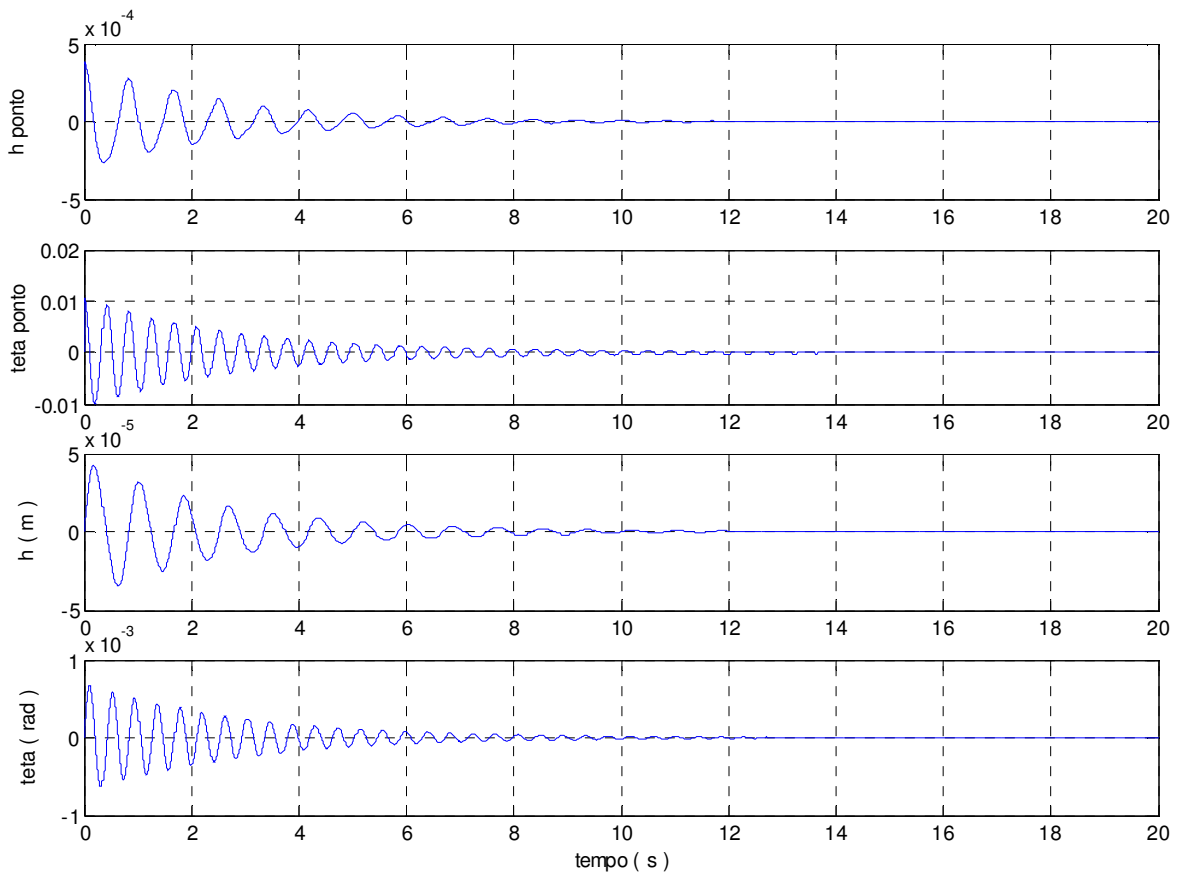

Figura 18 - Resposta no tempo para velocidade de $5 \mathrm{~m} / \mathrm{s}$
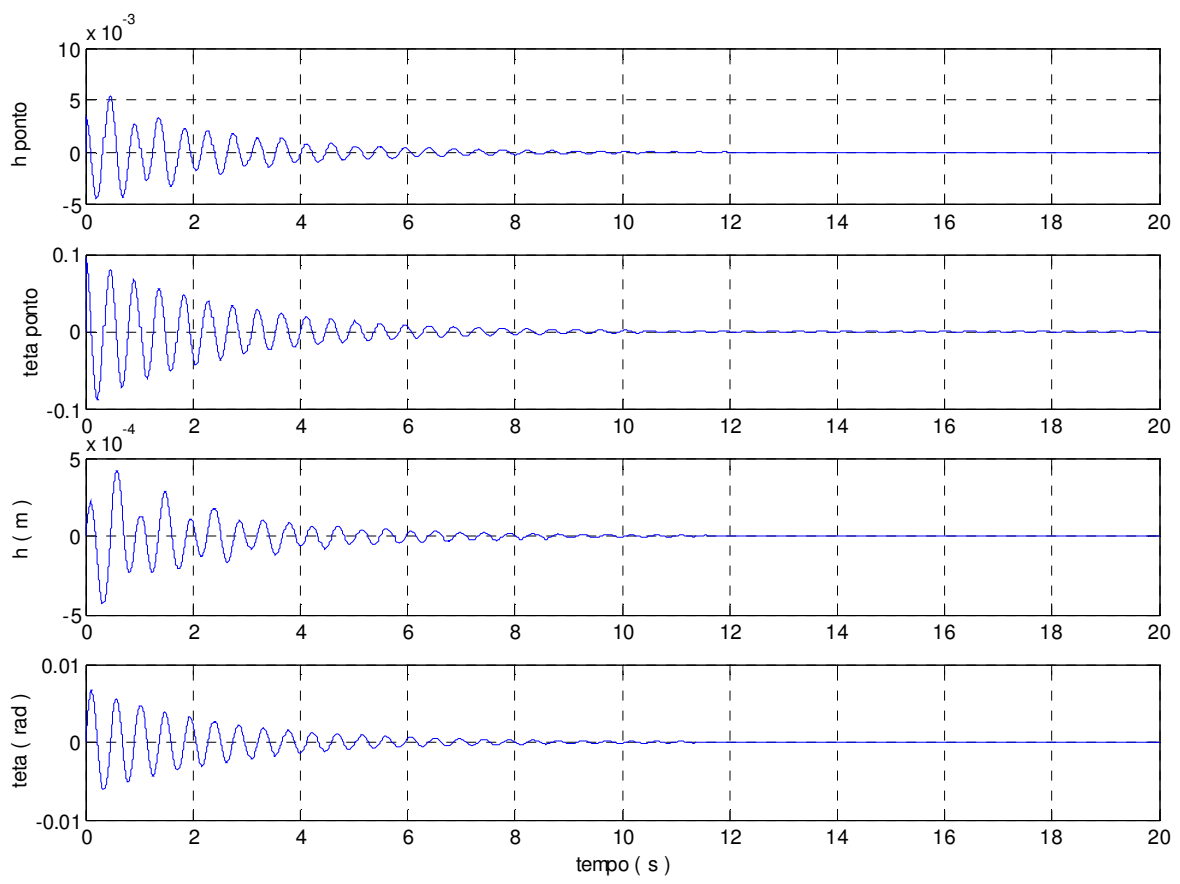

Figura 19 - Resposta no tempo para velocidade de $15 \mathrm{~m} / \mathrm{s}$ 

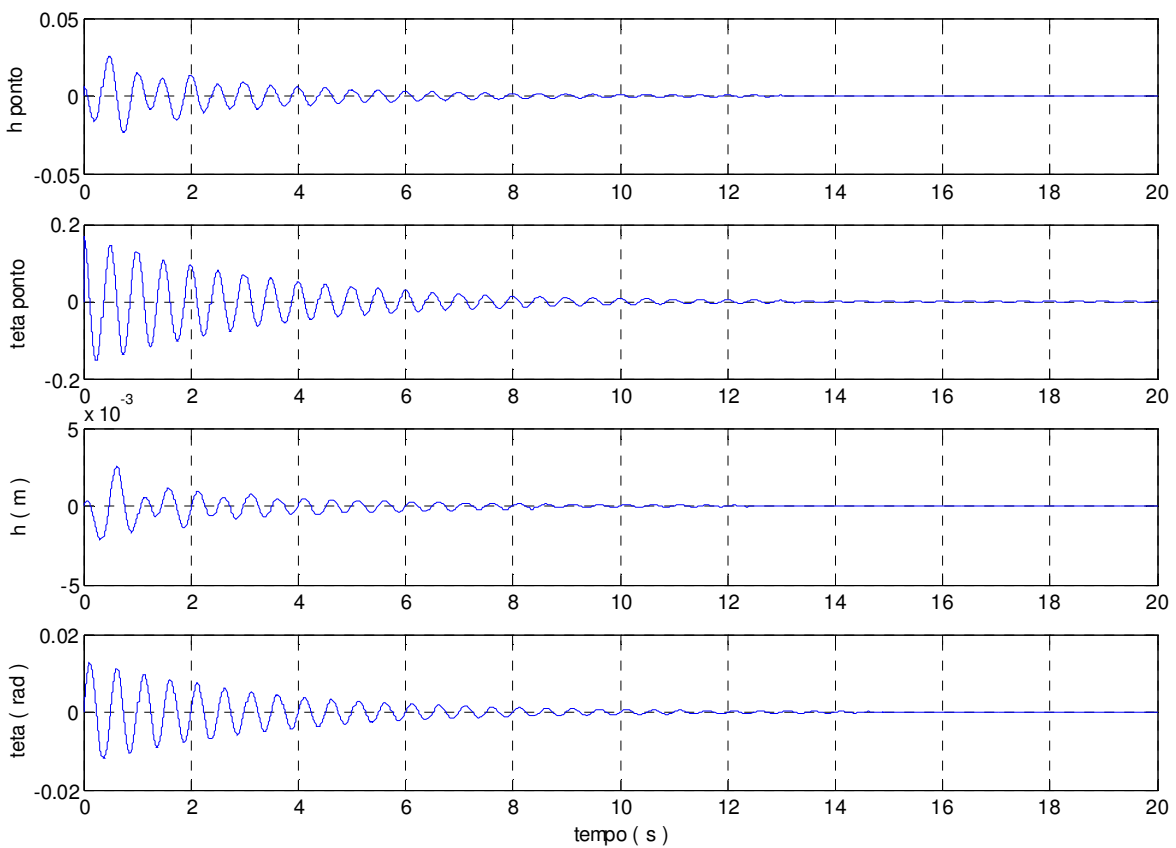

Figura 20 - Resposta no tempo para velocidade de $20 \mathrm{~m} / \mathrm{s}$
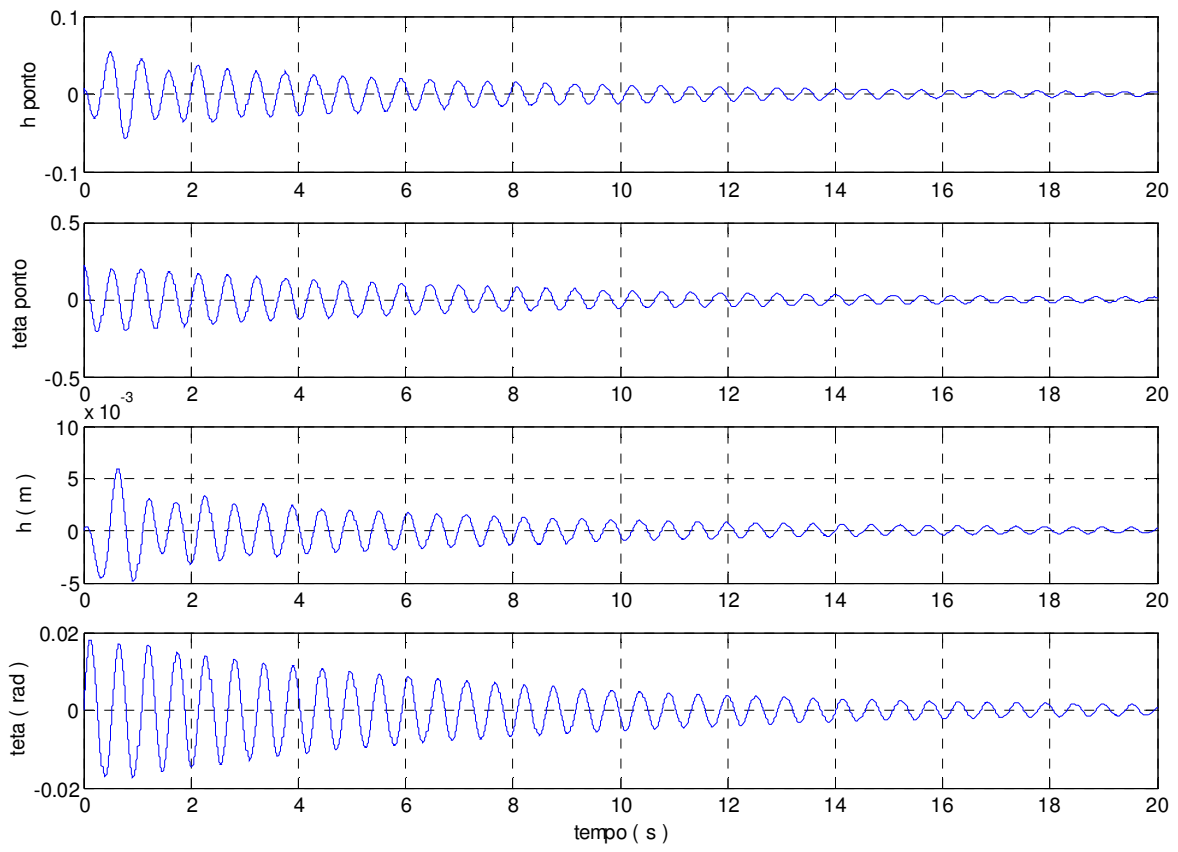

Figura 21 - Resposta no tempo para velocidade de $23 \mathrm{~m} / \mathrm{s}$ 

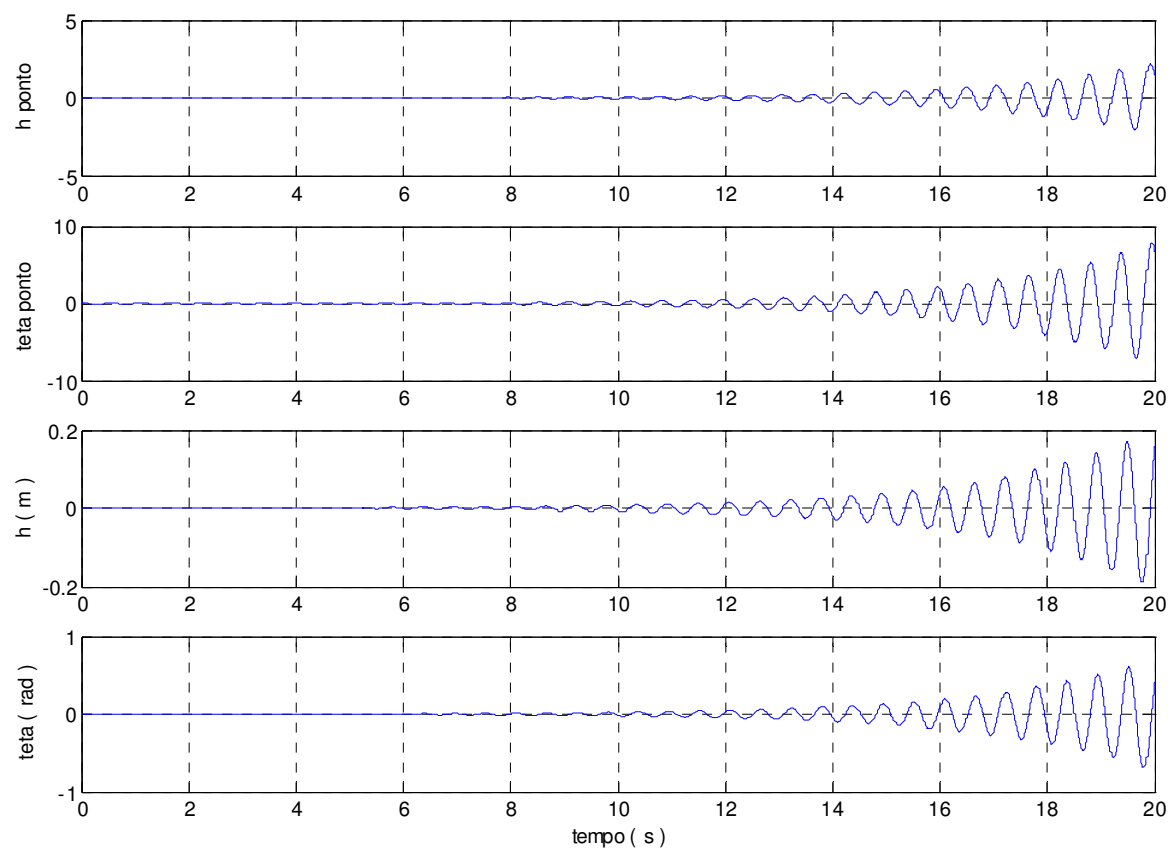

Figura 22 - Resposta no tempo para velocidade de $25 \mathrm{~m} / \mathrm{s}$

Com isso, será adotada para o dimensionamento a velocidade de flutter de $25 \mathrm{~m} / \mathrm{s}$.

Foi simulado ainda o acoplamento dos modos de vibração anteriormente citados de modo a saber a frequiência de vibração na ocorrência do flutter. O resultado é apresentado na figura 23, que mostra a Função Resposta em Freqüência do sistema, onde o modo de flexão (freqüência mais baixa) e o de torção (freqüência mais alta) se acoplam a uma velocidade em torno de $25 \mathrm{~m} / \mathrm{s}$.

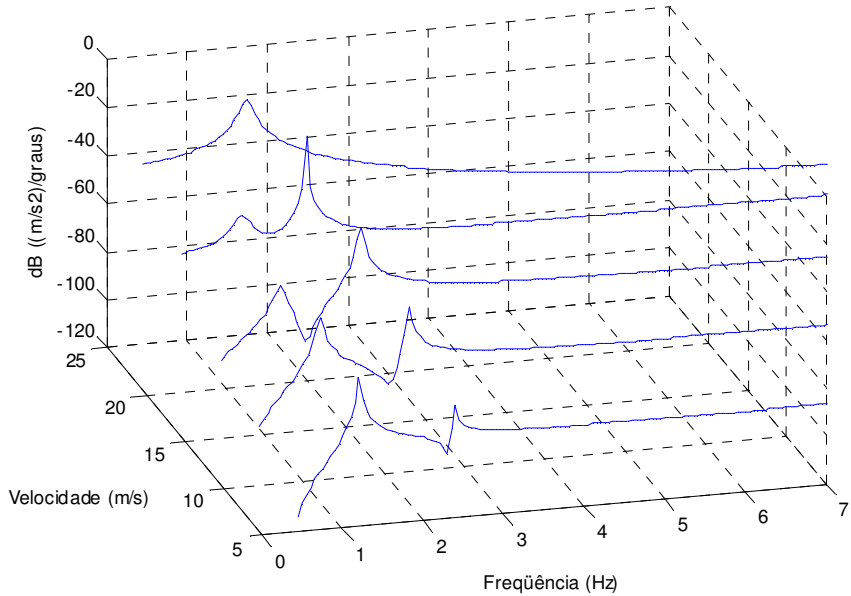

Figura 23 - Acoplamento dos modos de vibração 
Tais resultados demonstram que o fenômeno flutter deve ocorrer a uma freqüência de $1,8 \mathrm{~Hz}$.

\subsection{Cálculo da carga aplicada}

Apesar de a frequiência ser muito mais importante que a força aplicada por um excitador de flutter, será adotada, como ponto de partida para o projeto, a carga a ser aplicada, que é calculada a seguir.

Van Nunen \& Piazzoli (1979) afirmam que a única ressalva para a força aplicada por um excitador de flutter, é que ela tenha um valor tal que seja distinguível de uma suposta turbulência.

Tendo em vista que os modos de vibração a serem excitados são o primeiro de flexão e o primeiro de torção, será aplicada uma carga que provoque deformação nos dois modos citados.

Será, portanto, considerada uma carga que seja suficiente para a deformação de $10 \mathrm{~mm}$ na ponta da estrutura asa-suporte quando sujeita a flexão, e esta carga será aplicada em um ponto da corda média aerodinâmica tal que provoque uma torção de 2 graus na ponta da estrutura. Tais valores são considerados satisfatórios para a distinção de uma turbulência, atendendo ao comentário acima.

Para o cálculo do valor da carga será adotado o modelo representado na figura 24, que considera a aplicação de uma carga na ponta da estrutura considerada como uma viga semiengastada, com a rigidez obtida nos resultados de simulação presentes no anexo A. 


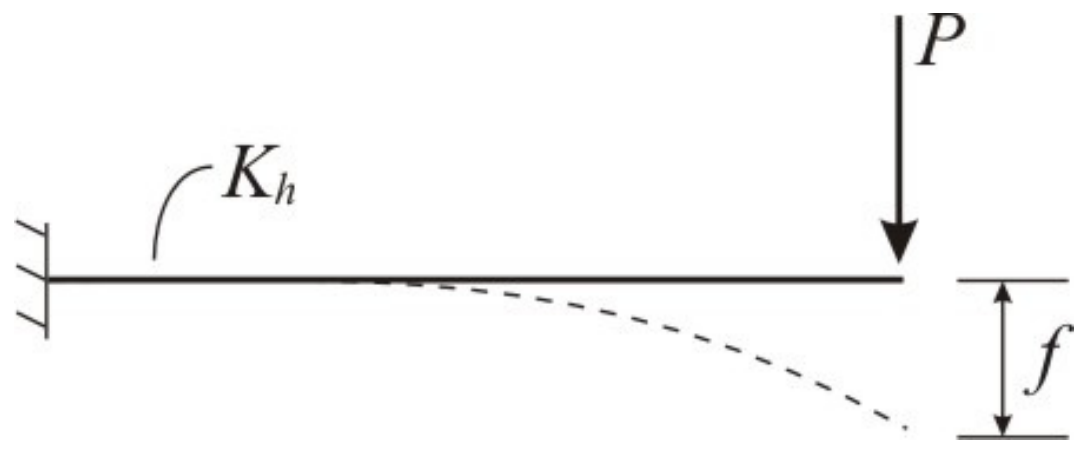

Figura 24 - Viga semi-engastada sujeita a flexão na sua extremidade

Para o modelo utilizado, o cálculo da carga é dado por

$$
P=f \times K_{h} \Leftrightarrow P=0,01 \times 860 \Rightarrow P=8,6 N
$$

Para o cálculo da melhor posição de aplicação da carga na corda média aerodinâmica faz-se necessária a definição de centro de pressão e centro aerodinâmico, fornecidas por Houghton \& Carpenter (2004).

Centro aerodinâmico é um ponto especial do aerofólio em que o valor do momento de arfagem em torno do mesmo é constante, independente do valor do coeficiente de sustentação $C_{L}$.

Para ângulos de ataque pequenos em aerofólios subsônicos este ponto se localiza muito próximo de $1 / 4$ da corda média aerodinâmica.

Centro de pressão é um ponto onde as cargas atuantes na seção do aerofólio (sustentação, arrasto e momento de arfagem) podem ser resumidas em apenas duas: sustentação e arrasto, ou seja, onde o momento de arfagem é nulo.

Este ponto varia com o ângulo de ataque e não necessariamente se localiza dentro da geometria do aerofólio.

A figura 25 apresenta as cargas atuantes no centro aerodinâmico e no centro de pressão. 

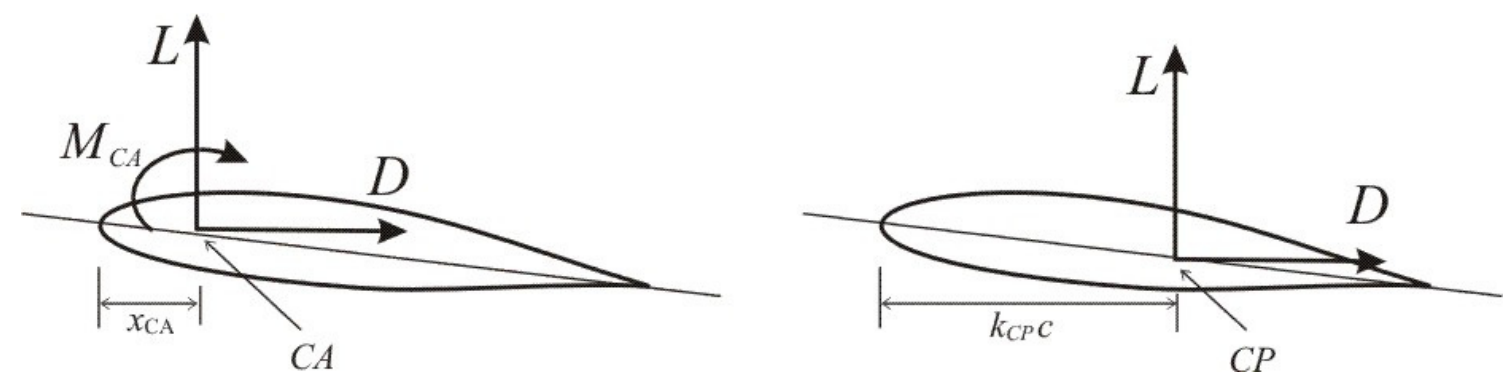

Figura 25 - Cargas atuantes no centro aerodinâmico (CA) e no centro de pressão (CP)

A posição do centro de pressão é dada por:

$k_{C P}=\frac{x_{C A}}{c}-\frac{C_{M_{C A}}}{C_{L} \cos \alpha+C_{D} \operatorname{sen} \alpha}$

Simplificando para pequenos ângulos de ataque, tem-se:

$k_{C P} \cong \frac{x_{C A}}{c}-\frac{C_{M_{C A}}}{C_{L}}$

Tal definição se assemelha com o conceito de centro de cisalhamento dado por Timoshenko (1945), que consiste no ponto da seção plana da estrutura em que pode se aplicar uma carga pontual sem que ela gere um momento torsor na mesma. Este ponto não precisa necessariamente estar dentro da seção.

Este ponto foi calculado por simulação conforme demonstrado no apêndice A e se encontra a 0,079 $m$ do centro aerodinâmico, na direção do bordo de ataque.

Com as definições acima e partindo da premissa de que o excitador deve causar uma deformação de 2 graus (ou 0,035 radianos) no aerofólio, pode-se calcular o momento aplicado em torno do centro aerodinâmico a partir da equação abaixo:

$$
M_{t}=K_{\theta} \times \theta=45 \times 0,035=1,57 N \cdot m
$$

Dessa forma, pode-se calcular a que distância do centro de cisalhamento será aplicada a carga calculada acima. 


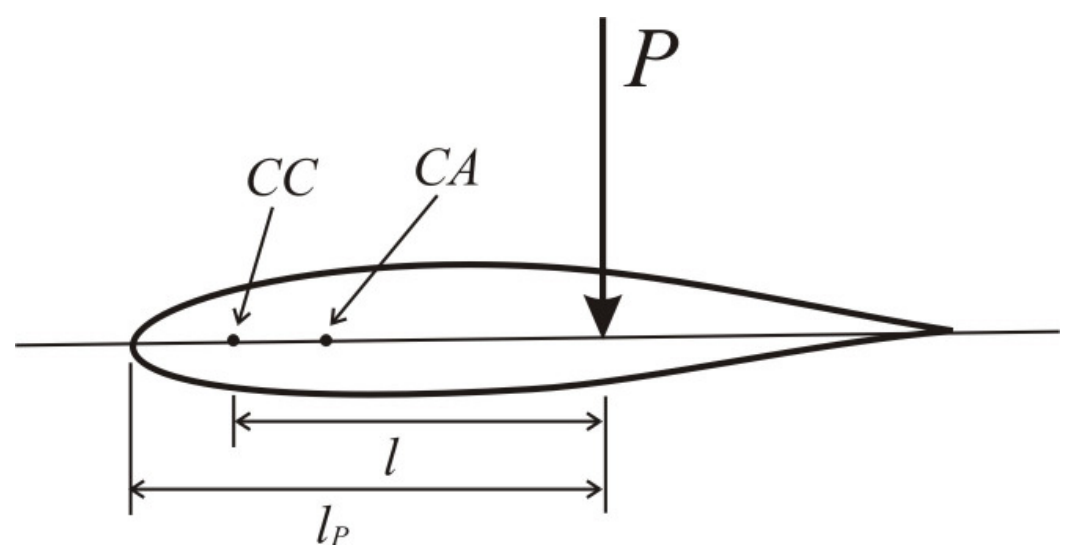

Figura 26 - Carga aplicada a uma determinada distância do centro de pressão

$l=\frac{M_{t}}{P}=\frac{15,5}{8,6}=0,183 m$

Que será aplicada a uma distância do bordo de ataque dada por

$$
l_{P}=l+\frac{c}{4}-0,175 \times c=0,183+\frac{0,45}{4}-0,175 \times 0,45 \cong 0,22 m
$$

\subsection{Propostas de excitador}

Lind et al. (1998) fazem uma comparação entre os seguintes mecanismos de excitação aeroelástica: turbulência atmosférica, comando do piloto e sistemas de excitação na ponta da asa. Seu estudo mostra que a primeira opção é insuficiente para se encontrar freqüências críticas de flutter, já que cobre apenas a faixa de frequiências mais baixas. Os comandos dados pelo piloto cobrem uma faixa de freqüência um pouco mais alta, mas mesmo assim é baixa demais para o ensaio, já que em muitos casos o fenômeno flutter acontece em freqüências mais altas. Tal fato é confirmado pelos estudos de Wright et al. (2003).

Dessa forma, a melhor opção para a utilização em ensaios de flutter seriam excitadores localizados na ponta das asas, que podem excitar a estrutura em diversas faixas diferentes de 
freqüência, suficientes para se excitar dois dos modos de vibração a fim de se observar um possível acoplamento em alguma condição ensaiada.

Tendo em vista esses fatos e a carga calculada anteriormente, serão avaliadas 5 propostas de excitadores para ensaios de flutter, apresentando seu projeto conceitual, dimensões, esquemas, suas vantagens e desvantagens, para posteriormente ser escolhida uma das alternativas.

\subsubsection{Aerofólio fino de arqueamento variável}

Esta proposta consiste na montagem, na ponta da asa, de um aerofólio fino (em forma de arco de círculo) feito de um material flexível, que pode ter seu formato alterado por um dispositivo mecânico, mudando a direção da força aplicada. A figura 27 apresenta um esquema do excitador proposto.

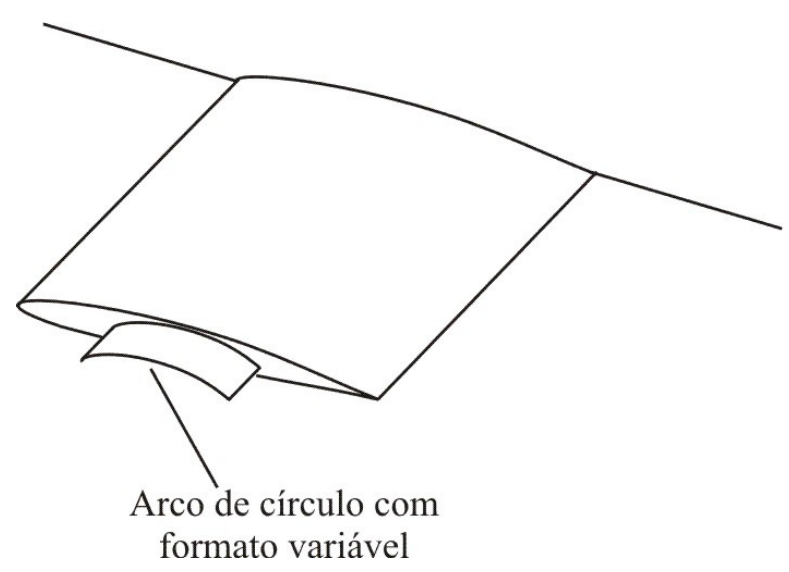

Figura 27 - Excitador com aerofólio fino de arqueamento variável

A estrutura de material flexível deve ser fixada por suas extremidades no aerofólio, e um dispositivo acionado por um motor elétrico interno à asa, com uma biela em seu eixo, 
possibilita que a seção de círculo possa ser alterada, invertendo a direção da força aplicada, conforme mostrado na figura 28 .

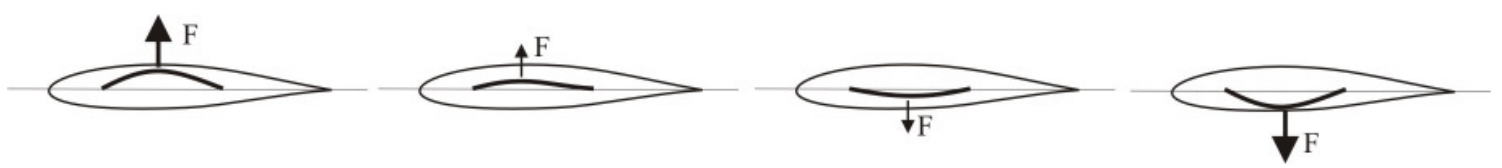

Figura 28 - Funcionamento do excitador proposto

Analogamente aos conceitos obtidos no caso anterior, sabe-se segundo Houghton \& Carpenter (2004), que o ponto ideal de posicionamento to excitador seria tal que o meio da seção de círculo estivesse localizado a $0,22 \mathrm{~m}$ do bordo de ataque, conforme calculado anteriormente.

Houghton \& Carruthers (1982) demonstram que é possível se obter sustentação a partir de um arco de círculo conforme mostrado na figura abaixo.

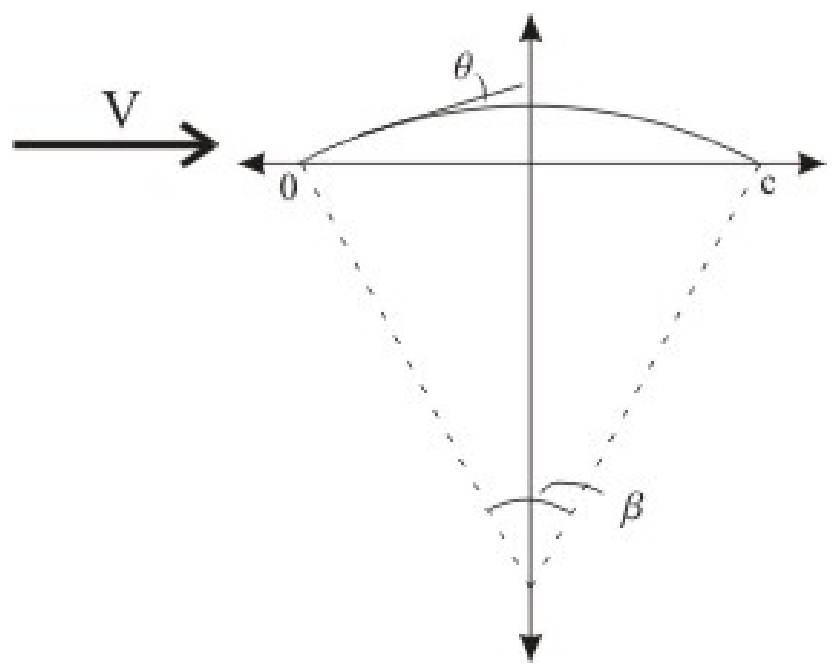

Figura 29 - Esquema de um aerofólio de arco circular

E que a sustentação obtida vale:

$$
L=2 \rho V^{2} \int_{0}^{c}\left[2 \beta \operatorname{sen} \theta+\alpha\left(\frac{1+\cos \theta}{\operatorname{sen} \theta}\right)\right] d x
$$


Que pode ser simplificada para

$$
L=\pi \rho V^{2} c(\alpha+\beta) \Rightarrow C_{L}=2 \pi(\alpha+\beta)
$$

Para este caso, o excitador será utilizado apenas em ângulo de ataque igual a zero, variando-se apenas o formato do arco, portanto os efeitos de variação do $C_{L \alpha}$ podem ser desprezados e o coeficiente de sustentação será sempre igual a $2 \pi \beta$.

Como premissa de projeto, foi considerado que o excitador deveria tangenciar o perfil a ser excitado, de tal forma que não ultrapassasse a espessura do mesmo. Para se avaliar essa premissa inicial, foi realizada uma simulação utilizando o software CFD++ de forma a se prever o comportamento aerodinâmico em torno da asa e do excitador utilizando conceitos de CFD (computational fluid dynamics). Foi utilizado, para a simulação, um valor genérico de envergadura para o excitador, já que a intenção era se obter um resultado qualitativo.

As figuras 30 e 31 apresentam as malhas geradas para a simulação, cujos resultados são apresentados em seguida.

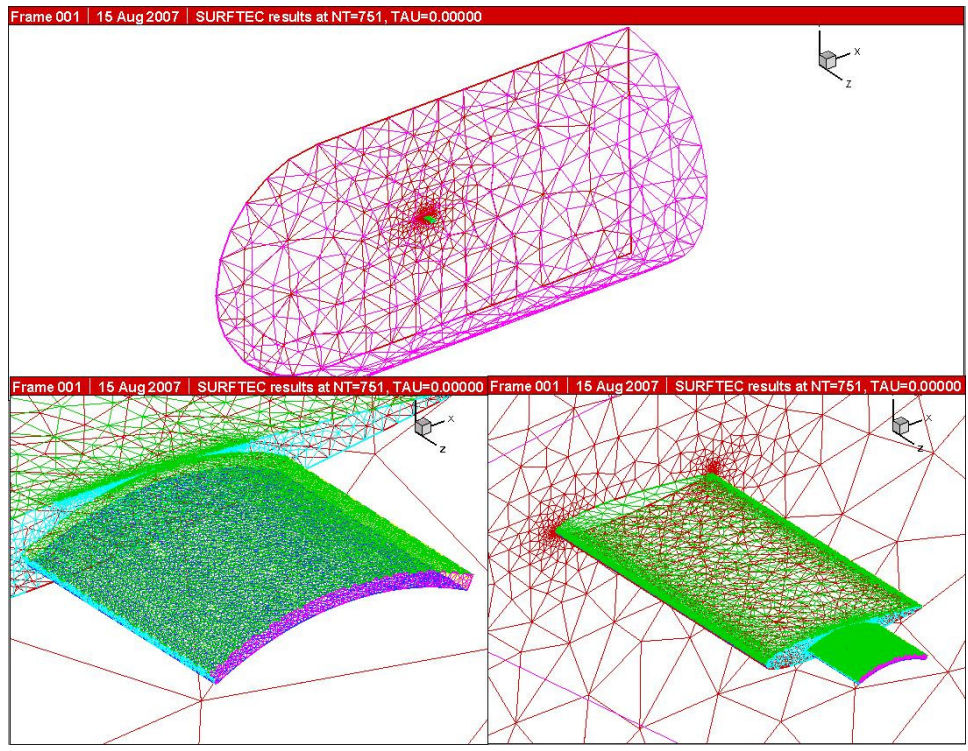

Figura 30 - Malha gerada para a simulação da estrutura e excitador em CFD 


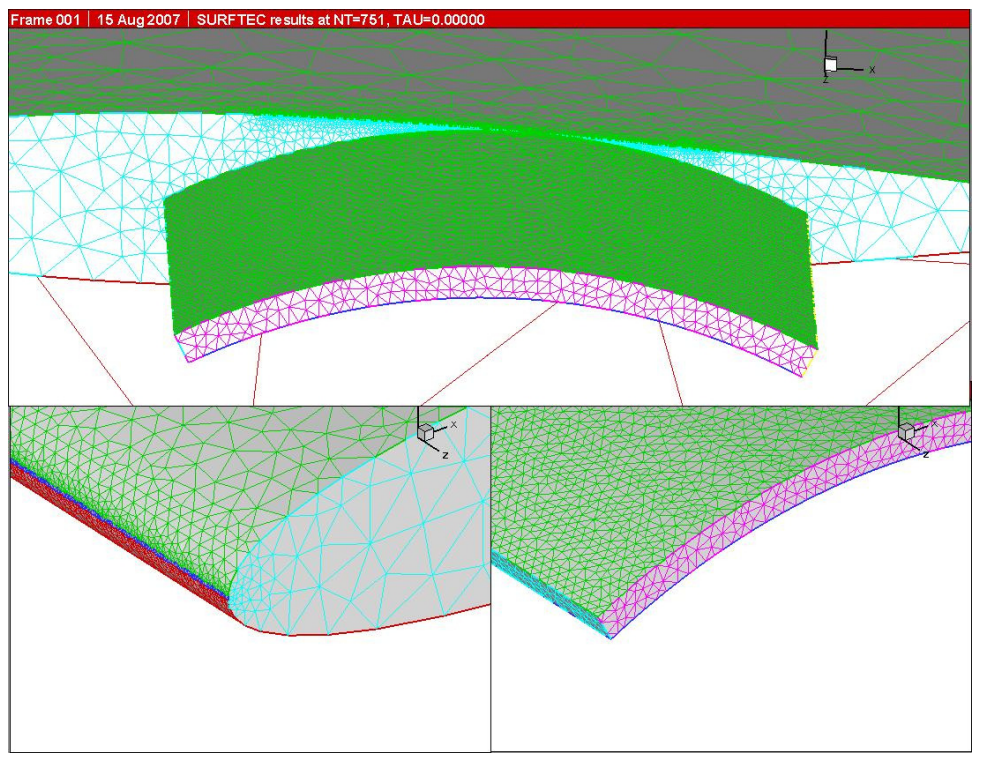

Figura 31 - Detalhes da malha gerada para a simulação

Para um fluxo livre de $25 \mathrm{~m} / \mathrm{s}$ ao nível do mar, foram simulados dois casos: no primeiro deles, representado na figura 32, o excitador foi montado de forma a ficar tangente ao perfil aerodinâmico da asa a ser excitada. A figura mostra as linhas de corrente aerodinâmica para o caso estudado.

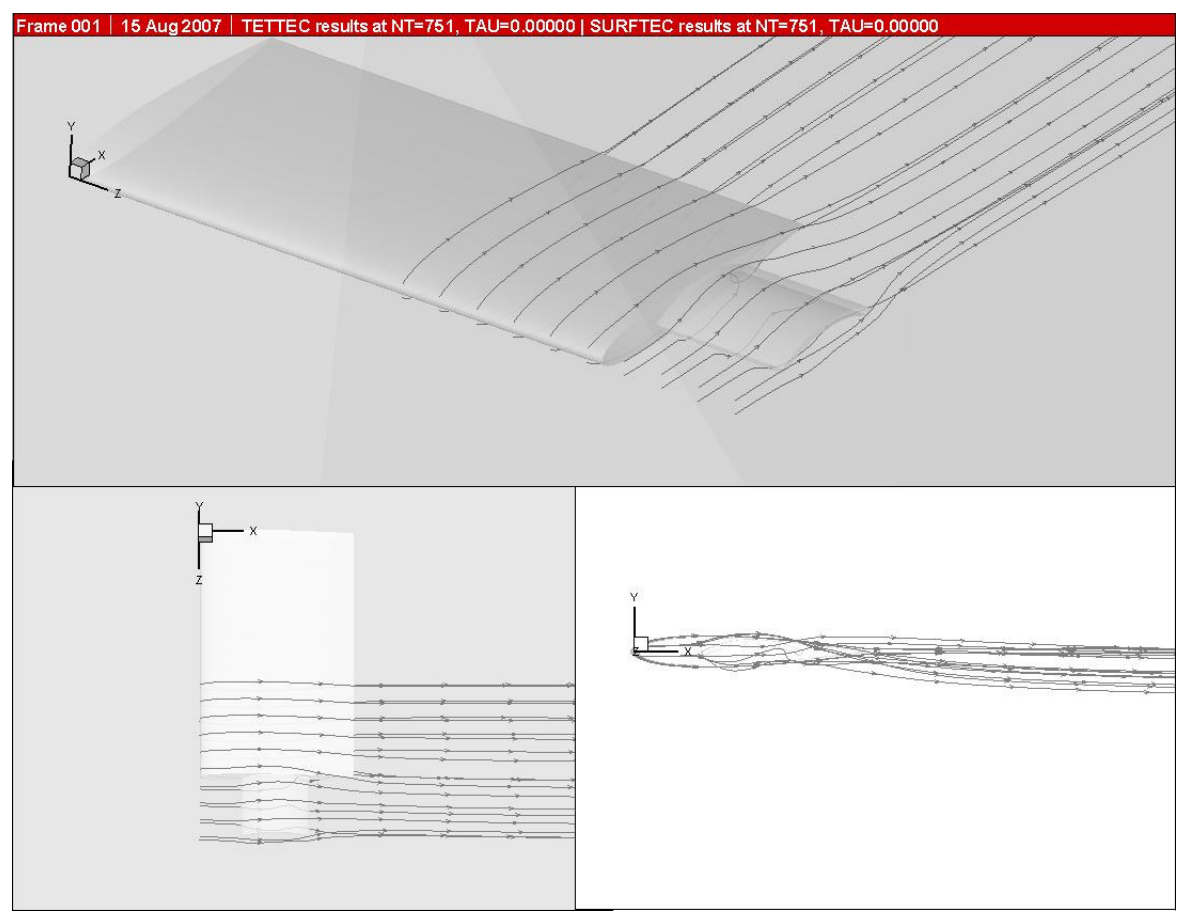

Figura 32 - Resultados do primeiro caso simulado 
No segundo caso, mostrado na figura 33, o conjunto foi simulado numa condição onde o excitador ultrapassa os limites do aerofólio.

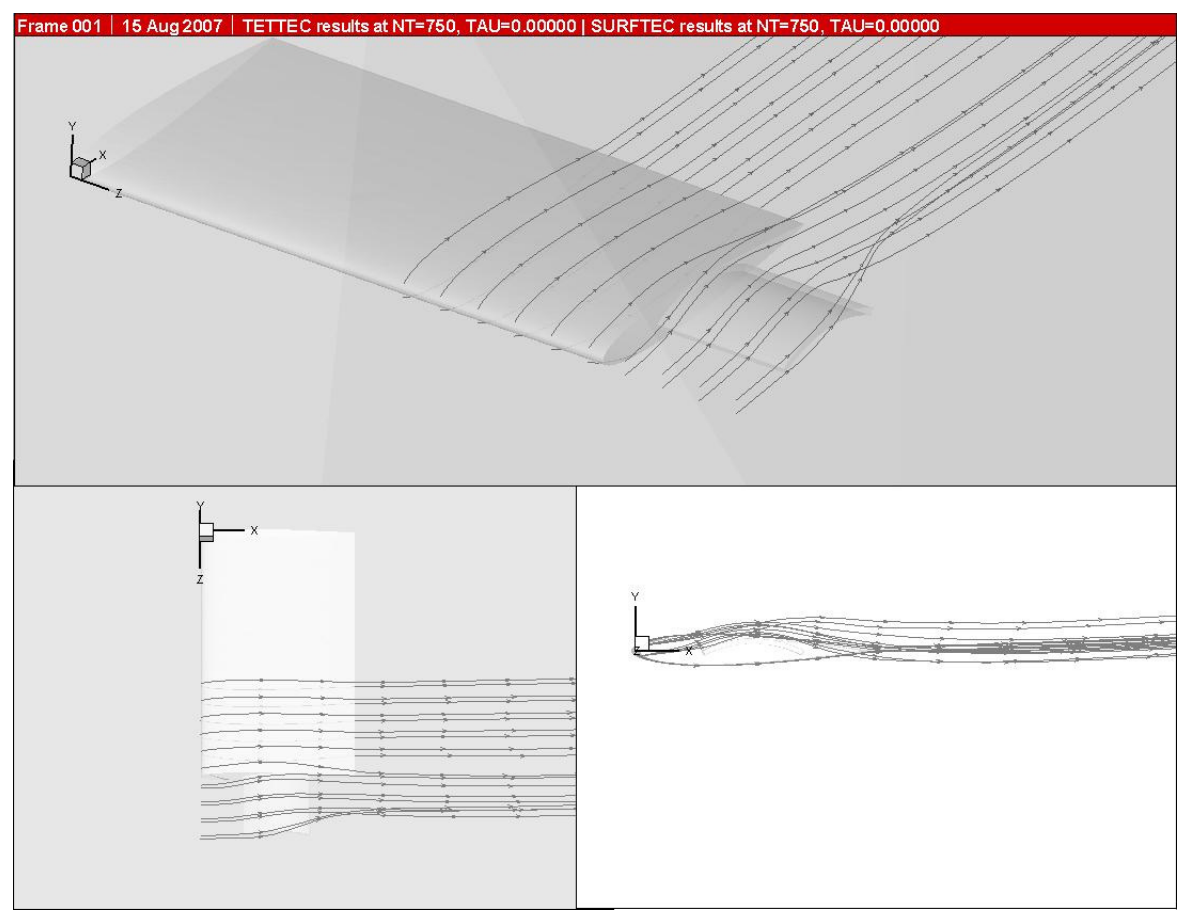

Figura 33 - Resultado do segundo caso simulado

Pode-se observar qualitativamente que no segundo caso existe a geração de um distúrbio no fluxo aerodinâmico, que pode alterar as características aerodinâmicas da asa, vindo a comprometer o funcionamento do excitador e dos resultados e conclusões relativas ao comportamento real da asa, sem excitador, em condições normais de vôo.

Dessa forma, conclui-se que a premissa de considerar o excitador limitado às dimensões do perfil aerodinâmico é vantajosa, e ela será utilizada em todas as propostas analisadas neste trabalho.

A fim de se encontrar o perfil circular que exigiria a menor envergadura, foi utilizado o software Solidworks, onde se desenhou o perfil aerodinâmico e plotou-se vários perfis circulares de diferentes dimensões. Todos os perfis tinham o ponto de $25 \%$ da corda coincidindo com o mesmo ponto do perfil aerodinâmico excitado e eram tangentes a ele. 
Dessa forma, foram calculados os raios de cada curvatura e seu respectivo ângulo $\beta$, conforme mostrado na figura abaixo.

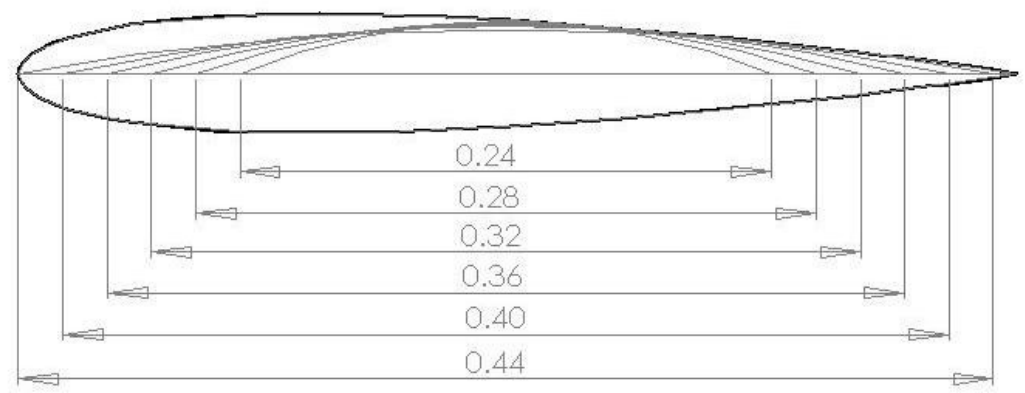

Figura 34 - Perfis circulares plotados no aerofólio

Das equações (10) e (21), tem-se que

$$
C_{L}=2 \pi \beta=\frac{L}{1 / 2 \rho V^{2} c \times b}
$$

Logo

$$
b=\frac{L}{\rho V^{2} c \pi \beta}
$$

Utilizando os dados obtidos pelo programa de CAD e a equação (23) foi possível construir a tabela abaixo calculando a envergadura do excitador necessária para se obter a carga calculada anteriormente para cada caso. As grandezas da tabela são representadas na figura 35 .

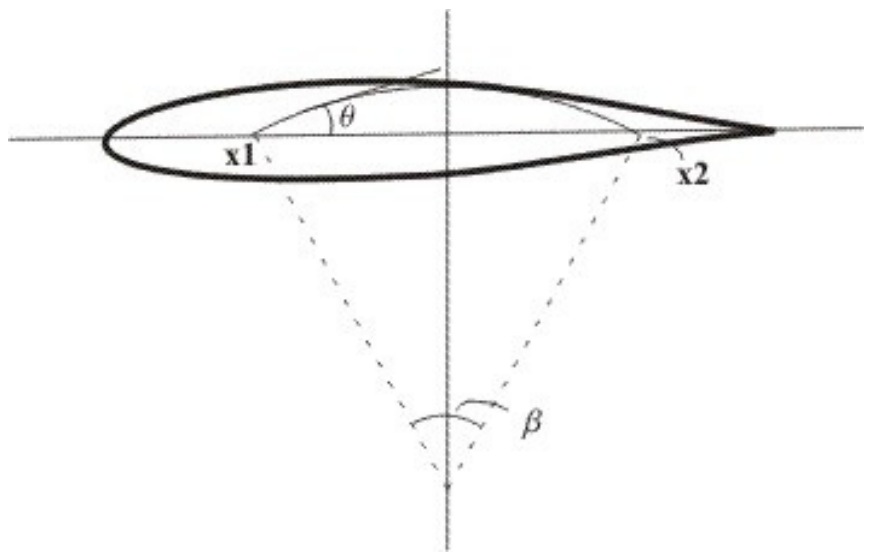

Figura 35 - Grandezas calculadas no dimensionamento do excitador 


\begin{tabular}{|c|c|c|c|c|c|c|c|}
\hline$\#$ & $\begin{array}{c}\mathbf{x 1} \\
{[\mathbf{m}]}\end{array}$ & $\begin{array}{c}\mathbf{x 2} \\
{[\mathbf{m}]}\end{array}$ & $\begin{array}{c}\text { corda } \\
{[\mathbf{m}]}\end{array}$ & $\begin{array}{c}\text { raio } \\
{[\mathbf{m}]}\end{array}$ & $\begin{array}{c}\text { Angulo } \\
{[\mathbf{d g}]}\end{array}$ & $\begin{array}{c}\text { Angulo } \\
{[\mathbf{r a d}]}\end{array}$ & $\begin{array}{c}\mathbf{b} \\
{[\mathbf{m}]}\end{array}$ \\
\hline 1 & 0,00 & 0,44 & 0,44 & 1,23 & 20,53 & 0,35832 & 0,02268 \\
\hline 2 & 0,02 & 0,42 & 0,40 & 0,95 & 24,24 & 0,42307 & 0,02113 \\
\hline 3 & 0,04 & 0,40 & 0,36 & 0,74 & 28,01 & 0,48887 & 0,02032 \\
\hline 4 & 0,06 & 0,38 & 0,32 & 0,58 & 32,30 & 0,56374 & 0,01982 \\
\hline 5 & 0,08 & 0,36 & 0,28 & 0,44 & 37,52 & 0,65485 & 0,01950 \\
\hline 6 & 0,10 & 0,34 & 0,24 & 0,32 & 44,21 & 0,77161 & 0,01931 \\
\hline 7 & 0,12 & 0,32 & 0,20 & 0,22 & 53,27 & 0,92974 & 0,01923 \\
\hline 8 & 0,14 & 0,30 & 0,16 & 0,15 & 66,38 & 1,15855 & 0,01929 \\
\hline 9 & 0,16 & 0,28 & 0,12 & 0,09 & 87,09 & 1,52001 & 0,01960 \\
\hline 10 & 0,18 & 0,26 & 0,08 & 0,05 & 124,05 & 2,16508 & 0,02064 \\
\hline 11 & 0,20 & 0,24 & 0,04 & 0,02 & 201,22 & 3,51195 & 0,02545 \\
\hline \multicolumn{7}{|c|}{ Tabela 4-Cálculo da envergadura do excitador } \\
\hline
\end{tabular}

Baseado nos cálculos, notou-se que quase todos os valores de corda exigiam uma envergadura em torno de 20 milímetros. Dentre todos eles, optou-se pelo excitador que teria menor corda com uma envergadura nominal menor de 20 milímetros. Logo adotou-se um excitador de 120 milímetros de corda e 20 milímetros de envergadura. Esse modelo foi desenhado em CAD e é mostrado abaixo.

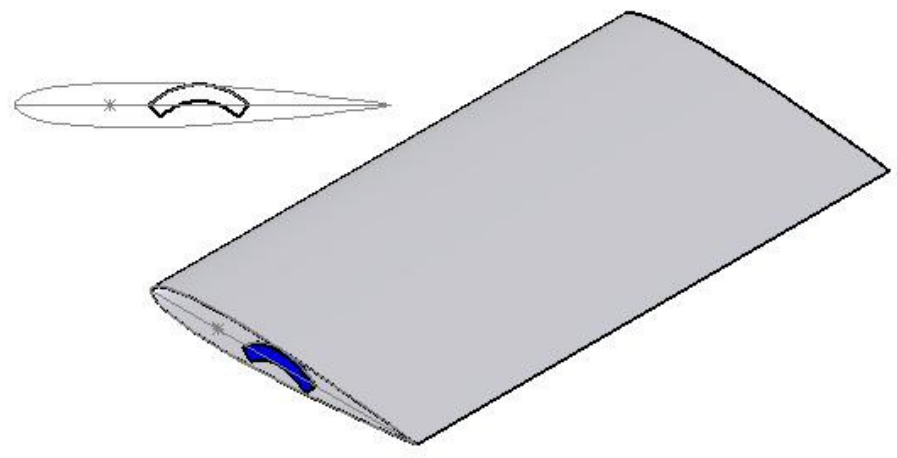

Figura 36 - Excitador de aerofólio fino com arqueamento variável 
Para as dimensões estabelecidas tem-se as seguintes propriedades do excitador.

\begin{tabular}{|l|c|c|}
\hline \multicolumn{1}{|c|}{ Propriedade } & Valor & Unidade \\
\hline $\begin{array}{l}\text { Posição da extremidade 1 } \\
\text { (sobre o camber do aerofólio) }\end{array}$ & 0,16 & $m$ \\
\hline $\begin{array}{l}\text { Posição da extremidade 2 } \\
\text { (sobre o camber do aerofólio) }\end{array}$ & 0,28 & $m$ \\
\hline corda & 0,12 & $m$ \\
\hline raio mínimo (maior sustentação) & 0,087 & $m$ \\
\hline ângulo máximo (maior sustentação) & 87,09 & $o$ \\
\hline envergadura calculada & 0,01960 & $m$ \\
\hline envergadura utilizada & 0,20 & $m$ \\
\hline \multicolumn{2}{|c|}{ Tabela 5 - Propriedades do excitador } \\
\hline
\end{tabular}

O perfil aerodinâmico com o excitador instalado é apresentado na figura abaixo.

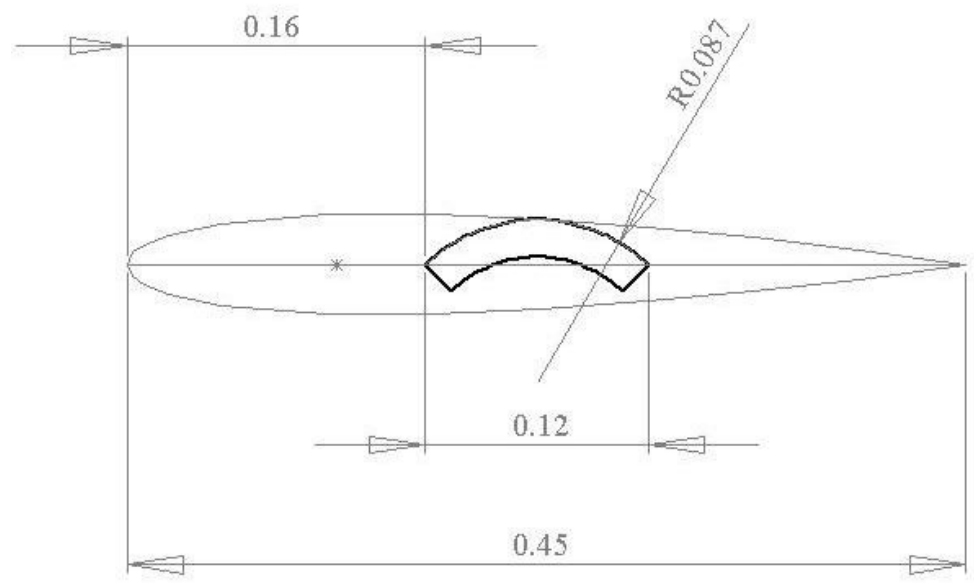

Figura 37 - Esquema da instalação do excitador

\section{$\underline{\text { Análise conceitual }}$}

Esta proposta de perfil apresenta as seguintes vantagens:

- Simplicidade de montagem, funcionamento e manutenção;

- Baixo peso, não alterando significativamente as características dinâmicas e inerciais da asa;

- A freqüência da excitação pode ser mudada facilmente;

- Pequenas dimensões, não alterando as características aerodinâmicas de forma significativa; 
E seus pontos negativos são:

- Seu funcionamento perfeito (simétrico) se dá apenas com ângulo de ataque zero;

- O material flexível pode apresentar deformações, diminuindo a confiabilidade de seu funcionamento;

- O material flexível está sujeito à fadiga.

\subsubsection{Perfil aerodinâmico com ângulo de ataque variável}

Esta proposta consiste em posicionar-se um pequeno perfil aerodinâmico na ponta da asa, tal que ele tenha um grau de liberdade para rotacionar em torno do eixo de sua envergadura. Dessa forma ele pode variar seu ângulo de ataque com amplitude e frequiência controláveis, variando assim a força aplicada na ponta da asa, provocando uma carga vibratória. A figura 38 mostra um esquema simplificado do excitador, cujo acionamento se dá pelo eixo de pivotamento do excitador na estrutura, que pode rotacionar acionado por um motor elétrico interno ao aerofólio.

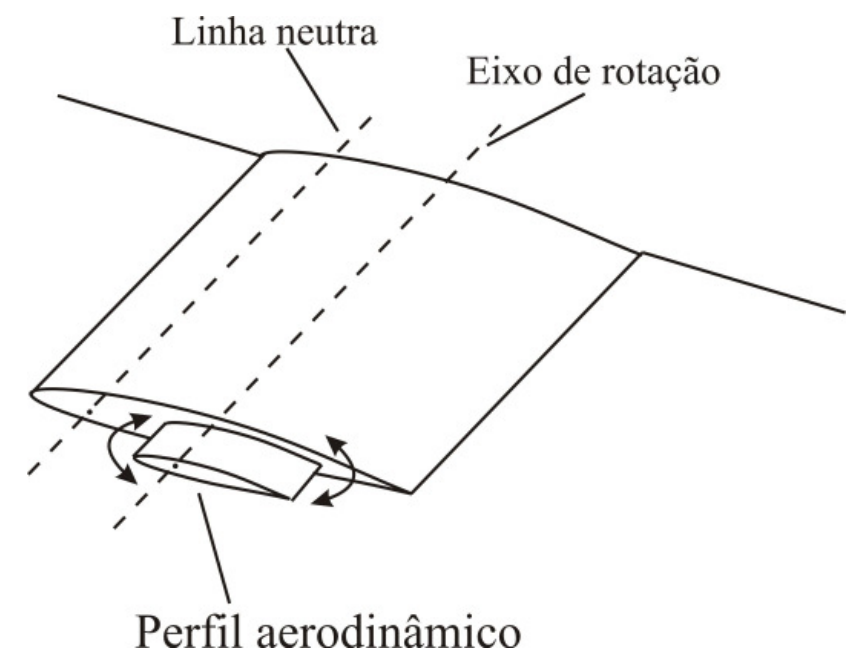

Figura 38 - Esquema do excitador com perfil aerodinâmico com ângulo de ataque variável 
Considerando que o excitador deve aplicar força em ambos os sentidos, optou-se por um perfil simétrico, para que a variação em seu ângulo de ataque para ambos os lados fornecesse a mesma carga para cima ou para baixo. Por simplicidade, foi escolhido o mesmo perfil utilizado na asa, o NACA0012.

Sendo o excitador um aerofólio de envergadura muito pequena, os efeitos de ponta de asa são sensíveis na obtenção da sustentação, portanto devem ser considerados durante o projeto.

Roskan (2000) apresenta um método para a obtenção de $C_{L \alpha}$ em um aerofólio tridimensional, que é dado pela expressão:

$$
C_{L \alpha}=\frac{2 \pi \overline{A R}}{2+\sqrt{4+\frac{\overline{A R}^{2} \beta^{2}}{\eta^{2}}\left(1+\frac{\tan ^{2} \Lambda_{c / 2}}{\beta^{2}}\right)}}
$$

Onde:

$\overline{A R}$ é a razão de aspecto;

$\Lambda_{c / 2}$ é o enflechamento na linha central da corda

$$
\beta^{2}=1-M^{2}
$$

$$
\eta=\frac{C_{\ell \alpha}}{2 \pi / \beta}
$$

A velocidade de flutter, conforme calculada anteriormente é de $25 \mathrm{~m} / \mathrm{s}$, o que ao nível do mar equivale a um Mach de 0,0754, $\log$ o

$$
\beta^{2}=1-0,0754^{2}=0,9943
$$

O enflechamento do aerofólio é zero e $C_{\ell \alpha}$ é a inclinação da curva $C_{L}$ x $\alpha$ para um aerofólio bidimensional, que é mostrada em Abbot (1959) e vale 6,160 $\mathrm{rad}^{-1}$ para o perfil NACA0012. Assim: 


$$
\eta=\frac{6,160}{2 \pi / 0,9972}=0,9776
$$

O coeficiente $C_{L \alpha}$ será calculado em função da razão de aspecto, para mais tarde serem calculadas as dimensões do aerofólio excitador. Logo:

$$
C_{L \alpha}=\frac{2 \pi \overline{A R}}{2+\sqrt{4+\frac{\overline{A R}^{2} 0,9943}{0,9776^{2}}}}=\frac{2 \pi \overline{A R}}{2+\sqrt{4+1,040 \overline{A R}^{2}}}
$$

Como já mencionado, a estrutura deve ser excitada no ponto calculado pela equação (19), que seria o melhor ponto para o pivotamento do aerofólio excitador sendo seu centro de pressão, localizado a $1 / 4$ da corda média aerodinâmica, em torno do qual o perfil deve rotacionar.

O aerofólio a ser excitado é um perfil simétrico, que deve ser ensaiado em diversos ângulos de ataque pequenos, sejam positivos ou negativos.

Para se evitar que o escoamento seja afetado na ponta da asa, o perfil será dimensionado de tal forma a não exceder os limites da seção da estrutura excitada mesmo quando trabalhando em seu limite de rotação, que foi adotado em 12 graus, conforme já discutido no caso anterior.

Além disso, é previsto que o excitador trabalhe, num ensaio em vôo, em condições de ângulo de ataque da aeronave diferentes de zero. Portanto para seu dimensionamento serão previstos ângulos de ataque da aeronave de até 8 graus, o que é bastante razoável, já que as condições de flutter são em alta velocidade, o que gera um baixo ângulo de ataque.

Dessa forma, o excitador será dimensionado partindo da máxima condição possível de rotação com relação à estrutura, que seria de 20 graus.

Utilizando o software Solidworks, desenhou-se o perfil a ser excitado e, na posição calculada anteriormente foi pivotado um perfil aerodinâmico a $25 \%$ de sua corda média aerodinâmica, com uma rotação de 20 graus. Foi calculado a máxima corda do perfil que 
permitisse que o mesmo não excedesse a seção da estrutura, cujo valor é 0,0784 metros. O desenho correspondente é apresentado na figura a seguir.

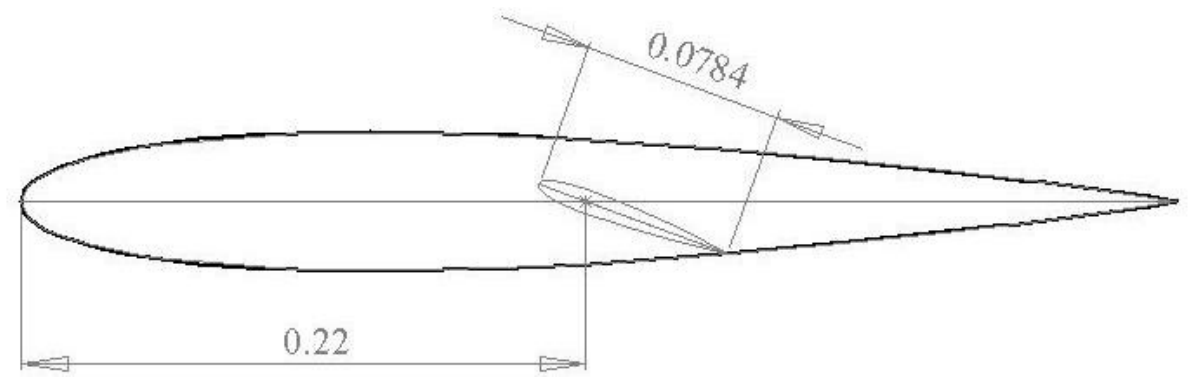

Figura 39 - Determinação da corda do excitador

Tendo em vista que a excitação deve ser sempre senoidal em torno de zero, a posição do excitador deve variar com o ângulo de ataque do perfil. Portanto deve ser previsto um sistema de controle que varie a excitação com o ângulo de ataque da aeronave. Porém, conforme dito anteriormente, tal fator não é tão crítico, já que as condições de ensaio prevêem baixos ângulos de ataque.

Para o cálculo da envergadura do excitador, será utilizada a equação (28), que apresenta a variação de $C_{L}$ com o ângulo de ataque em função da razão de aspecto do aerofólio.

Por imposição de projeto, deseja-se que com um ângulo de 12 graus o excitador apresente uma sustentação de 8,6 N.

Utilizando-se a equação (10) e sabendo-se que a amplitude total (pico a pico) da força senoidal de sustentação é 17,2 N, a densidade do ar é utilizada ao nível do mar (para ensaio em túnel de vento), a velocidade de flutter é $25 \mathrm{~m} / \mathrm{s}$ e a corda determinada acima é $0,0784 \mathrm{~m}$, tem-se:

$$
C_{L}=\frac{8,6}{1 / 2 \times 1,225 \times 25^{2} \times 0,0784 \times b}=\frac{0,2865}{b}
$$


Como o aerofólio é simétrico, sabe-se que com zero grau de ângulo de ataque, o excitador não deve apresentar sustentação. Dessa forma, é possível prever a curva de $C_{L} \mathrm{x} \alpha$ abaixo e calcular o $C_{L \alpha}$ do perfil.

Dessa forma a curva $C_{L}$ x $\alpha$ pode ser representada.

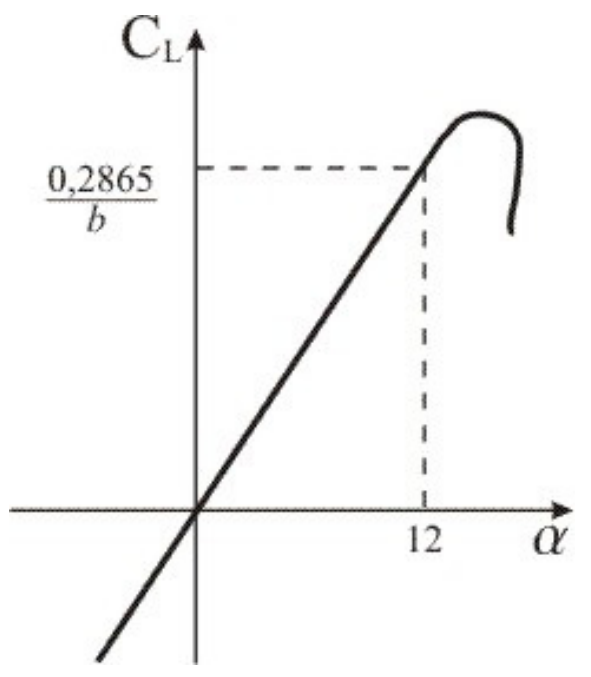

Figura 40 - curva $C_{L} x \alpha$ do perfil excitador

$C_{L \alpha}=\frac{0,2865}{b \times 0,2094}=\frac{1,368}{b}$

A razão de aspecto é dada por

$$
\overline{A R}=\frac{b^{2}}{S}=\frac{b^{2}}{b \times c}=\frac{b}{c}
$$

Utilizando a equação (29) é possível se calcular o $C_{L \alpha}$ do excitador em função da razão de aspecto. Substituindo o valor da corda encontrado acima, tem-se:

$$
\frac{1,368}{b}=\frac{2 \pi \frac{b}{0,0784}}{2+\sqrt{4+\frac{1,040 \cdot b^{2}}{0,0784^{2}}}}
$$

Desenvolvendo-se a equação obtém-se:

$$
b=0,118 m
$$


que é a envergadura do excitador. A figura 41 apresenta os desenhos em CAD do excitador em questão e seu posicionamento na estrutura excitada.

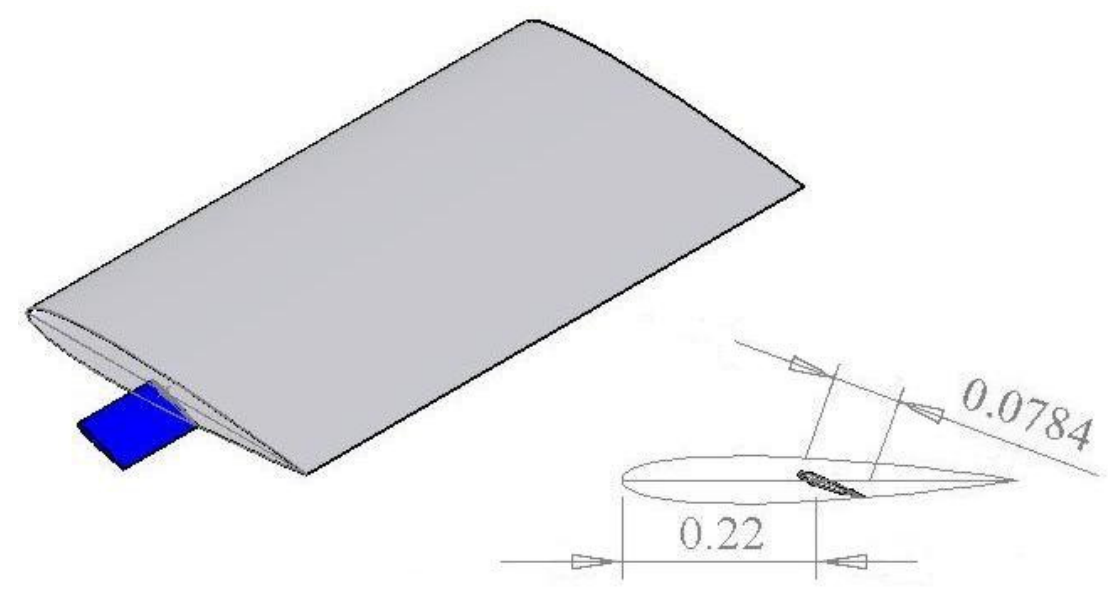

Figura 41 - Perfil aerodinâmico com ângulo de ataque variável

\section{$\underline{\text { Análise conceitual }}$}

Esta proposta de perfil apresenta as seguintes vantagens:

- Simplicidade de montagem, funcionamento e manutenção;

- Confiabilidade;

- Não altera significativamente as características dinâmicas e inerciais da asa;

- Seu melhor funcionamento é em altas velocidades, que é a faixa de execução dos ensaios de flutter;

- A freqüência da excitação pode ser mudada facilmente;

- Pode ser utilizado em qualquer condição de ângulo de ataque da estrutura.

E como desvantagens apresenta os seguintes pontos:

- Apresenta modificações no fluxo aerodinâmico na ponta da asa; 
- A atuação do excitador deve mudar com o ângulo de ataque do aerofólio, o que dificulta seu projeto;

- Em altos ângulos de ataque o excitador pode operar próximo ao limite de estol, anulando seu efeito.

\subsubsection{Excitador eletrodinâmico}

Consiste em fixar na ponta da estrutura uma massa que se movimente eletrodinamicamente, variando sua freqüência conforme a corrente aplicada no mesmo.

Buzdugan et al. (1986) e van Nunen \& Piazzoli (1979) apresentam a teoria de um excitador eletrodinâmico que é representado na figura abaixo

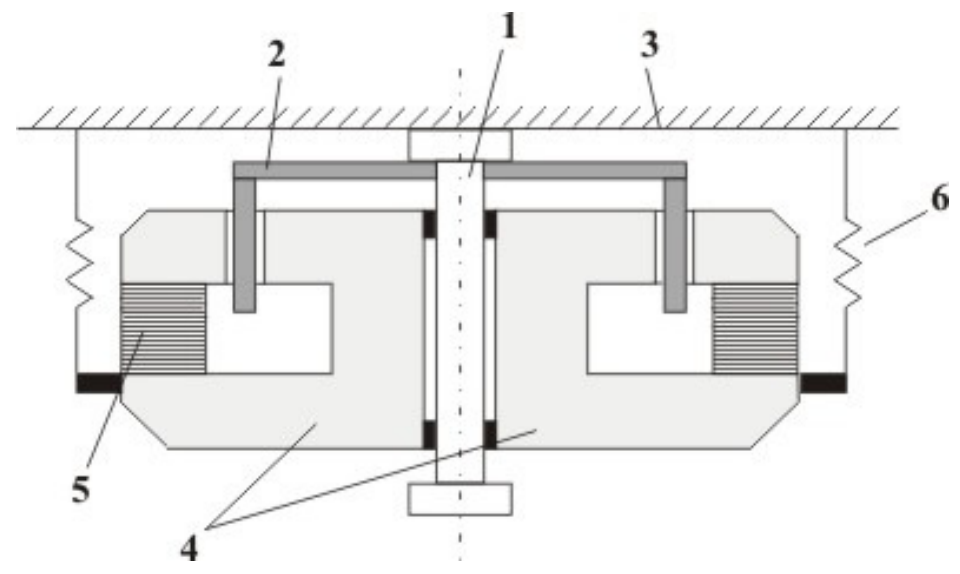

Figura 42 - Excitador eletrodinâmico

O excitador é preso na estrutura (3) pela haste (1), que suporta a bobina motora (2). Os ímãs (4) possuem massa $m$ e se movem pela haste, excitados pelo campo magnético gerado pela bobina móvel (5). A massa transmite o movimento para a estrutura pelas molas de suspensão (6). 
Van Nunen \& Piazzoli (1979) afirmam que a rigidez da mola deve ser tal que sua freqüência natural seja consideravelmente menor do que a menor freqüência a ser excitada, e afirmam ainda que a força de excitação gerada é dada por:

$$
F=H \cdot L \cdot i=-4 \cdot A \cdot m \cdot \pi^{2} f^{2}
$$

Onde:

$H$ é o campo magnético gerado pela bobina móvel;

$L$ é o comprimento do enrolamento presente na bobina motora;

$i$ é a corrente elétrica na bobina motora;

$m$ é a massa dos ímãs;

$A$ é a amplitude de oscilação dos ímãs;

$f$ é a freqüência de excitação.

Tipler (2000) afirma que o campo magnético gerado por uma bobina chata é dado por

$$
H=n \frac{\mu \cdot i_{b}}{2 \cdot R}
$$

Onde:

$n$ é o número de espiras;

$\mu$ é a permeabilidade magnética;

$i_{b}$ é a corrente aplicada na bobina;

$R$ é o raio da bobina.

Ward \& Strganac (1998) e National Test Pilots School afirmam que as frequiências a serem aplicadas devem ser tais que excitem os principais modos de vibração da estrutura. Van Nunen \& Piazzoli (1979) por sua vez afirmam que as freqüências mais críticas para excitadores desse tipo são as mais baixas, pois necessitam de maiores massas e/ou maiores amplitudes da bobina. 
No apêndice A pode-se observar que o modo de vibração com frequiência mais baixa para a estrutura em questão ocorre a 1,3 Hz. Dessa forma, será considerado, para se excitar o primeiro modo de vibração, freqüências a partir de $1,0 \mathrm{~Hz}$.

Com esses dados em mãos, pode-se calcular, pela equação (37), a massa necessária para se excitar o modo de vibração mais baixo. Para tal será considerada uma amplitude de oscilação de 50 milímetros, a fim de ser coerente com a espessura da estrutura excitada.

$$
F=-4 \cdot A \cdot m \cdot \pi^{2} \cdot f^{2} \Leftrightarrow 8,6=-4 \cdot 0,05 \cdot m \cdot \pi^{2} \cdot 1,0^{2} \Rightarrow m=4,36 \mathrm{~kg}
$$

Tal valor é considerado muito grande para o projeto, já que equivale a mais de um quarto da massa da estrutura e pode afetar consideravelmente suas propriedades dinâmicas.

Da mesma forma, limitou-se a massa do ímã em $1 \mathrm{~kg}$ e calculou-se a mínima frequiência que ele poderia gerar nas mesmas condições:

$$
F=-4 \cdot A \cdot m \cdot \pi^{2} \cdot f^{2} \Leftrightarrow 8,6=-4 \cdot 0,05 \cdot 1 \cdot \pi^{2} \cdot f^{2} \Rightarrow f=2,1 H z
$$

O que ainda seria acima da frequiência que se espera a ocorrência de flutter. Portanto conclui-se que para os ensaios em questão o excitador não é apropriado para as freqüências menores.

\section{$\underline{\text { Análise conceitual }}$}

Esta proposta de perfil apresenta as seguintes vantagens:

- Não altera significativamente as características aerodinâmicas da estrutura analisada;

- A frequiência da excitação pode ser mudada facilmente;

- Pode ser utilizado em qualquer condição de ângulo de ataque e velocidade;

E seus pontos negativos são:

- Baixa aplicabilidade a baixas freqüências; 
- Possui um peso considerável, que pode afetar, ainda que minimamente, as características dinâmicas da estrutura;

- As características elétricas dos materiais sofrem efeito da temperatura, o que pode afetar os ensaios em vôo;

- Altas frequiências de excitação requerem uma alta corrente elétrica, que seria consumida do gerador da aeronave.

\subsubsection{Perfil aerodinâmico de arqueamento variável}

Este excitador consiste em se fixar na ponta da asa um aerofólio feito de material flexível, que pudesse ter seu formato alterado, gerando forças alternadas que excitem a estrutura. Seu acionamento se daria por um sistema mecânico acionado por um motor elétrico, que teria capacidade de alterar seu formato, gerando sustentação alternadamente, excitando senoidalmente a estrutura, conforme mostrado na figura 43.
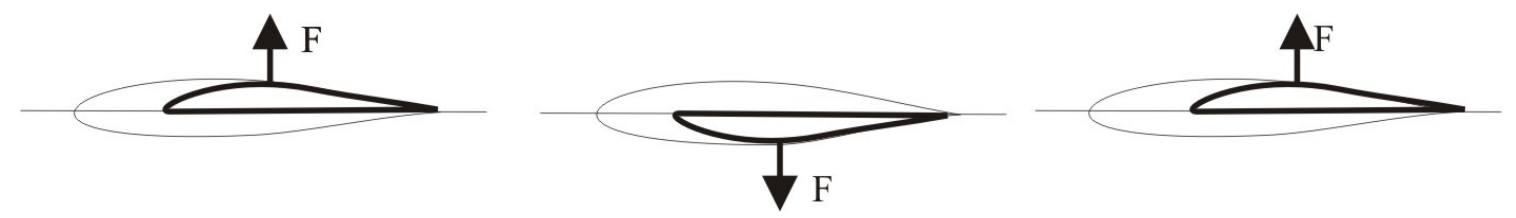

Figura 43 - Esquema de excitação por perfil aerodinâmico com arqueamento variável

Para tal, sabe-se que o centro aerodinâmico do excitador (localizado a $25 \%$ da corda média aerodinâmica) deve ser fixado no ponto de excitação, a 0,22 $\mathrm{m}$ do bordo de ataque. Como a estrutura a ser excitada é simétrica, optou-se por um aerofólio excitador também simétrico e que, enquanto gerasse sustentação, que não ultrapassasse os limites do perfil aerodinâmico, de forma a não prejudicar o fluxo aerodinâmico na ponta da asa e aproveitar ao máximo a carga aerodinâmica gerada pelo excitador. 
Dessa forma, foi possível prever que o bordo de fuga do excitador seria coincidente com o bordo de fuga da estrutura e, de acordo com as afirmações anteriores, sua corda deveria valer:

$$
c=4 / 3(0,45-0,22)=0,306 m
$$

Para essa corda foram traçados os seguintes perfis sobre um perfil NACA 0012 de 0,45 m de corda: NACA 0015, NACA 0018, NACA 0021 e NACA 0024 e constatou-se que todos eles ultrapassavam os limites do perfil da estrutura a ser excitada. Logo optou-se por utilizar o mesmo perfil NACA 0012 para o excitador, com a corda calculada pela equação (41).

Abbot e Von Doenhoff (1959) apresentam, para o perfil NACA0012, a distribuição de velocidades ao longo da superfície do perfil, que é apresentada na tabela a seguir.

\begin{tabular}{|c|c|c|}
\hline $\begin{array}{c}\boldsymbol{x} \\
{[\boldsymbol{\%} \mathbf{c}]}\end{array}$ & $\begin{array}{c}\boldsymbol{y} \\
{[\boldsymbol{\%} \mathbf{c}]}\end{array}$ & $\boldsymbol{v} / \boldsymbol{U}$ \\
\hline 0 & 0 & 0 \\
\hline 0,5 & $\ldots \ldots$ & 0,800 \\
\hline 1,25 & 1,894 & 1,005 \\
\hline 2,5 & 2,615 & 1,114 \\
\hline 5,0 & 3,555 & 1,174 \\
\hline 7,5 & 4,200 & 1,184 \\
\hline 10 & 4,683 & 1,188 \\
\hline 15 & 5,345 & 1,188 \\
\hline 20 & 5,737 & 1,183 \\
\hline 25 & 5,941 & 1,174 \\
\hline 30 & 6,002 & 1,162 \\
\hline 40 & 5,803 & 1,135 \\
\hline 50 & 5,294 & 1,108 \\
\hline 60 & 4,563 & 1,08 \\
\hline 70 & 3,664 & 1,053 \\
\hline 80 & 2,623 & 1,022 \\
\hline 90 & 1,448 & 0,978 \\
\hline 95 & 0,807 & 0,952 \\
\hline 100 & 0,126 & 0 \\
\hline
\end{tabular}

Tabela 6-Propriedades do perfil NACA 0012

Onde:

$U$ é a velocidade do fluxo aerodinâmico no meio em que se encontra o perfil; $v$ é a velocidade em cada ponto indicado. 
Houghton \& Carpenter (2004) afirmam que a sustentação de um aerofólio é a integral da pressão dinâmica ao longo da área, sendo que a pressão dinâmica se dá pela diferença gerada entre a superfície superior e inferior do aerofólio. Afirma ainda que a pressão dinâmica é dada pela equação:

$$
\Delta p=1 / 2 \rho v^{2}
$$

Considerando uma superfície plana em um dos lados, pode-se desprezar a pressão dinâmica aí gerada, e com os dados da tabela 6, considerando-se uma velocidade de $25 \mathrm{~m} / \mathrm{s}$ (velocidade de flutter) foi possível gerar a tabela abaixo, que apresenta o quadrado da velocidade em cada ponto do aerofólio em função da corda aerodinâmica que para esse caso vale $0,306 \mathrm{~m}$.

\begin{tabular}{|c|c|c|c|}
\hline $\begin{array}{c}\boldsymbol{x} \\
{[\mathbf{m}]}\end{array}$ & $\begin{array}{c}\boldsymbol{v} \\
{[\mathbf{m} / \mathbf{s}]}\end{array}$ & $\begin{array}{c}\boldsymbol{v}^{2} \\
{\left[(\mathbf{m} / \mathbf{s})^{2}\right]}\end{array}$ & $\begin{array}{c}\Delta p \\
{[\mathbf{P a}]}\end{array}$ \\
\hline 0 & 0,0 & 0 & 0 \\
\hline 0,00153 & 20,0 & 400 & 245 \\
\hline 0,003825 & 25,1 & 631 & 387 \\
\hline 0,00765 & 27,9 & 776 & 475 \\
\hline 0,0153 & 29,4 & 861 & 528 \\
\hline 0,02295 & 29,6 & 876 & 537 \\
\hline 0,0306 & 29,7 & 882 & 540 \\
\hline 0,0459 & 29,7 & 882 & 540 \\
\hline 0,0612 & 29,6 & 875 & 536 \\
\hline 0,0765 & 29,4 & 861 & 528 \\
\hline 0,0918 & 29,1 & 844 & 517 \\
\hline 0,1224 & 28,4 & 805 & 493 \\
\hline 0,153 & 27,7 & 767 & 470 \\
\hline 0,1836 & 27,0 & 729 & 447 \\
\hline 0,2142 & 26,3 & 693 & 424 \\
\hline 0,2448 & 25,6 & 653 & 400 \\
\hline 0,2754 & 24,5 & 598 & 366 \\
\hline 0,2907 & 23,8 & 566 & 347 \\
\hline 0,306 & 0,0 & 0 & 0 \\
\hline Tabela 7-Cálculo da pressão dinâmica do perfil
\end{tabular}

A partir da tabela acima foi possível plotar a pressão dinâmica em função da corda do aerofólio. 


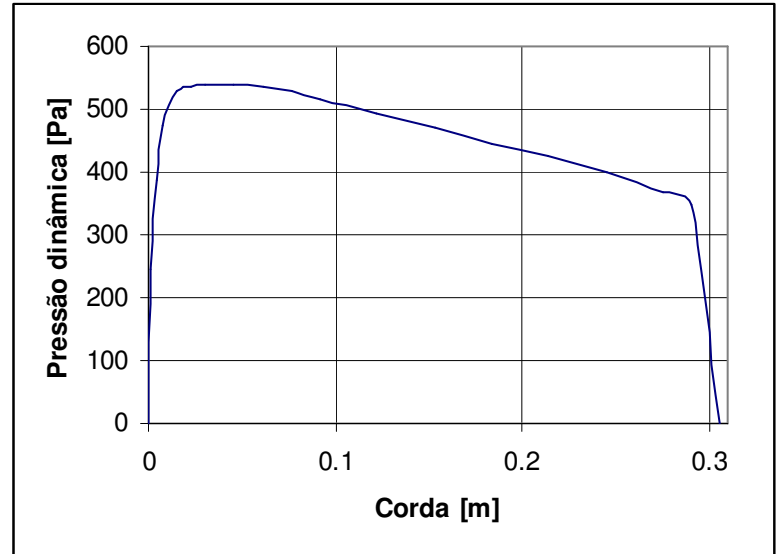

Figura 44 - Pressão dinâmica em função da corda do aerofólio

Com o auxilio do software Origin 7.5, foi possível calcular a área abaixo da curva, que corresponde à integral da pressão dinâmica ao longo da corda, que vale 137,20 N/m.

Considerando que a carga a ser gerada é de 8,6 N, conforme calculado pela equação (14), tem-se que a envergadura do excitador, considerando formato retangular, vale:

$$
b=\frac{P}{\int_{0}^{c} \Delta p d x}=\frac{8,6}{137,2}=0,063 m
$$

A figura 45 apresenta um projeto deste excitador em desenho de CAD.

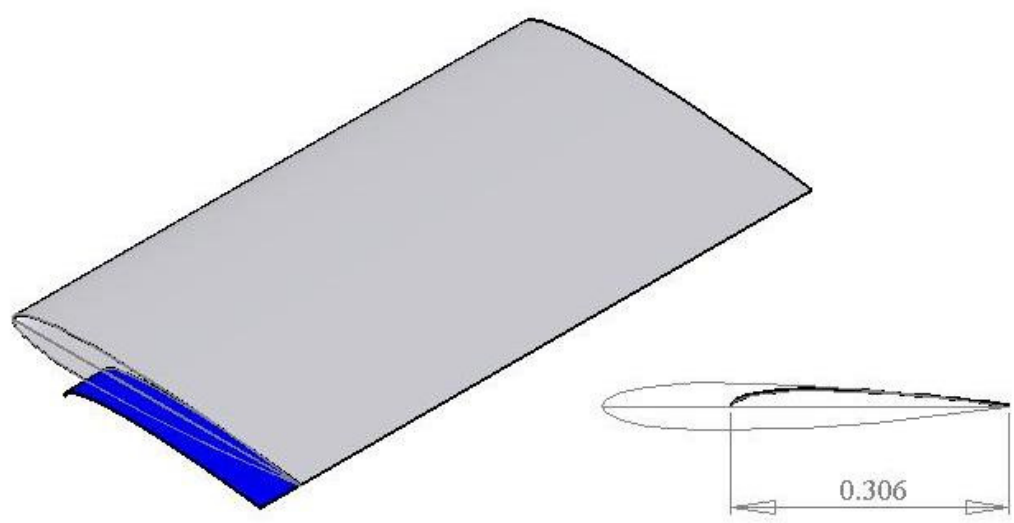

Figura 45 - Perfil aerodinâmico com arqueamento variável 
Devido ao princípio de funcionamento do excitador, a carga aplicada será simétrica (força para cima com o mesmo valor da força para baixo) apenas quando o ângulo de ataque for igual a zero. Porém, como os ensaios de flutter ocorrem sempre a altas velocidades, podese considerar que o seu funcionamento sempre vai ser muito próximo do ideal.

\section{$\underline{\text { Análise conceitual }}$}

Esta proposta de perfil apresenta as seguintes vantagens:

- Baixo peso, não alterando significativamente as características dinâmicas e inerciais da asa;

- A frequiência da excitação pode ser mudada facilmente;

- O formato não altera significativamente as características aerodinâmicas;

E seus pontos negativos são:

- Seu funcionamento perfeito se dá apenas com ângulo de ataque zero;

- O material flexível pode apresentar deformações, alterando o perfil e consequentemente a carga aplicada;

- O material flexível está sujeito à fadiga;

- Geração de alta força de arrasto.

\subsubsection{Cilindro rotativo}

A última proposta a ser analisada consiste em um cilindro rotativo, que pode variar sua direção de rotação, mudando a direção da força de sustentação gerada conforme a frequiência desejada, excitando a estrutura com vibrações nas condições impostas. Tal cilindro deve ser 
fixado por um eixo em seu ponto de pivotamento, que acionado por um motor elétrico pode ter seu sentido de rotação alterado conforme desejado.

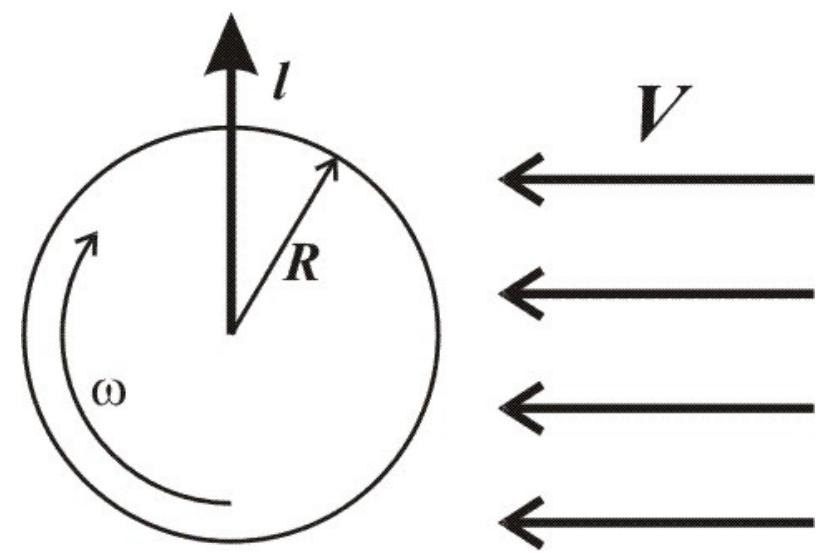

Figura 46 - Cilindro rotativo em fluxo aerodinâmico uniforme - caso bidimensional

Houghton \& Carpenter (2004) demonstram que a sustentação causada por um cilindro rotativo em um fluxo aerodinâmico uniforme, para o caso bidimensional, conforme apresentado na figura 46, pode ser obtido por

$l=\rho V \Gamma$

E a circulação para esse caso é dada por

$\Gamma=4 \pi R V$

Logo

$l=4 \pi R \rho V^{2}$

Para o caso tridimensional

$L=\int_{0}^{b} l \cdot d z \Rightarrow L=4 \pi R \rho V^{2} b$

Utilizando o software Solidworks mediu-se o máximo diâmetro possível para um cilindro com seu centro colocado no ponto de excitação calculado no item 3.2 deste trabalho 
sem que haja interferência para fora do perfil aerodinâmico de forma a não interferir no fluxo aerodinâmico da ponta do aerofólio. A figura 47 mostra o caso estudado.

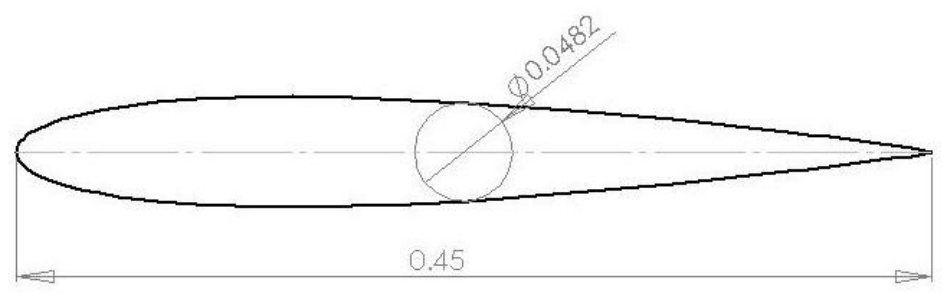

Figura 47 - Medida do máximo diâmetro do cilindro rotativo

Considerando-se o ensaio no túnel de vento do LAE, na velocidade de flutter de 25 $m / s$, a densidade do ar ao nível do mar e o diâmetro calculado acima, pode-se obter a envergadura do cilindro necessária para se obter 8,6 N de sustentação, conforme encontrado na equação (14), pela equação abaixo.

$$
8,6=4 \cdot \pi \cdot \frac{0,0482}{2} \cdot 1,225 \cdot 25^{2} \cdot b \Rightarrow b=0,037 m
$$

Do valor encontrado convenciona-se utilizar uma envergadura de $3,7 \mathrm{~cm}$, o que é uma medida aceitável para a excitação de uma estrutura de $80 \mathrm{~cm}$. A figura abaixo mostra a estrutura com o excitador em questão.

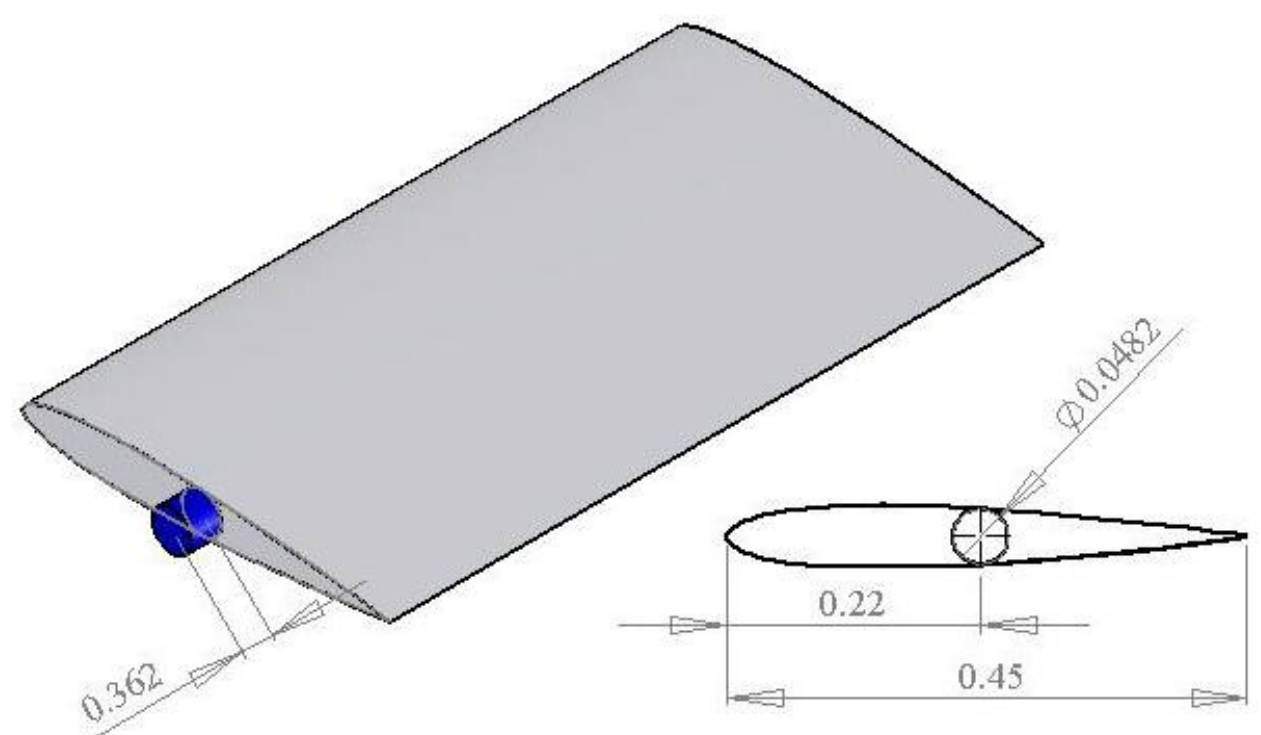

Figura 48 - Estrutura com o excitador cilíndrico acoplado 


\section{$\underline{\text { Análise conceitual }}$}

Esta proposta de perfil apresenta as seguintes vantagens:

- Um cilindro construído com material satisfatório gera baixo peso, não afetaria significativamente as características dinâmicas da estrutura;

- A freqüência da excitação pode ser mudada facilmente;

- Pode ser utilizado em qualquer ângulo de ataque com a mesma fidelidade;

E seus pontos negativos são:

- O formato do cilindro gera um arrasto significativo, podendo alterar as características aerodinâmicas do perfil;

- A resposta (sustentação) esperada pelo excitador não é imediata, pois depende da circulação em volta do cilindro;

\subsection{Escolha do melhor modelo}

Baseado nos estudos realizados, considerou-se que o mais adequado seria a excitação pelo perfil aerodinâmico com ângulo de ataque variável. Este modelo apresenta pequenas dimensões, baixo peso, confiável e simples, por isso considera-se que ele não deve interferir de forma significativa nas propriedades da estrutura excitada. Uma importante vantagem desse modelo é que ele pode ser ajustado para excitar a asa em qualquer condição de ângulo de ataque, bastando um sistema de controle simples.

Sua principal desvantagem é de que o seu funcionamento altera o escoamento aerodinâmico na ponta da asa, o que foi minimizado durante o projeto, fazendo com que o excitador tivesse pequenas dimensões e que ele não invadisse a área externa da estrutura excitada. 
Para o modelo adotado, seu acionamento é detalhado na figura 49 a seguir, onde a estrutura (1) fixa o excitador (2) por meio de um eixo que pode rotacionar livremente e uma biela (3), que é ligada a um motor elétrico interno à estrutura. Essa biela aciona o excitador (2) através de um came (4) e um eixo no próprio excitador. O motor elétrico deve funcionar a uma freqüência igual à que se pretende excitar a estrutura.

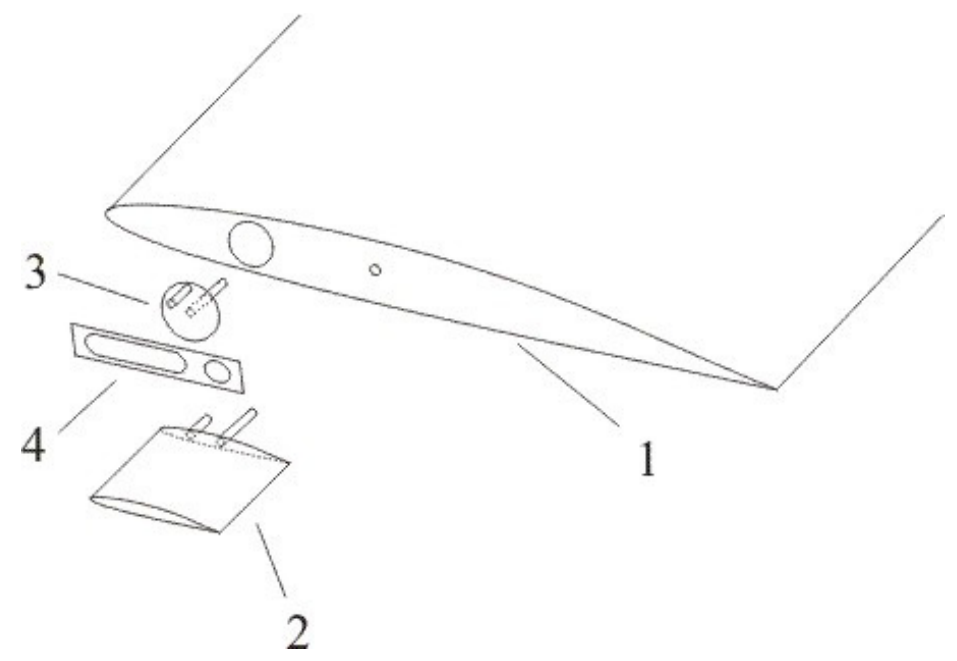

Figura 49 - Acionamento do excitador escolhido

O detalhamento de cada parte do excitador é dado a seguir.

A estrutura a ser excitada (1) deve ser preparada para receber o excitador, com um furo onde deve ser posicionado o eixo de rotação do excitador e o furo onde se deve prender a biela, conforme apresentado na figura a seguir.

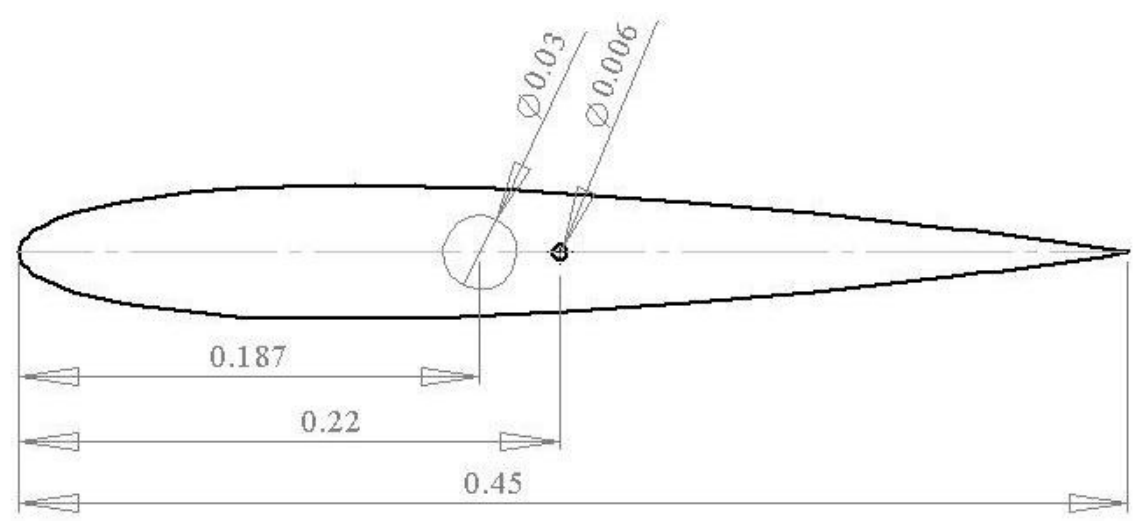

Figura 50 - Preparação da estrutura a ser excitada 
O excitador (2) deve possuir dois eixos. Um de rotação para ser fixado à estrutura e outro para o acionamento, conforme demonstrado na figura abaixo.

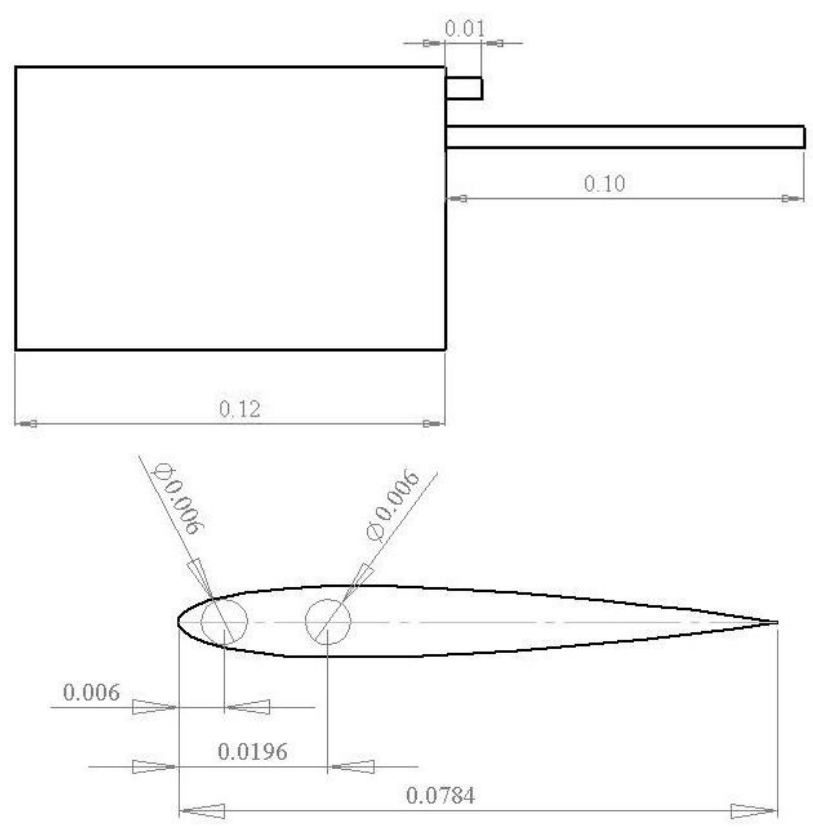

Figura 51 - Material flexível utilizado na montagem do excitador

A biela de acionamento (3) deve ser fixada em um motor elétrico dentro do perfil aerodinâmico, que deve ser acionado na mesma freqüência que se deseja excitar a estrutura. A figura abaixo mostra um desenho da peça em questão.

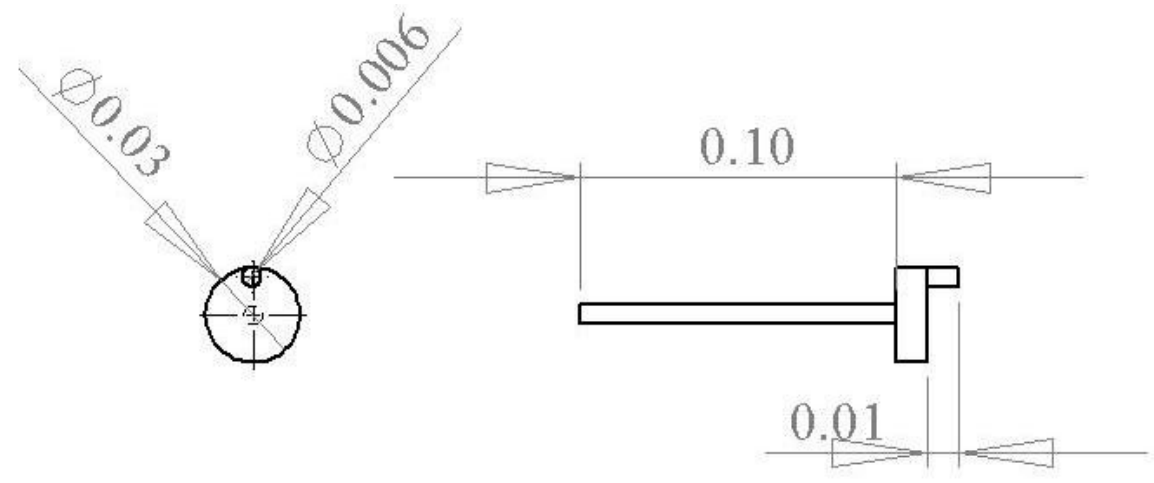

Figura 52 - Biela de acionamento do sistema

O came (4) tem a função de transmitir o movimento do motor elétrico até o excitador. Esta peça é mostrada na figura abaixo. 

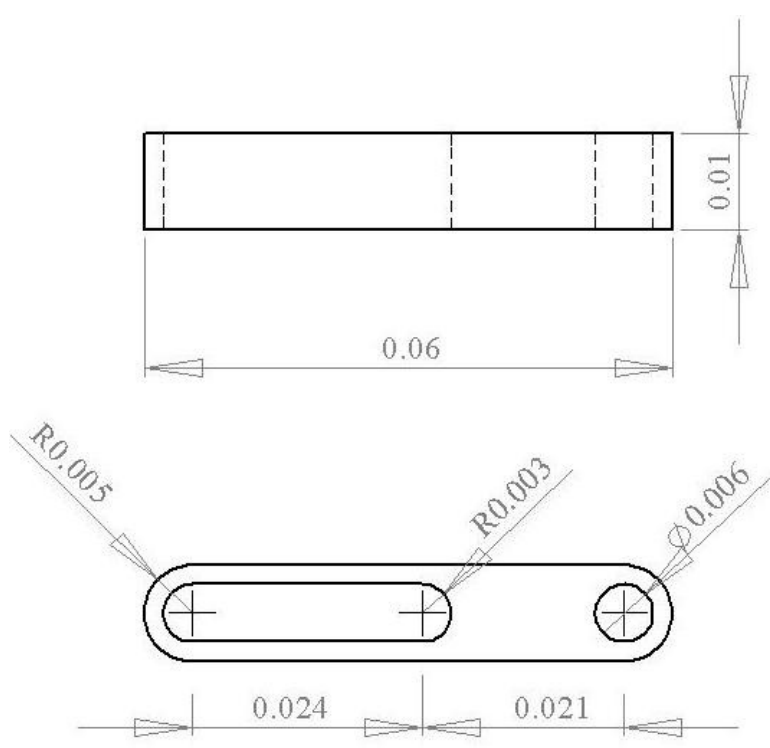

Figura 53 - Came utilizado no acionamento do sistema

Em um trabalho futuro e mais detalhado deve-se analisar e testar tal sistema de acionamento por meio de protótipos, fazendo-se a escolha do material utilizado. Adicionalmente deve-se analisar seu funcionamento em condições variadas de temperatura e pressão, a fim de se adaptar o seu funcionamento para ensaios em vôo reais 
Intencionalmente em branco 


\section{CONCLUSÕES}

O trabalho apresentou a escolha, dentre várias opções apresentadas, um modelo conceitual de excitador para ensaios em vôo de flutter. Para isso foram apresentados conceitos pertinentes de ensaio em vôo, fenômenos aeroelásticos e ensaios de flutter, com seu histórico, metodologia, instrumentação empregada, requisitos de certificação utilizados e análise de resultados.

Em seguida foram apresentados cinco modelos de excitadores com seu dimensionamento e análise conceitual, para enfim escolher o mais adequado com relação à precisão, simplicidade e confiabilidade.

O projeto foi dimensionado para utilização em túnel de vento, mas sempre visando um modelo que pudesse ser facilmente adaptado para ensaios em vôo, como é sugerido para trabalhos futuros visando a continuidade e aperfeiçoamento deste. 
Intencionalmente em branco 


\section{PROPOSTAS PARA TRABALHOS FUTUROS}

Para aperfeiçoamento e/ou continuação deste trabalho, é sugerido o projeto detalhado do excitador de flutter em questão, seu sistema de controle, sistema de acionamento, previsão de sua mudança de comportamento com variação da temperatura, causada pela altitude, escolha dos materiais mais apropriados para utilização e análise do fluxo aerodinâmico, por meio de simulações, com o excitador variando sua forma.

Em seguida é sugerida a construção do projeto em questão e o ensaio em túnel de vento, para confirmar sua viabilidade.

Uma fase seguinte seria a adaptação do projeto para utilização em ensaios em vôo, visando a diferença de altitude, velocidade, Mach e as condições pouco-favoráveis que podem ser encontradas numa atmosfera real.

Finalmente deve-se proceder a construção e utilização em um ensaio em vôo, atestando seu bom funcionamento para tal. 
Intencionalmente em branco 


\section{REFERÊNCIAS}

ABBOT, I. H. ; VON DOENHOFF, A. E. Theory of wing sections, Dover Publications, Inc. New York, 1959.

AIRFOIL DATABASE. Disponível em: <http://www.nasg.com/afdb/index-e.phtml>. Acesso em 11 out. 2006.

BISPlinghOFF, R. L. ; ASHLEY, H. ; HALFMAN, R. L. Aeroelasticity. Addison-Wesley Publishing Company, USA, 1955.

BRENNER, M. J. ; LIND, R. C. ; VORACEK, D. F. Overview of recent flight flutter testing research at NASA Dryden. NASA TM-4792, April 1997.

BUZDUGAN, G. ; MIHAILESCU, E. ; RADES, M. Vibration Measurement, Polytechnic Institute of Bucharest, Romania, 1986, cap. 6.

COLLAR, A.R. The Expanding Domain of Aeroelasticity. The Journal of the Royal Aeronautical Society, 1946, Vol.50, pp.613-636.

DE MARQUI, C. Estudo teórico e experimental de um controlador para supressão de 'flutter'. Tese (doutorado). Escola de Engenharia de São Carlos - USP. São Carlos, 2004.

DE MARQUI, C. ; BENINI, G. R. ; BELO, E. M. Uma revisão histórica do fenômeno flutter. In: XVI Congresso Brasileiro de Engenharia Mecânica, 2001, Uberlândia. Proceedings of COBEM 2001, Aerospace Engineering, 2001. v. 6. p. 136-144.

DEPARTAMENTO DE AVIAÇÃO CIVIL. Requisito Brasileiro de Homologação Aeronáutica (RBHA-25). Agosto 1990.

DOWELL, E.H. ; CLARK, R. ; COX, D. ; CURTISS JR., H. C. ; ESWARDS, J. W. ; HALL, K. C. ; PETERS, D. A. ; SCANLAN, R. ; SIMIU, E. ; SISTO, F. ; STRGANAC, T. W. A Modern Course in Aeroelasticity. Kluwer Academic Publishers, $4^{\text {th }}$ revised and enlarged edition, Netherland, 2004.

DYNAMIC ENGINEERING INCORPORATED. Report D-541 - Embraer flutter exciter operations manual. Virginia, March, 1995. 
EMBRAER. 190ALP002 - Flight Flutter Test Proposal, São José dos Campos, 2005. [Relatório interno da Empresa Brasileira de Aeronáutica S.A.]

EMBRAER. 190ALR002 - Flight Flutter Test Results, São José dos Campos, 2005. [Relatório interno da Empresa Brasileira de Aeronáutica S.A.]

EMBRAER. 190ICD0297 - Flight Test Instrumentation - Tail Flutter Vanes - Interface Control Document, rev. A, São José dos Campos, 2004. [Relatório interno da Empresa Brasileira de Aeronáutica S.A.]

EMBRAER. 190ICD0298 - Flight Test Instrumentation - Wing Flutter Vanes Interface Control Document, rev. B, São José dos Campos, 2003. [Relatório interno da Empresa Brasileira de Aeronáutica S.A.]

FEDERAL AVIATION ADMINISTRATION, DEPARTMENT OF TRANSPORTATION. Code of Federal Regulations, U.S. Government Printing Office, Washington, 2000.

FEDERAL AVIATION ADMINISTRATION - U.S. DEPARTMENT OF TRANSPORTATION. Flight Guide for Certification of Transport Category Airplanes AC25-7A. March, 1998.

HOUGHTON, E. L. ; CARPENTER, P. W. Aerodynamics for engineering students. $5^{\text {th }}$ ed. Elsevier Butterworth-Heinemann, 2004.

HOUGHTON, E. L. ; CARRUTHERS, N. B. Aerodynamics for engineering students. $3^{\text {rd }}$ edition, Edward Arnold (Publishers) Ltd., London, 1982.

KEHOE, M. W. A historical overview of flight flutter testing. NASA TM-4720, October 1995.

LIND, R. Flight-Test Evaluation of Flutter Prediction Methods. Journal of Aircraft, Vol. 40, No. 5, September-October 2003.

LIND, R. ; FREUDINGERL. C. ; VORACEK, D. F. Comparison of Aeroelastic Excitation Mechanisms. Journal of Aircraft, vol 35, No. 5, June 1998, pages 830-832.

NATIONAL TEST PILOTS SCHOOL. Introduction to Performance and Flying Qualities Flight Testing, $2^{\text {nd }}$ edition, Mojave, CA, United States, 1995. 
NAVAL TEST PILOTS SCHOOL. Flight test manual - Fixed Wing Performance, Theory and Flight Test Techniques, Naval Test Pilot School, Patuxent River, MD, 1992.

NITZSCHE, F. Introductory Aeroelasticity. Material de curso ministrado no LAE, Agosto 2001.

OLSON, W. M. Aircraft, Performance Flight Testing, Air Force Flight Test Center, United States, 2000.

RAO, S. Mechanical Vibrations.Addison-Wesley, Inc., 1990

ROSKAN, J. Airplane design Part IV: Preliminary calculation of aerodynamic, thrust and power characteristics. DAR Corporation, Lawrence, Kansas, 2000.

TIMOSHENKO, S. Resistência dos Materiais. Pan Americana, Rio de Janeiro, 1945

TIPLER, P. A. Física para cientistas e engenheiros: eletricidade e magnetismo / ótica. Tradução Horacio Macedo. 4.a edição. Livros Técnicos e Científicos., Rio de Janeiro, 2000.

VAN NUNEN, J. W. G. ; PIAZZOLI, G. Aeroelastic Flight Test Techniques and Instrumentation. AGARDOograph No. 160, Vol.9, London, 1979.

WARD, D. T. ; STRGANAC, T. W. Introduction to Flight Test Engineering, $2^{\text {nd }}$ edition, Kendall/hunt Publishing Company, United States, 1998.

WRIGHT, J. R. ; WONG, J. ; COOPER, J. E. ; DIMITRIADIS, G. On the Use of Control Surface Excitation in Flutter Testing. Journal of Aerospace Engineering, Vol. 217, June 2003, pages 317-332. 
Intencionalmente em branco 


\section{APÊNDICE A - Superfície aerodinâmica utilizada para o projeto}

Os excitadores de flutter foram desenvolvidos para servirem no ensaio de uma estrutura já existente no laboratório e que foi analisada por De Marqui (2004), e ao mesmo tempo considerando-se sua utilização em um ensaio em vôo real.

A estrutura consiste em uma asa de alumínio com perfil NACA 0012 presa a uma estrutura flexível, feita de alumínio e aço. O perfil é mostrado na figura a seguir.

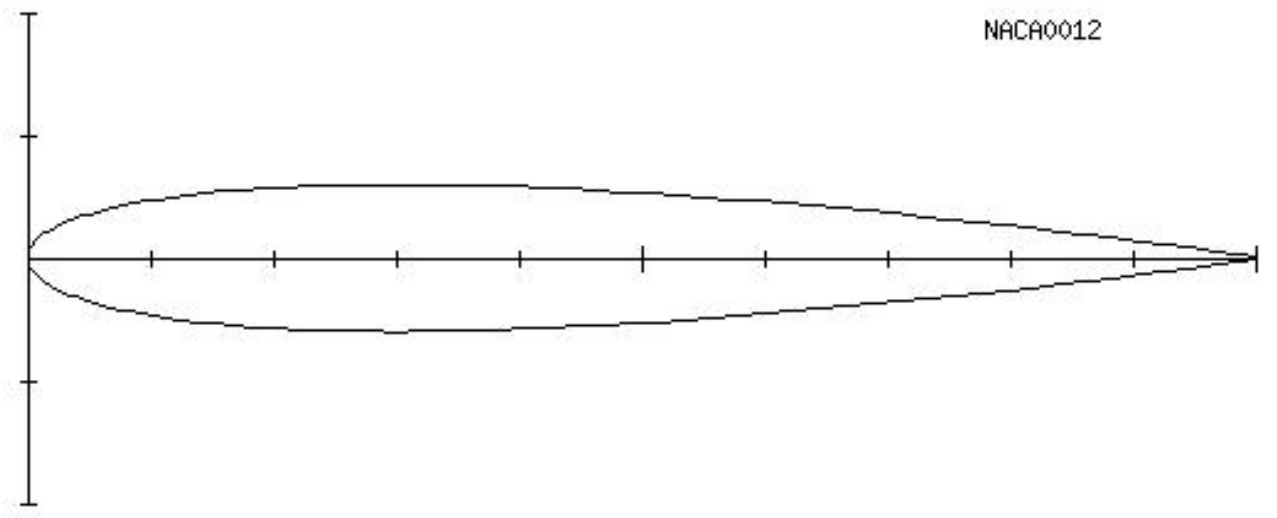

Figura 54 - Perfil NACA0012 - FONTE: Airfoil Database (2006)

A tabela 8 apresenta os pontos de um dos lados do perfil aerodinâmico NACA0012, já que este é simétrico, obtidos em Airfoil Database (2006).

\begin{tabular}{|c|c|}
\hline $\mathbf{x}$ & $\mathbf{y}$ \\
\hline 1,000000 & 0,001260 \\
\hline 0,987365 & 0,003019 \\
\hline 0,967647 & 0,005711 \\
\hline 0,947188 & 0,008436 \\
\hline 0,926179 & 0,011167 \\
\hline 0,904775 & 0,013881 \\
\hline 0,883095 & 0,016562 \\
\hline 0,861225 & 0,019198 \\
\hline 0,839225 & 0,021784 \\
\hline 0,817136 & 0,024314 \\
\hline 0,794988 & 0,026785 \\
\hline 0,772800 & 0,029195 \\
\hline 0,750587 & 0,031542 \\
\hline 0,728359 & 0,033825 \\
\hline 0,706124 & 0,036041 \\
\hline
\end{tabular}

\begin{tabular}{|c|c|}
\hline $\mathbf{x}$ & $\mathbf{y}$ \\
\hline 0,229991 & 0,058790 \\
\hline 0,210992 & 0,057966 \\
\hline 0,192796 & 0,056940 \\
\hline 0,175549 & 0,055730 \\
\hline 0,159376 & 0,054361 \\
\hline 0,144366 & 0,052861 \\
\hline 0,130560 & 0,051263 \\
\hline 0,117950 & 0,049596 \\
\hline 0,106485 & 0,047887 \\
\hline 0,096086 & 0,046154 \\
\hline 0,086659 & 0,044413 \\
\hline 0,078106 & 0,042673 \\
\hline 0,070329 & 0,040940 \\
\hline 0,063240 & 0,039216 \\
\hline 0,056760 & 0,037501 \\
\hline
\end{tabular}




\begin{tabular}{|c|c|c|c|}
\hline 0,683889 & 0,038188 & 0,050819 & 0,035794 \\
\hline 0,661658 & 0,040265 & 0,045356 & 0,034091 \\
\hline 0,639437 & 0,042268 & 0,040318 & 0,032390 \\
\hline 0,617230 & 0,044194 & 0,035663 & 0,030684 \\
\hline 0,595041 & 0,046039 & 0,031351 & 0,028970 \\
\hline 0,572875 & 0,047799 & 0,027354 & 0,027240 \\
\hline 0,550736 & 0,049470 & 0,023644 & 0,025489 \\
\hline 0,528630 & 0,051046 & 0,020203 & 0,023708 \\
\hline 0,506562 & 0,052521 & 0,017015 & 0,021891 \\
\hline 0,484538 & 0,053889 & 0,014071 & 0,020026 \\
\hline 0,462567 & 0,055143 & 0,011365 & 0,018106 \\
\hline 0,440656 & 0,056275 & 0,008901 & 0,016117 \\
\hline 0,418816 & 0,057276 & 0,006684 & 0,014050 \\
\hline 0,397062 & 0,058138 & 0,004734 & 0,011895 \\
\hline 0,375412 & 0,058851 & 0,003076 & 0,009646 \\
\hline 0,353887 & 0,059404 & 0,001742 & 0,007302 \\
\hline 0,332519 & 0,059786 & 0,000771 & 0,004888 \\
\hline 0,311348 & 0,059988 & 0,000194 & 0,002449 \\
\hline 0,290429 & 0,059997 & 0,000052 & 0,001235 \\
\hline 0,269832 & 0,059805 & 0,000000 & 0,000000 \\
\hline 0,249649 & 0,059404 & & \\
\hline
\end{tabular}

Tabela 8 - Pontos do perfil aerodinâmico NACA0012

A figura 55 apresenta fotos da asa.
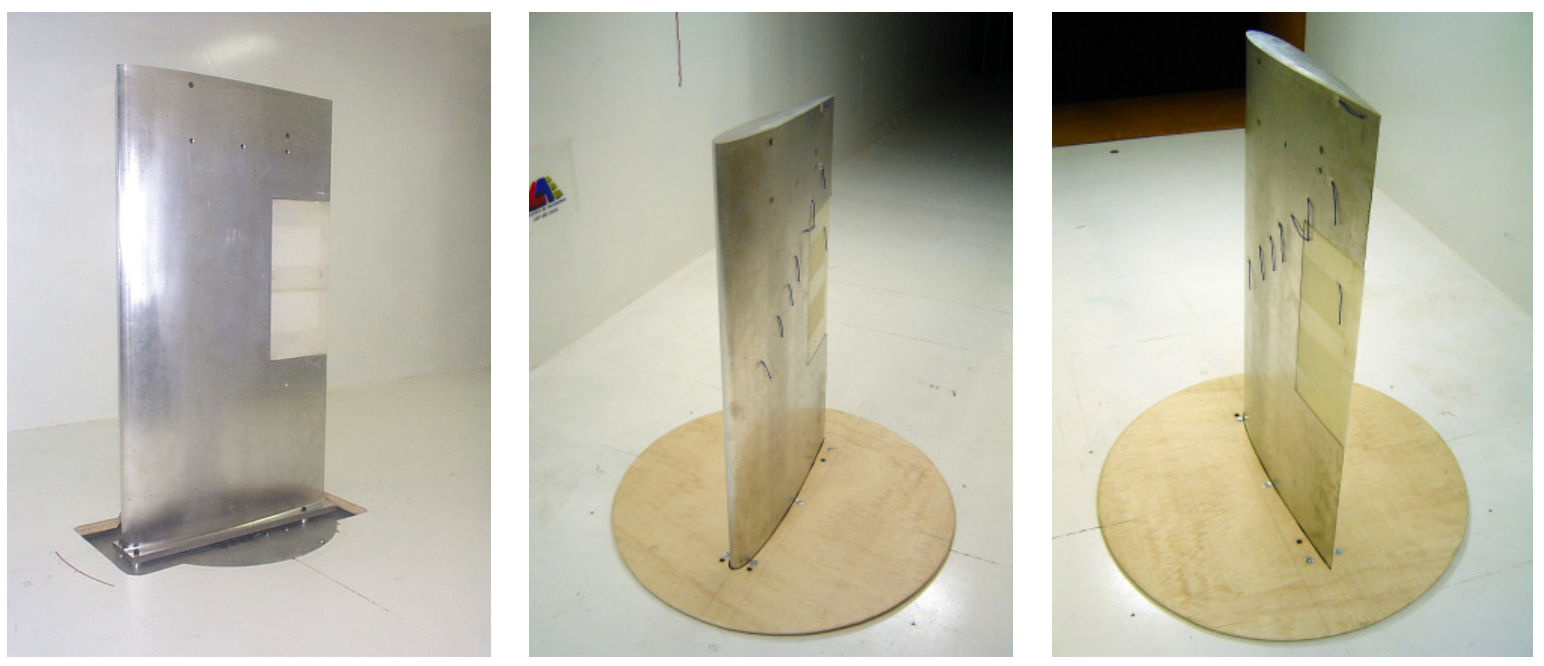

Figura 55 - Fotos asa engastada na estrutura, utilizada no trabalho

A asa foi engastada a uma estrutura flexível composta de uma base ligada a uma placa superior por uma viga central e quatro eixos circulares, que são mostrados na figura a seguir. 


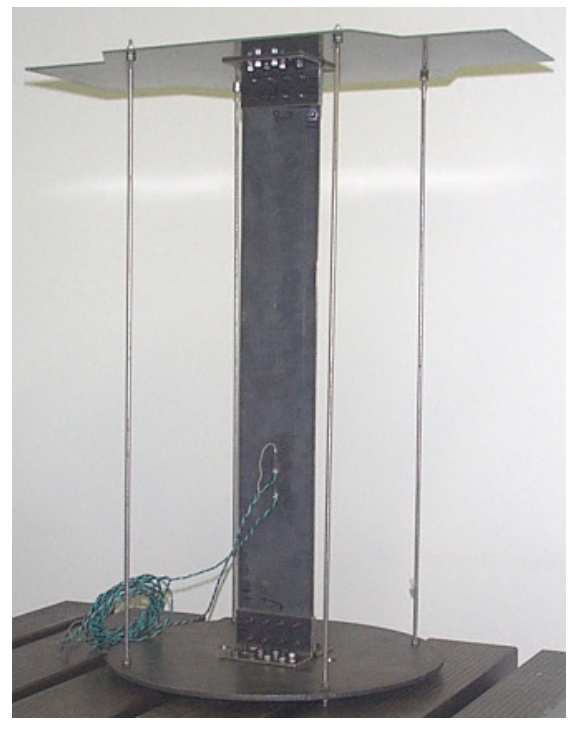

Figura 56 - Estrutura flexível utilizada como apoio do aerofólio

O esquema de montagem da asa na estrutura e seu posicionamento no túnel de vento é mostrado na figura 57.
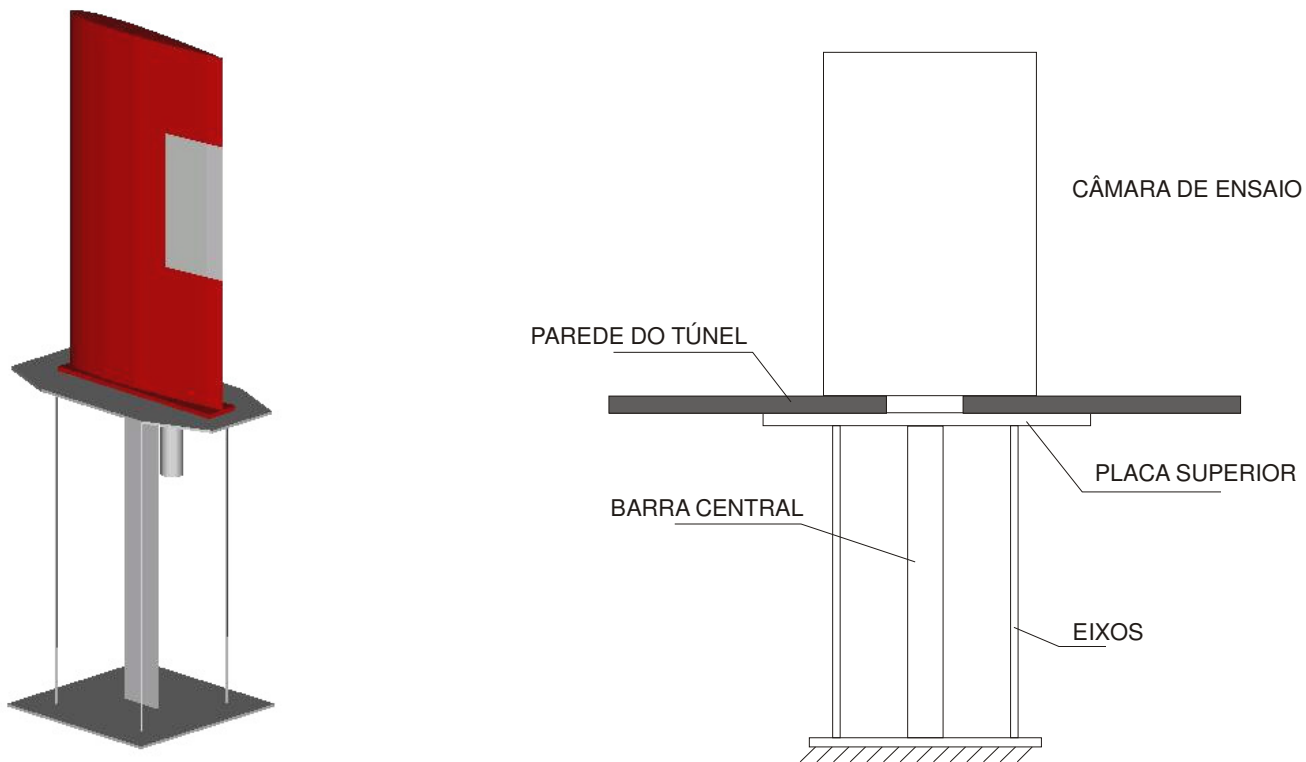

Figura 57 - Esquema de montagem do sistema e seu posicionamento no túnel de vento

As dimensões de cada elemento da estrutura são apresentadas na tabela 9. 


\begin{tabular}{|c|c|c|}
\hline \multirow{2}{*}{ Elemento } & \multicolumn{2}{|c|}{ Dimensões [mm] } \\
\hline \multirow{2}{*}{ Barra Central } & Comprimento & 700 \\
\cline { 2 - 3 } & Largura & 101 \\
\cline { 2 - 3 } & Espessura & 2 \\
\hline Eixos & Diâmetro & 5,5 \\
\hline Placa superior & Espessura & 5,8 \\
\hline \multirow{2}{*}{ Asa } & Envergadura & 800 \\
\cline { 2 - 3 } & Corda & 450 \\
\hline
\end{tabular}

Tabela 9 - Dimensões de cada elemento da estrutura

De Marqui (2004) simulou as estruturas pelo método dos elementos finitos para a obtenção de suas propriedades. As figuras a seguir mostram os cinco primeiros modos de vibração do conjunto obtidos pelo método aplicado.

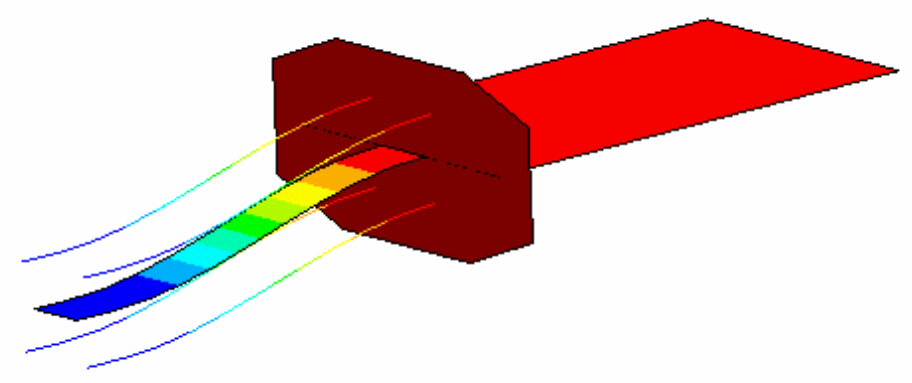

Figura 58 - Primeiro modo de vibração da estrutura (flexão) determinado a 1,3 Hz

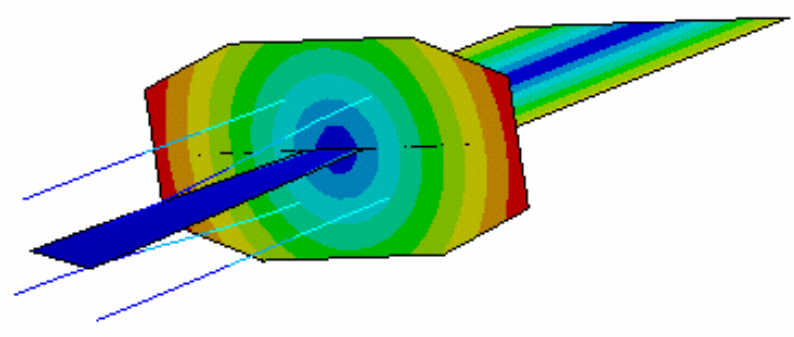

Figura 59 - Segundo modo de vibração da estrutura (torsão) determinado a 2,1 Hz 


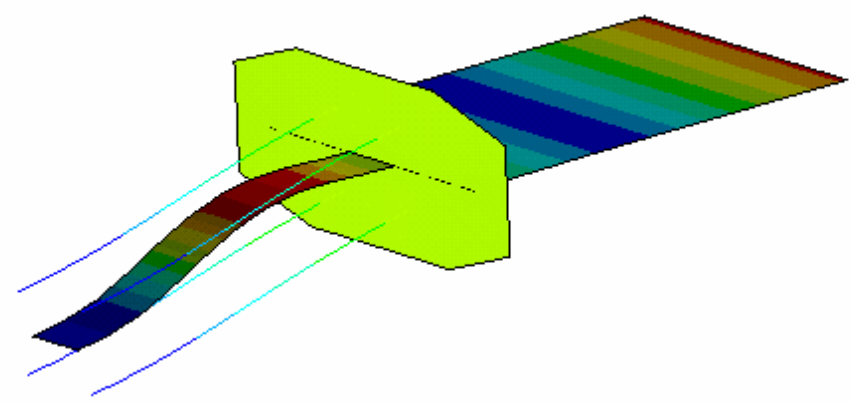

Figura 60 - Terceiro modo de vibração da estrutura (flexão) determinado a 13,6 Hz

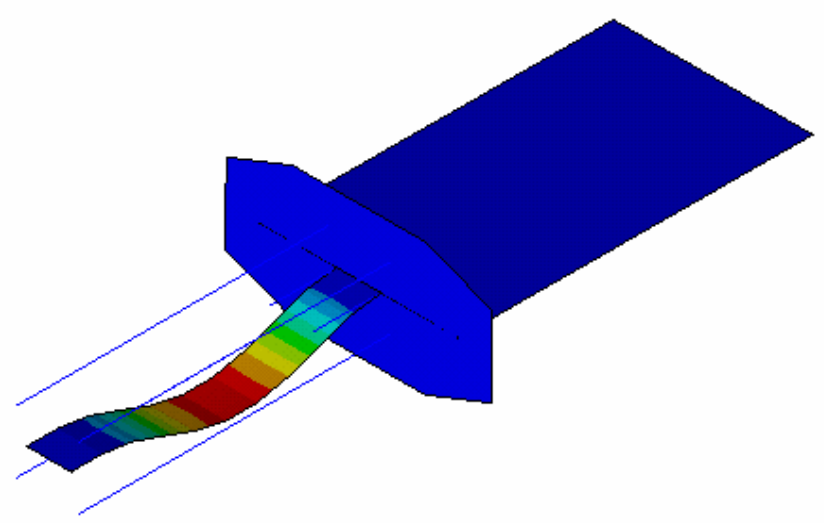

Figura 61 - Quinto modo de vibração da estrutura (barra central) determinado a 27,8 Hz

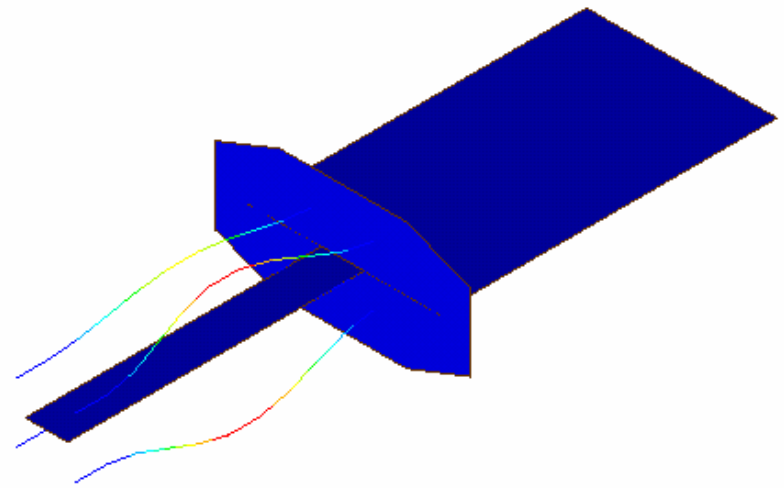

Figura 62 - Sexto modo de vibração da estrutura (eixos) determinado a 45, $1 \mathrm{~Hz}$ 
A partir dessas simulações foi possível obter algumas propriedades do conjunto, que são apresentadas na tabela 10 .

\begin{tabular}{|c|l|c|c|}
\hline Símbolo & \multicolumn{1}{|c|}{ Descrição } & Valor & Unidade \\
\hline$m$ & Massa & 16,862 & $\mathrm{~kg}$ \\
\hline$c$ & Corda & 0,45 & $\mathrm{~m}$ \\
\hline$\rho$ & Densidade & 1,103 & $\mathrm{~kg} / \mathrm{m}^{3}$ \\
\hline$I$ & Momento de Inércia & $1,843 \times 10^{-7}$ & $\mathrm{~m}^{4}$ \\
\hline$K_{h}$ & Rigidez de flexão & 860 & $\mathrm{~N} / \mathrm{m}$ \\
\hline$K_{\theta}$ & Rigidez de torção & 45 & $\mathrm{~N} \cdot \mathrm{m}$ \\
\hline$\omega_{h}$ & Freqüência natural de flexão & 7,5 & $\mathrm{rad} / \mathrm{s}$ \\
\hline$\omega_{\theta}$ & Freqüência natural de torção & 14,4 & $\mathrm{rad} / \mathrm{s}$ \\
\hline$\zeta_{\theta}$ & Razão de amortecimento em torção & 0,0010 & - \\
\hline$\zeta_{h}$ & Razão de amortecimento em flexão & 0,0014 & - \\
\hline$b$ & Envergadura & 0,80 & $\mathrm{~m}$ \\
\hline$l$ & Distância entre centro de cisalhamento e aerodinâmico & $-0,175 \mathrm{c}$ & $\mathrm{m}$ \\
\hline$S$ & Área & 0,36 & $\mathrm{~m}^{2}$ \\
\hline
\end{tabular}

Tabela 10 - Propriedades físicas da estrutura

Os primeiros modos de vibração da estrutura obtidos na simulação pelo método dos elementos finitos são apresentados na tabela a seguir.

\begin{tabular}{|c|l|c|}
\hline Modo & \multicolumn{1}{|c|}{ Descrição } & $\begin{array}{c}\text { Freqüiência } \\
{[\mathrm{Hz}]}\end{array}$ \\
\hline 1 & Primeiro modo de flexão & 1,3 \\
\hline 2 & Primeiro modo de torsão & 2,1 \\
\hline 3 & Segundo modo de flexão & 13,6 \\
\hline 4 & Primeiro modo lateral & 15,5 \\
\hline 5 & Primeiro modo da barra central & 27,8 \\
\hline 6 & Primeiro modo dos eixos & 45,1 \\
\hline
\end{tabular}

Tabela 11 - Modos de vibração da estrutura

A tabela 12 fornece os valores das derivadas de estabilidade e controle obtidos por um programa de Malha de Vórtices. 


\begin{tabular}{|c|c|}
\hline Derivada & Valor \\
\hline$C_{L 0}$ & 0 \\
\hline$C_{M 0}$ & 0 \\
\hline$C_{L \alpha}$ & 2,643 \\
\hline$C_{M \alpha}$ & 0,1065 \\
\hline$C_{L \dot{\alpha}}$ & 0,0213 \\
\hline$C_{M \dot{\alpha}}$ & $-0,0044$ \\
\hline$C_{L q}$ & $-0,0113$ \\
\hline$C_{M q}$ & $-0,007$ \\
\hline$C_{L \delta T E}$ & 0,5270 \\
\hline$C_{M \delta T E}$ & $-0,1063$ \\
\hline
\end{tabular}

Tabela 12 - Derivadas de estabilidade e controle 
Intencionalmente em branco 


\section{ANEXO A - Requisito de certificação utilizado para estabilidade aeroelástica}

\section{$\S 25.629$ Aeroelastic stability requirements.}

(a) General. The aeroelastic stability evaluations required under this section include flutter, divergence, control reversal and any undue loss of stability and control as a result of structural deformation. The aeroelastic evaluation must include whirl modes associated with any propeller or rotating device that contributes significant dynamic forces. Compliance with this section must be shown by analyses, wind tunnel tests, ground vibration tests, flight tests, or other means found necessary by the Administrator.

(b) Aeroelastic stability envelopes. The airplane must be designed to be free from aeroelastic instability for all configurations and design conditions within the aeroelastic stability envelopes as follows:

(1) For normal conditions without failures, malfunctions, or adverse conditions, all combinations of altitudes and speeds encompassed by the VD/MD versus altitude envelope enlarged at all points by an increase of 15 percent in equivalent airspeed at both constant Mach number and constant altitude. In addition, a proper margin of stability must exist at all speeds up to VD/MD and, there must be no large and rapid reduction in stability as VD/MD is approached. The enlarged envelope may be limited to Mach 1.0 when MD is less than 1.0 at all design altitudes, and

(2) For the conditions described in $\$ 25.629(\mathrm{~d})$ below, for all approved altitudes, any airspeed up to the greater airspeed defined by;

(i) The VD/MD envelope determined by $\S 25.335(\mathrm{~b})$; or, 
(ii) An altitude-airspeed envelope defined by a 15 percent increase in equivalent airspeed above $\mathrm{VC}$ at constant altitude, from sea level to the altitude of the intersection of 1.15 VC with the extension of the constant cruise Mach number line, MC, then a linear variation in equivalent airspeed to $\mathrm{MC}+.05$ at the altitude of the lowest $\mathrm{VC} / \mathrm{MC}$ intersection; then, at higher altitudes, up to the maximum flight altitude, the boundary defined by a .05 Mach increase in MC at constant altitude.

(c) Balance weights. If concentrated balance weights are used, their effectiveness and strength, including supporting structure, must be substantiated.

(d) Failures, malfunctions, and adverse conditions. The failures, malfunctions, and adverse conditions which must be considered in showing compliance with this section are:

(1) Any critical fuel loading conditions, not shown to be extremely improbable, which may result from mismanagement of fuel.

(2) Any single failure in any flutter damper system.

(3) For airplanes not approved for operation in icing conditions, the maximum likely ice accumulation expected as a result of an inadvertent encounter.

(4) Failure of any single element of the structure supporting any engine, independently mounted propeller shaft, large auxiliary power unit, or large externally mounted aerodynamic body (such as an external fuel tank).

(5) For airplanes with engines that have propellers or large rotating devices capable of significant dynamic forces, any single failure of the engine structure that would reduce the rigidity of the rotational axis.

(6) The absence of aerodynamic or gyroscopic forces resulting from the most adverse combination of feathered propellers or other rotating devices capable of significant dynamic forces. In addition, the effect of a single feathered propeller or rotating device must be coupled with the failures of paragraphs (d)(4) and (d)(5) of this section. 
(7) Any single propeller or rotating device capable of significant dynamic forces rotating at the highest likely overspeed.

(8) Any damage or failure condition, required or selected for investigation by $§ 25.571$. The single structural failures described in paragraphs $(d)(4)$ and $(d)(5)$ of this section need not be considered in showing compliance with this section if;

(i) The structural element could not fail due to discrete source damage resulting from the conditions described in $\S 25.571(\mathrm{e})$, and

(ii) A damage tolerance investigation in accordance with $\$ 25.571(\mathrm{~b})$ shows that the maximum extent of damage assumed for the purpose of residual strength evaluation does not involve complete failure of the structural element.

(9) Any damage, failure, or malfunction considered under $\S \S 25.631,25.671,25.672$, and 25.1309.

(10) Any other combination of failures, malfunctions, or adverse conditions not shown to be extremely improbable.

(e) Flight flutter testing. Full scale flight flutter tests at speeds up to VDF/MDF must be conducted for new type designs and for modifications to a type design unless the modifications have been shown to have an insignificant effect on the aeroelastic stability. These tests must demonstrate that the airplane has a proper margin of damping at all speeds up to VDF/MDF, and that there is no large and rapid reduction in damping as VDF/MDF, is approached. If a failure, malfunction, or adverse condition is simulated during flight test in showing compliance with paragraph (d) of this section, the maximum speed investigated need not exceed VFC/MFC if it is shown, by correlation of the flight test data with other test data or analyses, that the airplane is free from any aeroelastic instability at all speeds within the altitude-airspeed envelope described in paragraph (b)(2) of this section. 